\title{
INFLUENCE OF FORMWORK LINERS ON FRESH, MECHANICAL AND DURABILITY PROPERTIES OF CAST CONCRETES
}

\author{
By \\ SUNNY RAJA GURBANI \\ B.E, NED UET, Pakistan, 2012 \\ A report \\ presented to \\ Ryerson University \\ in partial fulfillment of the \\ requirements for the degree of \\ Master of Engineering \\ in the Program of \\ Civil Engineering
}

Toronto, Ontario, Canada, 2013

(CSUNNY RAJA GURBANI 2013 


\section{AUTHOR'S DECLARATION}

I hereby declare that I am the sole author of this project. This is a true copy of the project, including any required final revisions as accepted by examiner.

I thereby authorize Ryerson University to reproduce or lend this project by photocopying or by other means, in total or in part, at the request of other institutions or individuals for the purpose of scholarly research.

I understand that this project may be made electronically available.

Author's signature

Date 


\begin{abstract}
Influence of Formwork Liners on Fresh, Mechanical and Durability Properties of Cast Concretes
\end{abstract}

\title{
Sunny Raja Gurbani
}

\section{Department of Civil Engineering, Ryerson University}

The following study investigates the influence of formwork liners on fresh, mechanical and durability properties of cast concretes. In order to investigate the influence of formwork liners (Weather Shield, Poligloss and Zemdrain) manufactured by Newark Group on concrete properties, column and other specimens were cast in conventional moulds (steel, wood and plastic) with and without formwork liners. As per ASTM Standards Surface characteristics, compressive strength, water absorption, sorptivity, chloride penetration, freeze thaw and salt scaling tests were conducted and results are analyzed. It is found that by the application of formwork liners Zemdrain and Weather Shield, compressive strength, water absorption, sorptivity, chloride penetration resistance, freeze thaw resistance and salt scaling resistance were improved. By the application of Poligloss, concrete surface was found to be homogenous without any visible blow-holes. 


\section{Acknowledgements}

All the praise for Almighty indeed, who gave us the verve and strength to complete this project. I am deeply grateful to my project supervisor Professor Dr. Anwar Hossain for his magnificent guidance, moral support, patience and trust throughout this project. I am also thankful to undergraduate students Armando Chocron and Fouzan Karim for their unconditional support, advice and kind nature which helped me in this research project.

I would also like to thank Ryerson Civil Engineering Lab technicians, who provided me technical assistance throughout this project. I am especially thankful to Technician of Concrete Lab, Min Yao who helped me at every step of this project. I would also like to thank my fellows for their help and assistance during the project. 


\section{DEDICATION}

This project is dedicated to my beloved parents and family for their understanding, encouragement and undying support throughout the project. 


\section{TABLE OF CONTENT}

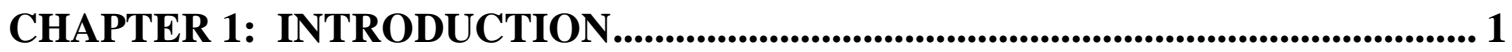

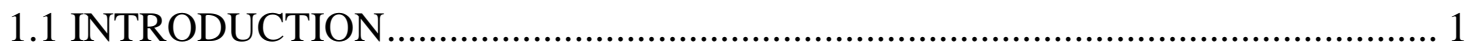

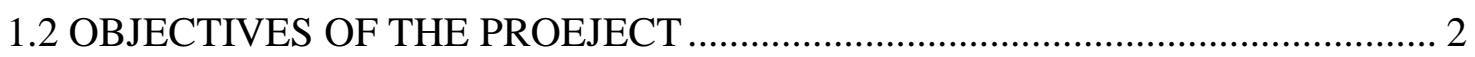

1.3 SCOPE OF THE PROJECT.......................................................................... 3

CHAPTER 2: LITERATURE REVIEW.............................................................. 4

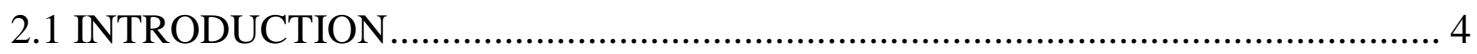

2.2 FORMWORK LINER........................................................................................ 5

2.2.1 Significance of Formwork liner...................................................................... 5

2.2.2 Formwork Liner Applications ........................................................................ 6

2.2.3 Practical Implementation ................................................................................... 7

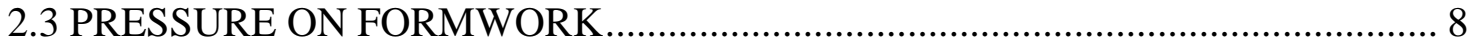

2.4 EFFECT OF FORMWORK LINER ON HEAT OF HYDRATION (CURING)... 11

2.5 INFULENCE OF FORMWORK LINER ON SURFACE CHARACTERISTICS 12

2.6 INFULENCE OF FORMWORK LINER ON STRENGTH.................................... 13

2.7 INFULENCE OF FORMWORK LINER ON PERMEABILITY ........................... 15

2.7.1 Influence of formwork liner on Air Permeability............................................... 15

2.7.2 Influence of formwork liner on Water absorption/Sorptivity............................. 16

2.8 INFULENCE OF FORMWORK LINER ON CHLORIDE PENETRATION....... 17

2.9 INFULENCE OF FORMWORK LINER ON FREEZE AND THAW

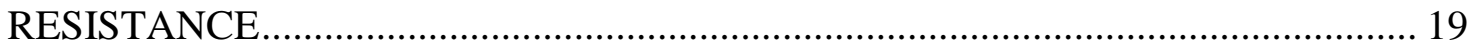

2.10 INFULENCE OF FORMWORK LINER ON SALT SCALING RESISTANCE 21

2.11 PAPERBOARD MATERIALS PROPERTIES ..................................................... 22

2.12 REVIEW OF LITERATURE....................................................................... 23

CHAPTER 3: EXPERIMENTAL INVESTIGATION ................................................. 24

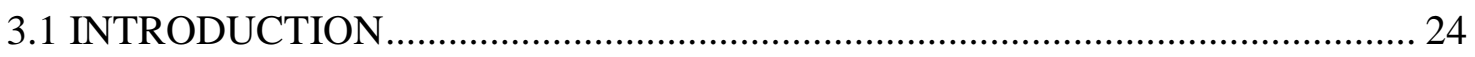

3.2. COMMERCIAL CONCRETES .................................................................. 26

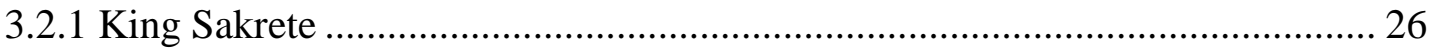

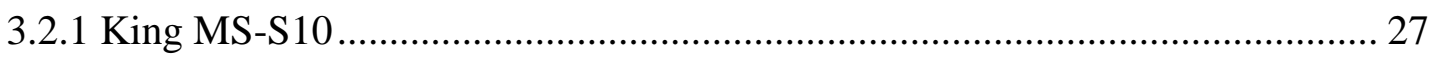

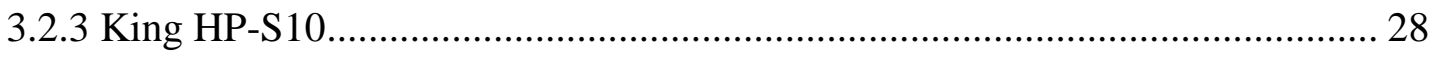

3.2.4 King MS-S10 SCC .................................................................................... 29 


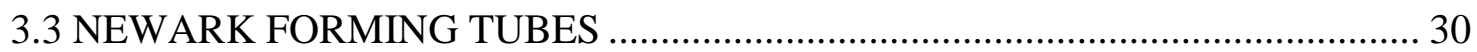

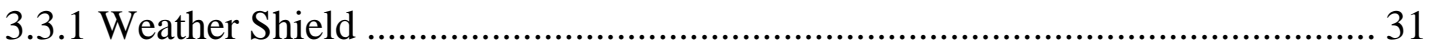

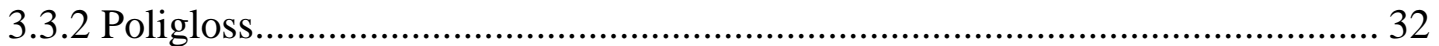

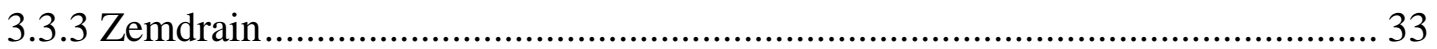

3.4 CASTING CONCRETE IN FORMUNG TUBES............................................. 34

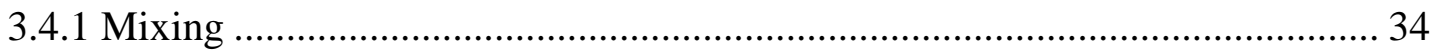

3.4.2 Slump and slump flow tests on fresh concretes............................................ 34

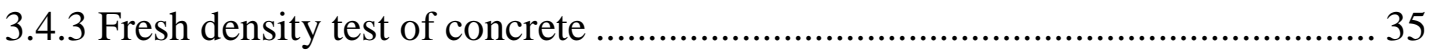

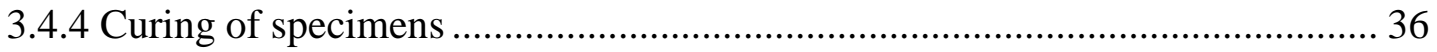

3.5 MONITORING PRESSURE DEVELOPMENT DURING CASTING ................. 36

3.6 MONITORING OF TEMPERATURE DEVELOPMENT IN CAST FORMING

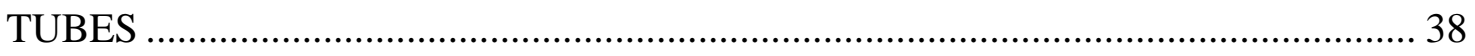

3.7 OBSERVATION OF SURFACE CHARACTERSITICS .................................. 38

3.8 ABSORPTION OF FORMWORK LINER ...................................................... 40

3.9 COMPRESSIVE STRENGTH FROM CYLINDERICAL SPECIMENS.............. 40

3.10 WATER ABSRORTION AND DENSITY TESTS........................................ 43

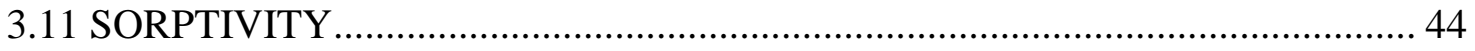

3.12 RAPID CHLORIDE PENETRATION (RCP) TEST ...................................... 46

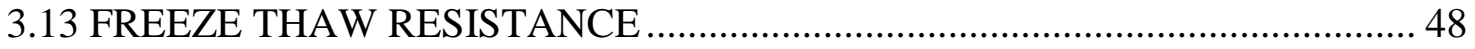

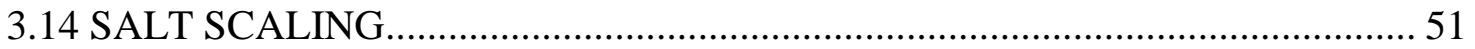

3.15 AXIAL COMPRESSIVE STRENGTH OF FORMING TUBE ........................ 53

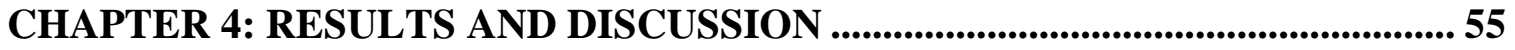

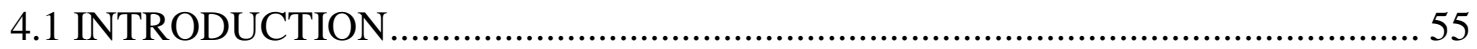

4.2 FRESH STATE PROPERTIES .............................................................. 55

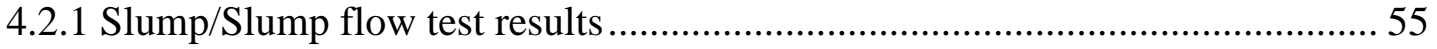

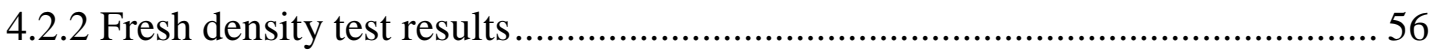

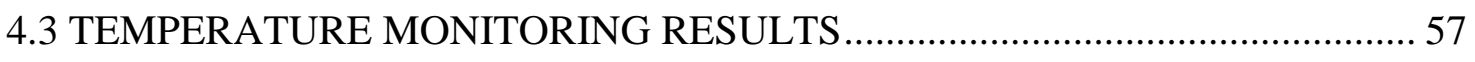

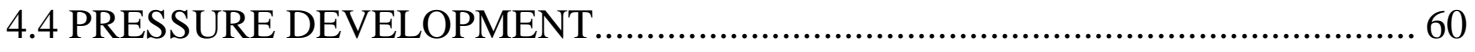

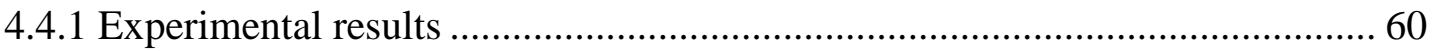

4.4.2 Comparsion of theoretical and experimental pressure.................................. 65

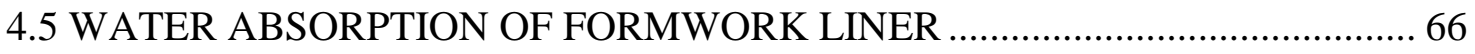


4.6 INFULENCE OF TUBES ON SURFACE CHARACTERSITICS AND SURFACE

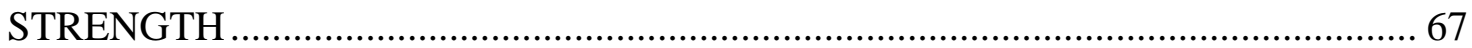

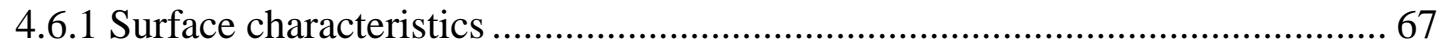

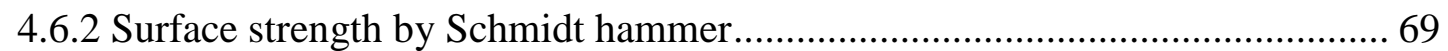

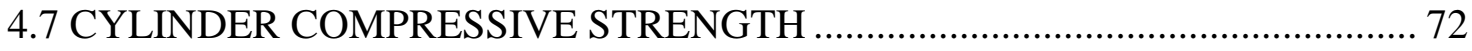

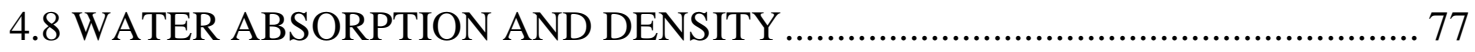

4.9 INFULENCE OF NEWARK FORMING TUBES ON SORPTIVITY ................. 81

4.10 INFULENCE OF NEWARK FORMING TUBES ON CHLORIDE

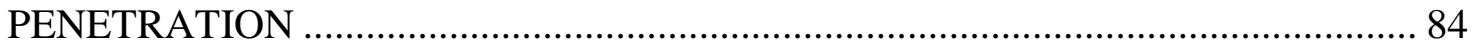

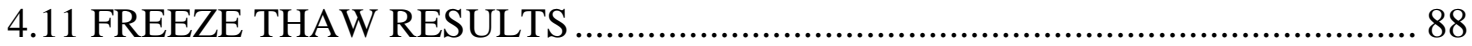

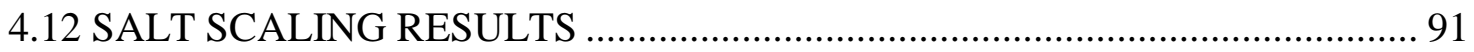

4.13 AXIAL COMPRESSIVE STRENGTH OF FORMING TUBE ......................... 94

CHAPTER 5: CONCLUSION AND RECOMENDTAIONS ................................... 95

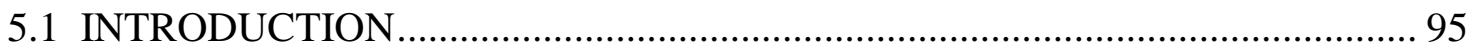

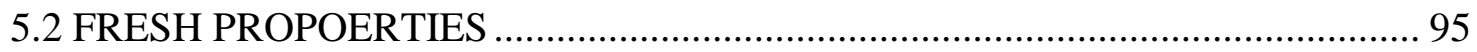

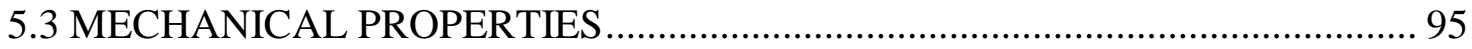

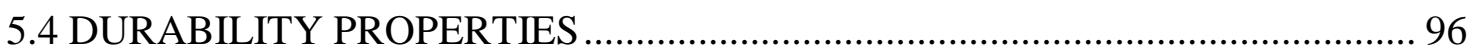

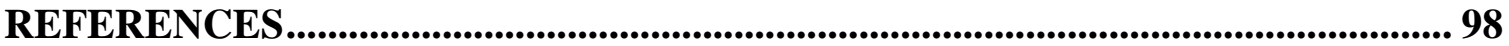




\section{LIST OF TABLES}

Table 3.1: Qualitative indication of chloride ion penetration ....................................... 47

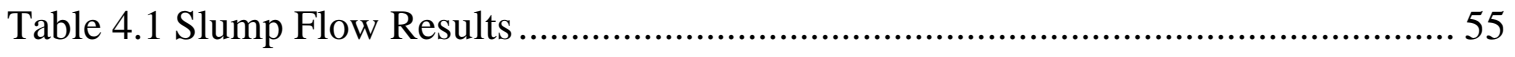

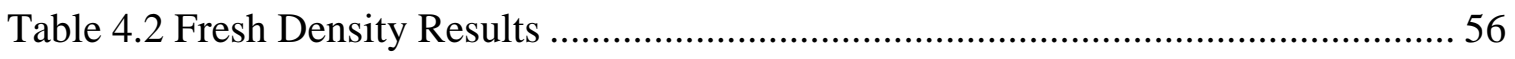

Table 4.3 Maximum temperature developed by concretes ......................................... 57

Table 4.4 Temperatures at max pressure for all concrete ............................................ 59

Table 4.5: Maximum pressure exerted on the face of wall of Weather Shield Tube........ 64

Table 4.6: Lateral Pressure of All concretes using Gardner's model .............................. 65

Table 4.7: Lateral Pressure of All concretes using ACI committee model ...................... 65

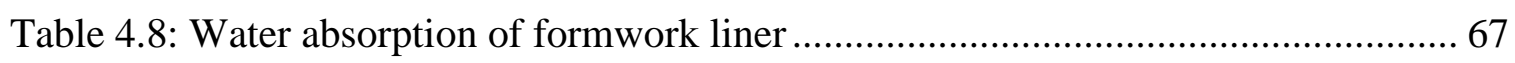

Table 4.9: Average compressive Strength of all Specimens and Concrete ..................... 72

Table 4.10: Comparison of Schmidt hammer with Crushing of specimen ...................... 76

Table 4.11 Test Results for Average Absorption, Bulk Density and Volume of Permeable

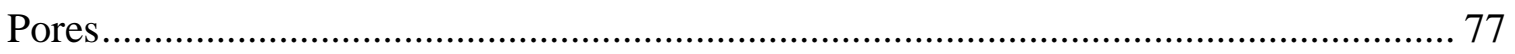

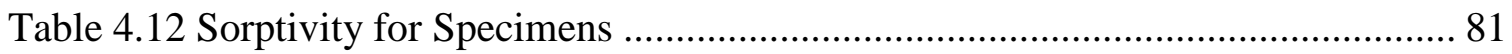

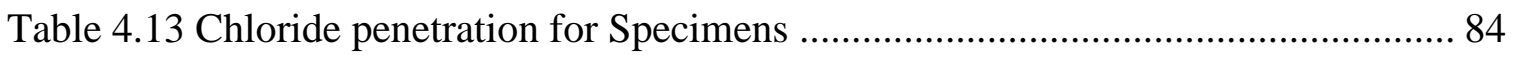

Table 4.14: Weight and Time of wavelength of each specimen at different cycles for

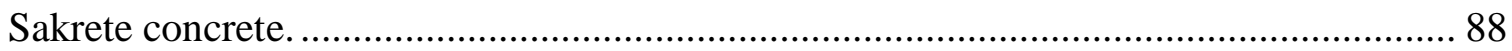

Table 4.15 Relative Modulus for each sample of Sakrete Concrete .............................. 89

Table 4.16: Durability Factor for each sample of Sakrete Concrete............................... 90

Table 4.17: Salt scaling initial and final weight for each sample of Sakrete concrete after

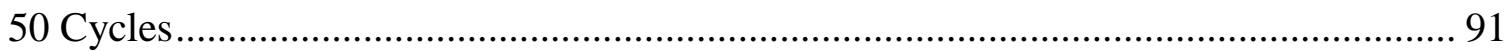

Table 4.18: Salt scaling initial and final weight for each sample of MS-S10 SCC after 50

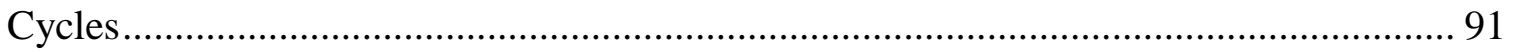

Table 5.1 Performance evaluation of forming tubes for mechanical properties ............... 96

Table 5.2 Performance evaluation of forming tubes for durability properties................. 96

Table 5.3 Specification of Formwork liner observed by experiments ............................ 97 


\section{LIST OF FIGURES}

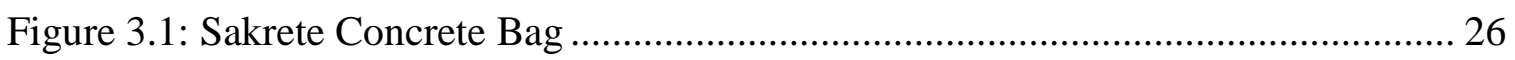

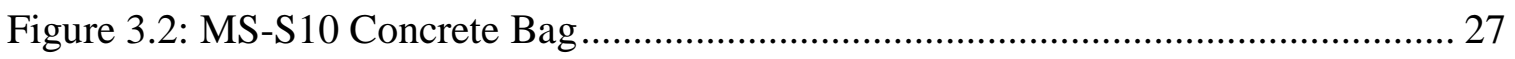

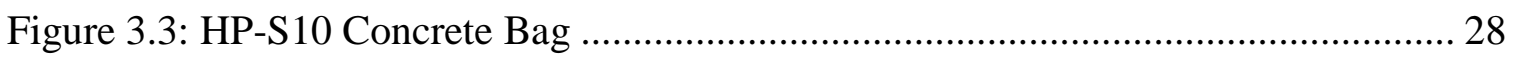

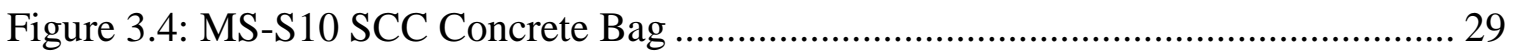

Figure 3.5: Weather Shield Material and Weather Shield Tube .................................... 31

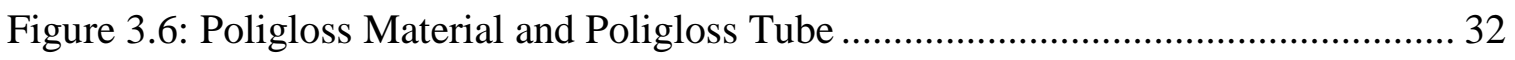

Figure 3.7: Zemdrain Material and Zemdrain Tube .................................................... 33

Figure 3.8: Commercial mixture used for all casting .................................................. 34

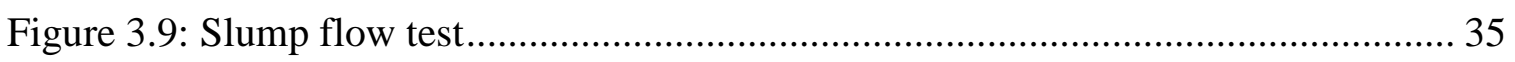

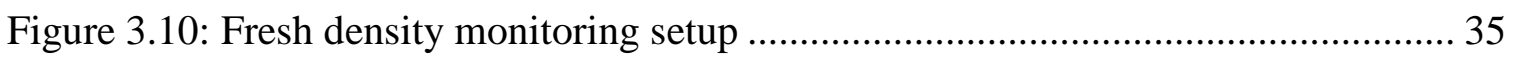

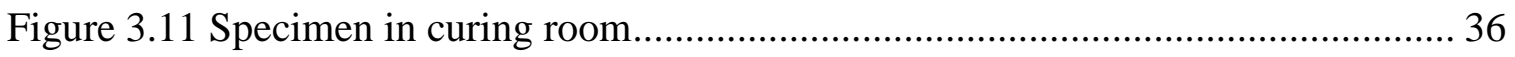

Figure 3.12: schematic diagram for pressure and heat of hydration monitoring ............. 37

Figure 3.13: Pressure transducers installed in the Weather Shield tube .......................... 37

Figure 3.14: Temperature thermocouple introduced at core and at surface of Weather

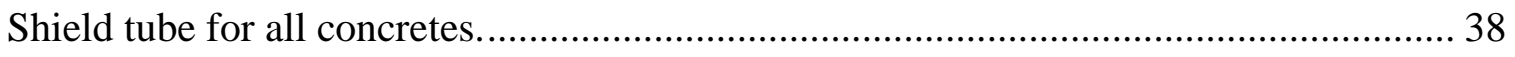

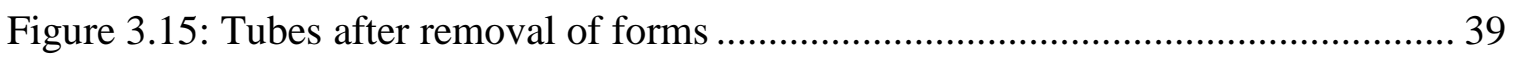

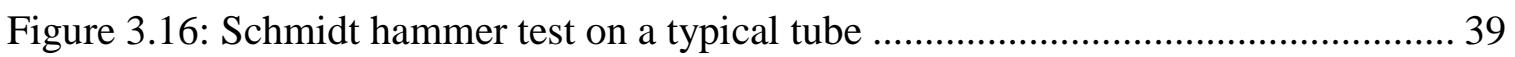

Figure 3.17: Setup for water absorption of formwork liners. ...................................... 40

Figure 3.18: Compressive Strength molds for Weather Shield, Poligloss and Zemdrain 41

Figure 3.19: Typical experimental setup of Compressive testing machine. .................... 41

Figure 3.20: Specimen after Compressive Strength ................................................. 42

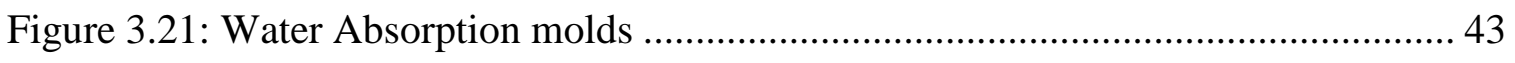

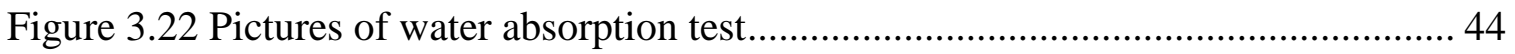

Figure 3.23: Sorptivity molds for Weather Shield, Poligloss and Zemdrain ................... 44

Figure 3.24: Experimental setup for sorptivity test .................................................... 45

Figure 3.25: Chloride penetration molds for Weather Shield, Poligloss and Zemdrain ... 46

Figure 3.26: Experimental Setup of chloride penetration test ..................................... 47

Figure 3.27: Freeze Thaw molds for Weather Shield, Poligloss and Zemdrain ............... 48

Figure 3.28: Experimental setup for freeze thaw test and UPVI .................................. 49

Figure 3.29: Sakrete specimens after 65 Cycles of freezing and thawing ....................... 50 
Figure 3.30: Salt scaling molds for Weather Shield, Poligloss and Zemdrain 51

Figure 3.31 Salting scaling samples placed in freezer ................................................ 52

Figure 3.32: Condition of Sakrete concrete specimen surface after 50 cycles ................. 52 Figure 3.33: Experimental setup for compressive strength of Weather Shield forming tube 53

Figure 3.34: Weather Shield forming tube after compressive test............................... 54

Figure 4.1: Variation of fresh Density with time for various concretes ......................... 57

Figure 4.2a Temperature -time history of fresh cast concrete (Sakrete) ......................... 58

Figure 4.2b Temperature -time history of fresh cast concrete (MS-S10) ....................... 58

Figure 4.2c Temperature -time history of fresh cast concrete (HP-S10) ........................ 59

Figure 4.2d Temperature -time history of fresh cast concrete (MS-S10 SCC)................ 59

Figure 4.3a Pressure development with time at different heights (Sakrete) .................... 60

Figure 4.3b Pressure development with time at different heights (MS-S10) .................. 61

Figure 4.3c Pressure development with time at different heights (HP-S10) ................... 61

Figure 4.3d Pressure development with time at different heights (MS-S10 SCC)........... 62

Figure 4.4a Pressure variation with height at different times (Sakrete) .......................... 62

Figure 4.4b Pressure variation with height at different times (MS-S10) ......................... 63

Figure 4.4c Pressure variation with height at different times (HP-S10) .......................... 63

Figure 4.4d Pressure variation with height at different times (MS-S10 SCC) ................ 64

Figure 4.5: Concrete finish after removing formwork for Sakrete ................................67 67

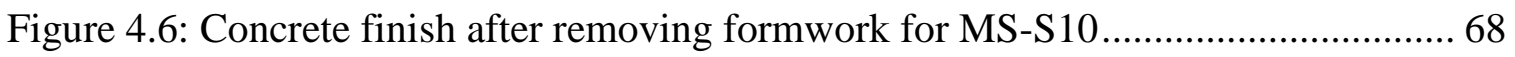

Figure 4.7: Concrete finish after removing formwork for HP-S10 ............................... 68

Figure 4.8: Concrete finish after removing formwork for MS-S10 SCC ....................... 68

Figure 4.9: Compressive Strength of Sakrete Concrete tubes from sides by Schmidt

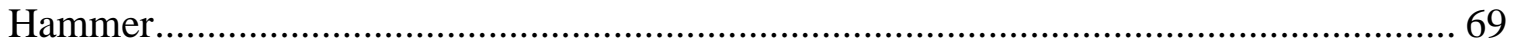

Figure 4.10: Compressive Strength of MS-S10 Concrete tubes from sides by Schmidt Hammer. 70

Figure 4.11: Compressive Strength of MS-S10 Concrete tubes from sides by Schmidt Hammer 70

Figure 4.12: Compressive Strength of HP-S10 Concrete tubes from sides by Schmidt

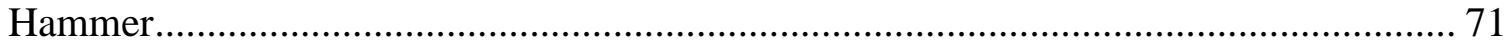

Figure 4.13: Comparison of change in strength from control (Sakrete Mix) ................... 73 
Figure 4.14: Comparison of change in strength from control (MS-S10 Mix) ................. 74

Figure 4.15: Comparison of change in strength from control (HP-S10 Mix).................. 74

Figure 4.16: Comparison of change in strength from control (MS-S10 SCC Mix) ......... 75

Figure 4.17: Comparison of change in water absorption from control (Sakrete Mix) ..... 78

Figure 4.18: Comparison of change in water absorption from control (MS-S10 Mix ..... 78

Figure 4.19: Comparison of change in water absorption from control (HP-S10 Mix)..... 79

Figure 4.20: Comparison of change in water absorption from control (SCC Mix).......... 80

Figure 4.21: Comparison of change in sorptivity with respect to control (All concretes) 82

Figure 4.22 Absorption versus time for all of concrete with different forming tubes...... 83

Figure 4.23: Comparison of change in chloride penetration from control (Sakrete)........ 84

Figure 4.24: Comparison of change in chloride penetration from control (MS-S10 ) ..... 85

Figure 4.25: Comparison of change in chloride penetration from control (HP-S10) ....... 86

Figure 4.26: Comparison of change in chloride penetration from control (SCC Mix)..... 86

Figure 4.27: Time to travel Wavelength for each sample of Sakrete Concrete................ 89

Figure 4.28: Percentage change in mass of Sakrete samples after 50 cycles .................. 92

Figure 4.29: Condition of Sakrete concrete Surface after 50 Cycle .............................. 92

Figure 4.30: Condition of SCC concrete Surface After 50 Cycle................................. 93

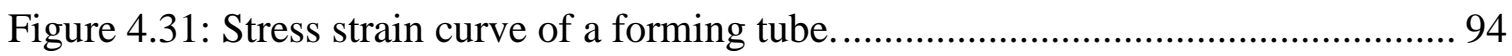




\section{List of notations}

RC Reinforced concrete

PC Portland cement

CPF Controlled permeability formwork

$\mathrm{P}_{\max } \quad$ Maximum pressure on the face of wall

PFA Pulverized fly ash

GGBS Ground granulated blast furnace slag

MK Metakaolin

CSF Condensed silica fume

WR Water-reducing admixture

SP Super plasticizer admixture

AE Air entrainment admixture

WP Water proofing admixture

Ka Air Permeability coefficient

$\mathrm{kPa} \quad$ Kilopascal

MPa Megapascal

Psi Pounds per square inch

Psf Pounds per square feet

$\mathrm{C}_{\mathrm{w}} \quad$ Coefficient for correcting specific weight

$\mathrm{C}_{\mathrm{c}} \quad$ Coefficient for correcting chemical composition and additives

I Absorption 


\section{CHAPTER 1: INTRODUCTION}

\subsection{INTRODUCTION}

Millions of dollars are spent on the formwork for construction of reinforced concrete (RC) structures in North America. The poor quality formwork is one of the major sources of problem in the construction stage producing poor quality concrete and subsequent deterioration of concrete structures due to durability issues in the service stage (Mindess et al 2003). With decreasing budget allocations for infrastructure maintenance, rehabilitation, and replacement, the need for high performance formwork for concrete construction is apparent.

The Newark Group is one of the leading manufacturers of innovative concrete forming tubes in the North America using recycled paper products. The use of newly introduced Weather Shield, Poligloss and Zemdrain forming tubes produced by the Newark Group in construction is an emerging technology. The application of these tubes as formwork can produce quality concretes through improved water resistance, handling extensive vibration/hydrostatic pressure during casting, better surface finish and enhancing concrete durability. Over all, such engineered tubes as formwork can lead to efficient/speedy construction, extend the service life of structures due to better durability and promote sustainable construction through the use of recycled products. It is essential to produce design standards and performance based specifications for the Newark forming tubes through experimental/theoretical investigations in the construction and service stages.

For achieving long term durability, permeability is important factor for concrete structures. It can be achieved by increasing cement content for entire pack of concrete and reducing water to cement ratio. Other method is to use formwork liner which can improve the impermeability of concrete cover without increasing the cement content (Cuicui et al., 2012). 


\subsection{OBJECTIVES OF THE PROEJECT}

Extensive investigations on the Newark forming tubes are warranted to study various aspects such as: performance of formwork and influence on short/long term mechanical/durability properties of various types of concretes. The main objectives of this project are to do extensive experimental investigations in order to:

- The review of previous research studies conducted on influence of formwork liner on concrete fresh, mechanical and durability properties.

- Evaluate the tube performance as formwork in the construction stage by monitoring lateral pressure development (during construction) due to fresh concrete of different types having varying mix design parameters.

- Evaluate the temperature developed by heat of hydration in the enclosed forming tube.

- Evaluate ease of construction/handling/formwork removal and finished surface characteristics.

- Evaluate short and long term mechanical (strength \& surface hardness) and durability (porosity, water absorption, sorptivity, chloride penetration resistance, freeze-thaw resistance and salt scaling) properties of cast concretes.

- To find the stress-strain curve of a Weather Shield forming tube.

- To evaluate performance of the Newark forming tubes compared with traditional (steel, wood and plastic) formworks based on the construction stage behaviour as well as improvement in mechanical/durability properties of cast concrete. 


\subsection{SCOPE OF THE PROJECT}

The scope of the project includes literature review and experimental investigation covering different concrete mix, fresh, mechanical and durability tests in order to identify the influence of formwork liners (Weather Shield, Poligloss and Zemdrain) on concrete properties. Fresh property test include slump/slump flow, heat of hydration and pressure measurement. Mechanical properties include compressive strength test and durability properties include water absorption, sorptivity, chloride penetration, salt scaling resistance and freeze thaw.

Analysis of test results and recommendations on formwork liners are also included in the scope of this project. Various aspects of the research conducted on formwork liners will be conducted in various chapters of this project.

Chapter 2 provides a literature review of previous research studies and information relevant to formwork liners including application, significance and properties on concrete.

Chapter 3 presents the experimental program highlighting concrete used and their properties/ specifications. It also describes the methodology that applied on fresh, mechanical and durability tests. The mixing, casting and curing methods are also described.

Chapter 4 describes the results and discussion on fresh, mechanical and durability properties of concrete cast with Weather Shield, Poligloss and Zemdrain liners.

Chapter 5 represents the conclusion drawn from the results and the performance evaluation of different forming tubes. 


\section{CHAPTER 2: LITERATURE REVIEW}

\subsection{INTRODUCTION}

Formworks have great importance in concrete construction as they mold concrete to the required shape, size, alignment, position and aesthetic. Controlled permeability formworks, manufactured from different formwork liners have been used in the construction of bridge piers, retaining walls, building structures, tunnels and dams. Plenty of benefits have been evidenced by construction industry. Surface free from defects, honeycombing and improved surface strength have also remarked (Basheer et al., 2008). For long term durability of structure, improvement of impermeability of concrete is necessary. Moreover without changing the mix design one can increase durability of concrete by using formwork liners.

When concrete is vibrated in the formwork it produces air and excess water near the formwork surface. If this excess air and water remained entrapped, they eventually turn into macro voids and make the concrete weak and unaesthetic. However, when formwork liners are adopted, air and water are absorbed or removed from the formwork which make concrete surface stronger (Schubel et al., 2008).

Studies indicate that formwork liner could markedly improve the appearance as well as the durability of concrete structures. A formwork liner of any type (Zemdrain, Poligloss and Weather Shield) are intended to lower the water-cement ratio of the near-surface zone, A direct comparison of the liner formed and conventional formwork (Wood and Steel) formed surfaces can be easily be done for mechanical and durability tests. The basic form of a formwork liner is the use of permeable liner against a vertical or inclined formwork. Zemdrain type liner is manufactured from $100 \%$ polypropylene fibers and is thermally bonded (Basheer et al., 2008).

The outer $20 \mathrm{~mm}$ surface created by formwork liner are very important, they can effect porosity, water-cement ratio and cement contents of the surface. Irrespective of cement 
type, mix, strength admixture and formwork orientation, Water-cement ratio is decreased which increase the surface strength. This process can reduce porosity and increase resistance to chemical attack, abrasion and carbonation (McCarthy el at., 1999). Sha'at at al. (1992) concluded in their research that Zemdrain liner can improve first 10-20mm layer in permeability and durability properties.

\subsection{FORMWORK LINER}

Formwork liner is a one or two layered consist of an engineered planned filter laminated to a formwork. Its thickness is generally less than $2.5 \mathrm{~mm}$. It fabrics have a pore size of $0.050 \mathrm{~mm}$, which helps to retain the cement particles and allow the removal of air and water from concrete surface. Its absorbance should not be large enough so it may not remove plenty of water while casting. Maximum absorbency of 0.1 liters $/ \mathrm{m}^{2}$ is recommended. Liners are attached to conventional formwork after attaching they behave as a single entity. The liners can be reused depending upon the type of liner some are one time use other may be used for multiple times (Cigna et al., 2003).

\subsubsection{Significance of Formwork liner}

By using formwork liner in construction many issues can be solved, the most important among them are removal of excess air and water, which cause blow holes and surface defects. It also avoids surface contamination, increase cement content near surface and act as a curing membrane. By the use of formwork liner, the durability of first 15-20 mm of surface improved (Wilson, 2007). Schubel et al., (2008) evaluated the permeability of formwork liner with the fine materials of ground granulated blast furnace slag (GGBS) and pulverized fly ash (PFA). They investigated the interference of finer materials with the pores of formwork liner and the increase water to cement ratio near surface. The result showed that the permeability of polypropylene CPF liners before and after the cast was same which means no mineral additives were lodged in the pores of formwork liner. 


\subsubsection{Formwork Liner Applications}

Permeable formwork liner has been used on plenty of structures around the globe. They are utilized to improve the surface characteristics in marine structures, surface where deicing salts are used, treatment plants, bridges etc. Formwork liner was initially used in 1955 in Scotland at the Glen Shira dam, where celotex boards were attached to formwork to reduce water-cement ratio (Cigna et al., 2003).

Nonwoven fabric form liner was used in the construction of Confederation Bridge, Canada. Formwork liner worked as an ice shield. This bridge span was around $13 \mathrm{~km}$. Initially it was planned to use steel collar around the pier, considering the cost effectiveness factor monolithic reinforced concrete was used. Fabric-Lined Wooden formwork was used for the piers, when formwork was stripped, a bug-hole free surface was formed which is very important for bridge structures (Malone, 1999).

Woven fabric liners have been used in the immersed-tube precast tunnel segments to achieve denser surface. These techniques have been employed in Hong Kong, Sydney Harbour Tunnel and Australia (Malone, 1999).

Non-Woven Fabric liners were used in preparation of precast concrete traffic barriers for the Champlain Bridge in Montreal. The old deteriorated barriers were replaced with the new (cast with formwork liner) ones. Steel forms were lined with fabric by attaching the fabric to boltendon wooden attachment plated. Liners were used for one time casting only. This technique was used to achieve an aim of creating smooth surfaced concrete barrier structure with a minimum 25-Years life period (Malone, 1999).

In 1987 controlled permeable formwork was used in Uk for the building of $26 \mathrm{ft}$. high retaining wall for Oakhampton Bypass. Formwork design engineer used a non-woven geotextile formwork liner which reduced the formwork pressure. This method was also demonstrated in Concrete Europe conference, where $13 \mathrm{ft}$. high section was cast in 15 minutes (Harrison, 1991). 
Japanese contractors have been applying textile and silk formwork liners in the construction, Each system has its own pros and cons. Experiments on silk form formwork liner showed the decrease of $10 \%$ water to cement ratio and increase in surface strength by $36 \%$. Textile forms were used for the piers of the Kaita Bridge, Japan. Japan also used this forms for dam construction and repair, tunnels, retaining walls, and buildings. Textile based formwork are also used on some bridges in Sweden (Harrison, 1991) .

\subsubsection{Practical Implementation}

Plenty of old sites where Zemdrain formwork liner was used are in service for last 15 years. Out of which many sites have been investigated e.g. bridge, marine and waste water structures were visually inspected and no deterioration was examined (Wilson, 2007).

A pier was cast in the Dock Street Bridge using Zemdrain liner. Results suggest that Zemdrain formwork liner has better durable properties as compared to normal Ply Wood Shuttering after 7 years of service (Rankin \& Cummings, 1999).

In marine structures one can experience greatest chloride ingress. Study on marine structures showed that the use of formwork liner reduced the chloride ingress by $40 \%$ on the surface and $80 \%$ to the depth for both splash and tidal zones. Conducting laboratory experiments on marine structures showed that the advantages of using formwork liner are similar to increasing the concrete cover by 15-20mm (McCarthy et al., 2001).

Inspection was done on mild to medium violent condition water treatment plants. Parts of structures which were cast with Zemdrain liner showed no visible deterioration, while the normal surface concrete has significant algae growth. For the strong aggressive environment both surfaces shows the degradation but the liner cast surfaces has much less deterioration as compare to normally cast (Wilson, 2002). 


\subsection{PRESSURE ON FORMWORK}

Formwork is subjected to different types of load during its short life which include selfweight of formwork, dead load of the concrete, wind load, live load (equipment and workers) and lateral pressure on formwork (caused by liquid and semi-liquid state of fresh concrete). Lateral pressure of concrete has great importance because normal concrete need intense vibration whereas self-consolidating concrete has high lateral fluid pressure. Formwork for walls and columns are subjected to internal lateral pressure for the depth of poured concrete. When concrete is vibrated near the top and at the greater depth it acts as a liquid and generates lateral pressure equal to liquid head. Many other factors also contribute to the lateral pressure which should be considered in design (Johnston, 2008).

From the adequate research on concrete lateral pressure concrete it is clear that the factors on which it depends are; rate of placing of concrete, temperature of concrete mix, consistency of concrete mix, consolidation method, any impact during pouring, shape and size of formwork, unit weigh of concrete, vibration, amount of rebars, pore water pressure, cement type, use of admixture and permeability of formwork (Meitn el at., 2004).

Designs of vertical formwork are depended on the lateral pressure estimated to act on the formwork wall. Formwork must be design to support all the weight caused by fresh concrete along with live and other load. Lateral pressure of concrete is important to contractors and engineers since overestimation of the pressure may result in increase of formwork costs. Further, an underestimation of pressure cause poor quality concrete also the structure failure. Main objective of designing of lateral pressure on formwork is to produce concrete elements with safety quality and cost effective. Importance of lateral pressure has been the central idea of many researchers and engineers. Normal concrete is cast in wall and column is vibrated and placed in lifts. The vibrators are submerged into the concrete to an equal length lift to have a fully consolidated concrete. Many theories and equation have been developed and publish by researchers. Through the years the two main ways of solving the problem have been developed are; Formulation of an empirical 
equation from the laboratory experiments and Conceptual model of problem using the mechanical and rheological properties of fresh concrete (Puente et al., 2010).

Garnder (1982) performed series of experimental works and proposed a pressure envelope. The maximum pressure exerted by concrete cannot be greater than hydrostatic pressure produced by concrete fluid density, He concluded that the maximum lateral pressure exerted on the wall of formwork depend on the depth of vibration, rate of placement, concrete temperature, slump, percentage of fly ash or slag present in the mix concrete (Puente et al., 2010; Gardner, 1982). The value of $\mathrm{P}_{\max }$ exerted on the face wall is given by Equation (2.1).

$$
P_{\max }=24 \mathrm{hi}+\frac{3000 H P}{d}+\frac{d}{40}+\frac{400 R^{1 / 2}}{18+T} *\left(\frac{100}{100-\% F}\right)+\frac{\alpha-75}{10}
$$

Where, $\mathrm{P}_{\max }(\mathrm{kPa})$ is the maximum lateral pressure against formwork, $\mathrm{d}(\mathrm{mm})$ is the minimum dimension of form, hi (m) is the vibration length immersion, HP is the vibrator's horse power, $\mathrm{R}(\mathrm{m} / \mathrm{h})$ is the rate of placement of concrete, $\mathrm{T}\left({ }^{\circ} \mathrm{C}\right)$ is the concrete temperature, $\% \mathrm{~F}$ is the percentage of fly ash or slag in design mix and $\alpha(\mathrm{mm})$ is the slump of concrete.

The ACI committee 347 (2004) proposed a pressure envelope. The coefficients should be used for correcting the concrete specific weight $\left(\mathrm{C}_{\mathrm{w}}\right)$ and chemical composition and additives $\left(\mathrm{C}_{\mathrm{c}}\right)$. The maximum pressure equation is given by equation (2.2)

$$
P_{\max } \mathrm{C}_{\mathrm{w}} \mathrm{C}_{\mathrm{c}}\left[7.2+\frac{785 R}{T+17.8}\right]
$$

$\mathrm{P}_{\max }$ should be greater than $30 \mathrm{C}_{\mathrm{W}}$, but no higher than the hydrostatic pressure produced by a fluid with concrete density (Punete at al., 2010). 
The value of $\mathrm{C}_{\mathrm{w}}$ depends upon the concrete unit weight; Concrete weighing less than 140 pcf equation 2.3 can be used to calculate $C_{w}$, whereas $C_{w}$ cannot be less than 0.8 .

$$
C_{w}=0.5(1+w / 145)
$$

For concrete weighing in between $140 \mathrm{pcf}$ and 150 pcf, equation 2.4 can be used to calculate $\mathrm{C}_{\mathrm{w}}$.

$$
C_{w}=1
$$

For concrete weighing greater than $150 \mathrm{pcf}$, equation (2.5) can be used to calculate $\mathrm{C}_{\mathrm{w}}$.

$$
C_{w}=\mathrm{w} / 145
$$

Knowing the values of $\mathrm{C}_{\mathrm{W}}, \mathrm{C}_{\mathrm{C}}$, Temperature, Rate of pouring, Depth, Vibration immersion length, HP of vibrator with the values of wet density we can find pressure of each concrete at any condition by using these models.

In 1980s, site measurements were carried out by cement concrete association for a revision of construction industry research and information Association (CIRIA). They investigated that concrete lateral pressure depends $90 \%$ on pore water. If formwork liner is used which has affinity to absorb water, it can reduce formwork pressure (Harrison, 1991).

Metin et al., (2004) investigated the effect of formwork surface materials on the concrete lateral pressure. They selected seven different formwork prepared from four different materials i.e. populus nigra timber, pinus silvestris timber, plywood and steel sheet. Except steel sheet all other materials were investigated with and without watering the 
surface. They found that by wetting the surface of formwork lateral pressure was increased. Formwork pressure on steel was larger than populus nigra, pinus silvestris, and plywood formworks. Pinus silvestris showed the lowest pressure which was 3.3\%, 7.2\%, and $21 \%$ less than populus nigra, plywood, and steel formwork, respectively. The increase in pressure was caused by swelling of concrete. Water absorption of wood formwork caused swelling on formwork surface. Swelling of formwork surface was not same for all surface materials this was the main cause of different lateral pressure for different formwork surfaces.

\subsection{EFFECT OF FORMWORK LINER ON HEAT OF HYDRATION (CURING)}

Blow-hole free surface was obtained from controlled permeability formwork. Denser concrete cover with lower water-cement ratio is formed. This cover made the concrete more durable to the environmental and physical attacks. If formwork liner is not strip off early, concrete with optimum hydration will be achieved as filler keeps the concrete moist and reduce it sensitivity to poor curing (Cinga et al., 2003).

Basheer et al., (1997) suggested that attention must be given to the concrete mix containing more than $50 \%$ slag. Special attention is also required for good concrete practice, curing time and depth of cover for reinforcing steel. Different formwork liner can be employed to have complete hydration, curing and other durability enhancement.

Large quantity of reinforcement is provided to accommodate the thermal effects arising from hydration of concrete. If it is not provided, thermal cracking may occur within 24 hours of placing the concrete. When formwork liner was used it increased the cement content near surface. Researchers suggest that this increase is in the order of 50-100 $\mathrm{kg} / \mathrm{m}^{3}$. A critical review of literatures showed that early cracking didn't occur in areas where formwork liners were applied. Main reason for this mechanism is that the formwork liner holds water within its pores some of which is also used by concrete to assist curing. Thus in the period before the formwork has been removed the concrete has already suffered a degree of curing. Therefore by employing formwork liners to the 
concrete can enhance the curing method and hence increase the life span of structure (Philip \& Chirag, 2008).

Zemdrain consists of a textile liner which allow air bubbles and surface water to drain out but holding the cement particles on the surface; which enables the surface near the liner to become very dense and make concrete to hydrate optimally (Coutinho et al., 2001).

Permeable formwork liner can absorb up to 0.5 Liter of water per square meter of fabric. This absorb water can help concrete in curing after setting. Researches proved that this absorb water can be reused by concrete during curing. After the formwork and liner are removed they curing requirements are similar to conventional formwork. Investigations suggest that the concrete cast against absorptive liner have less chances of incomplete curing. Surface hardening effects of permeable formwork liners can cause less moisture loss in air-cured specimen and reduced moisture in moist-cured specimens. In past when absorptive panels were used, after removing the formwork the panels were place in contact with concrete surface during curing (McKenna, 2005).

Long et al., (1995) tested concrete specimens cast with formwork liner and conventional formwork. They cured the samples in air, in saturated liner and with curing compounds. After removal of formwork all samples were placed at $20^{\circ} \mathrm{C}$ and 55 percent relative humidity. Enhanced properties of concrete were suggested to be better for concrete cast with permeable formwork liner than conventional formwork and any curing method. It means formwork liner can produce the concrete with optimum hydration and curing.

\subsection{INFULENCE OF FORMWORK LINER ON SURFACE CHARACTERISTICS}

Blemishes can be created by trapping of air and water on the surface of concrete can cause blowholes, pinholes, scouring, crazing, plastic cracking, dusting, retardation and discoloration. These blowholes can provide the space for water to be contaminated and the growth of different bacteria which can cause problem to the sensitive structures worldwide (Wilson, 2007). 
Basheer et al., (1997) in their research investigated concrete blocks cast with different tube liner. They concluded that concrete cast with formwork liner has very less no of blowholes and defects on the surface as compare to the normal formwork. They also noticed that the liner concrete was darker as compare to conventional formwork. Darker shows the coarse and more condense concrete. They further mentioned that this is because of increase in cement content and decrease in water due to permeability of forming liner.

Chinese researches inspected many unwanted blowholes on the surface of concrete cast with steel mold as compare to CPF liner, which has smooth surface without any defects. The reasons for the defects were that the concrete was mixed air bubbles broke at the surface of steel mold. Bleeding was also noticed at the surface of steel mold (Cuicui et al., 2012).

Coutinho (2001) did a comparative analysis of Zemdrain liner, high density 5-layer wood and conventional impermeable plywood formwork on white cement. They investigated the effect of different formwork liner on the surface and other physical properties. He found that the percentage area of blow holes ratio was $0 \%$ for Zemdrain liner, whereas 5layer wood based formwork had the blowholes ratio of $5 \%$ as compared to conventional plywood.

\subsection{INFULENCE OF FORMWORK LINER ON STRENGTH}

Sha'aat. (1994) examined the surface strength formed from Zemdrain liner was 3 times higher than the impermeable formwork. Chinese engineers checked the strength of surface with rebound hammer and they noticed strength increase of $11-28 \%$ on formwork liner as compare to conventional molds (Cuicui, at al., 2012). From the two OPC mix (different w/c) it was noticed the strength increase was in the concrete with formwork liner but the percentage change was not very remarkable (Basheer et al., 2008).

Schubel et al., (2007) conducted research on three different formwork liner of different absorption and compared surface roughness, surface hardness and surface tensile strength 
with control impermeable plywood formwork. He found that the surface roughness, surface hardness and surface tensile strength were increased up to 33, 22 and 133\%, respectively. They concluded that the surface quality is a function of filler medium surface roughness. No blowholes and scouring was evidence on any of the formwork liner system. A darken surface was developed by all the concrete cast with liner which shows higher concentration of cement particles.

Philip \& Chirag (2008) in there laboratory research investigated the effect of formwork liners on five different kind of cement (PC, PFA, GGBS, MK and CSF), three different strengths (25MPa, 37MPa and 45MPa) and four different types of admixtures (WR, SP, AE \& WP). From the rebound hammer test, they noticed an average increase in strength by $45 \%, 24 \%$ and $45 \%$ for different cement, grade and admixture respectively. They also investigated the effect of formwork liner application on new and old sites and found an increase of $40 \%$ strength as compared to conventional formwork.

Coutinho (2001) did a comparative analysis of Zemdrain liner, high density 5-layer wood and conventional impermeable plywood formwork on white cement. They noticed that the surface strength was increase by $68 \%$ for Zemdrain and $0 \%$ for 5-layer wood based Formwork.

Schubel at al., (2007) cast different mix of grade $30 \mathrm{MPa}$ composed with GGBS (50 \% and $70 \%$ ) and PFA (25\% and $40 \%$ ) in formwork liner. They found that high dosage mineral addition to the mix doesn't affect the compressive strength at 7 days but the strength was increased to three folds at 28 days. Basheer et al., (2008) performed comparison analysis of 3 different mixes with two different forms. They found that the tensile strength of permeable formwork showed the increase of $33 \%$ as compared to conventional plastic and steel forms. Nolan et al., (1995) investigated conventional formwork with microsilica, silane and formwork liner. The maximum tensile strength was found when microsilica and formwork liner were used in combination. 


\subsection{INFULENCE OF FORMWORK LINER ON PERMEABILITY}

\subsubsection{Influence of formwork liner on Air Permeability}

Permeability of concrete plays very important role on the durability of concrete, more the permeability less durable it is. Permeability of concrete allows external agencies to attack concrete and the driving of moisture during heating and freezing. Water to cement ratio also affect the permeability of concrete as w/c ratio increase near the surface, it increases permeability and decreases strength. Formwork plays an important role on the permeability of concrete because if formwork is porous it can extract the excess water and make the concrete surface less permeable and more durable to external attack.

Basheer at al., (2008) in their study found that air permeability index, $\mathrm{K}_{\mathrm{a}}$ is higher for the surface with formwork liners as compare to conventional formwork, which proves that liner decrease the permeability of concrete surface. For water to cement ratio 0.45 they found that permeability was reduced by $56 \%$ by using formwork liners. According to Chinese researches, the mercury intrusion porosity meter showed the drop of $11 \%$ in porosity of concrete cast with formwork liner as compare to conventional steel mould (Cuicui et al., 2012).

Nolan et al., (1995) in his research worked on comparing three durability enhancing products on the physical properties of concrete near surface. They choose a low viscosity liquid which prevent the ingress of water and salt into the capillarity pores. Other product was microsilica which is also known as condensed silica fumes whose grain size is smaller than cement particles which provide large surface area for the hydration reaction. Last product was formwork liners which drain away all the excess water and air when concrete is vibrated instead of clogging near the surface (like in conventional formwork) . This reduced water to cement ratio near surface and lead to a surface region with enhanced surface properties. From there research they investigated that the formwork liner was the most effective way to decrease the air permeability near the concrete surface. 


\subsubsection{Influence of formwork liner on Water absorption/Sorptivity}

Price (1992) mention in his technical report that 80\% improvement was observed of the surface of concrete lined with Zemdrain liner. Sha'aat (1994) after doing research on different water to cement ratio informed that $75 \%$ improvement was seen in the sorptivity when Zemdrain liner was using as the forming liner.

Coutinho (2001) in his laboratory research proved that the concrete mix partially replaced cement with Portuguese Rise husk ash performs well with Zemdrain liner. Basheer (1997) did the comparative analysis of two $\mathrm{mix}(0.45 \mathrm{w} / \mathrm{c}$ and $0.5 \mathrm{w} / \mathrm{c})$ cast with formwork liner and found the improvement of $29 \%$ and $43 \%$ respectively as compare to control. Cuicui et al., (2012) found that the water absorption was $59 \%$ less in the formwork liner's concrete as compare to the steel mold's concrete. The decrease in water absorption is very important for the durability of structure and resistance of surface water absorption depend on the formwork absorbency (Schubel et al., 2007).

Philip \& Chirag (2008) conducted a laboratory research on the application of formwork liners on three different grades of concrete, five different cement and four different types of admixtures. They found that the average capillarity porosity was decreased by $20 \%$, $30 \%$ and $35 \%$ for different grade, cement type and admixture respectively. They also investigated the effect of formwork liner on old and new construction sites of UK and they found the capillarity porosity was decreased by $30 \%$ on new sites and $40 \%$ on old sites by using formwork liner.

Coutinho (2001) proved from his research that the sorptivity values were decreased by $78 \%$ for Zemdrain and $1 \%$ for 5-layer Formwork as compare to conventional impermeable formwork and the corresponding water absorption was decreased by 64\% and $3 \%$ respectively. 


\subsection{INFULENCE OF FORMWORK LINER ON CHLORIDE PENETRATION}

The admission of chloride is a main cause for reinforcement corrosion in any structure Chloride ions have an ability to destroy the passive oxide film of steel even in the presence of alkalis. Iron-chloride complex is formed which result in the formation of rust and allow more chloride to attach. In the absence of oxygen chloride ions can also results in the formation of non-expansive ferrous chloride corrosion products (Mindness et al., 2003).

Controlled permeability formwork is one of the known methods to enhance the protection of concrete in chloride environment. The formwork liner attached to the formwork allows the excess mix water and excess air to drain out during construction. This cause a densified microstructure and enriched cement content on the surface. This led to improved barrier to the attacking chlorides and reduce rate of deterioration and increase service life (McCarthy et al., 2001).

Price (1992) proved from his research by using concrete mix with Fly Ash (FA) and Ground Granulated Blast Furnace Slag, the chloride penetration was dramatically decreased by using the permeable formwork. Basheer et al., (1995) in their research found that regardless of the curing methodology and different mix all the formwork liner gives better performance than conventional formwork. Basheer et al., (2008) checked the chloride penetration depth of two different mix at 100 and 178 days and they found that formwork liner has less penetrated chloride depth as compare to conventional formwork.

Price (1992) informed that the use of Zemdrain liner increases cement content and decrease water to cement ratio near the surface. For this reason the more chloride was bonded near the surface, which will not allow the chloride to penetrate deeper thus provides physical barrier to the chloride ion penetration. In his another research, he sprayed chlorine salt to the samples for 75 cycles with continuous spraying and drying and found that Zemdrain liner shows the better penetration resistance than impermeable forming liner. 
Coutinho (2003) in his laboratory research proved that the Zemdrain liner performed well for chloride penetration resistance when he changes his mix by partially replaced cement with Portuguese Rise husk ash. McCarthy \& Giannakou (2002) conducted the research in marine environment and they also proved the reduction in chloride penetration by using Zemdrain liner. Sha'at (1994) in his thesis mentioned that 90-95 \% fall in chloride penetration of OPC concrete cast in Zemdrain liner formwork. Cuicui, et al., (2012) after passing current for $6 \mathrm{~h}$ under $60 \mathrm{~V}$, formwork liner concrete shows the decrease of $24 \%$ as compare to same concrete cast in steel mold.

In hot climates more chloride ingress can be experienced, for that reason in Situ tests in United Arab Emirates have been recorded over the period of 3 years to check the performance of Zemdrain liner. Structures cast with 50\% PC and $50 \%$ GGBS mix and PC with 0.4 w/c showed substantial decrease on chloride levels. The use of formwork liner in aggressive chloride rich environment is equivalent to increase the concrete strength by $15 \mathrm{MPa}$. The use of formwork liner can also be effective for the carbonation durability, research proved the use of formwork liner for carbonation attack is equal to providing an extra cover of 15mm (Wilson, 2007).

Philip \& Chirag (2008) found that the chloride penetration resistance was increased by 50 $\%$ by using formwork liner with different types of cement. They also noticed an increased resistance of $65 \%$ when concrete of different grades was cast with permeable formwork liner. Upon comparison of old and new construction sites in UK, they found that the chloride penetration was decreased to $75 \%$ by the application of formwork liner.

It was found that after passing the current for 6 hours from $\mathrm{NaCl}$ and Noah, Zemdrain showed the chloride penetration resistance increase of $43 \%$ and for 5-Layer wood based formwork chloride penetration resistance was increased by $13 \%$ as compare to impermeable wood formwork (Coutinho, 2001). 


\subsection{INFULENCE OF FORMWORK LINER ON FREEZE AND THAW RESISTANCE}

Freeze-thaw resistance is an important durability property of concrete, it has a great importance to structures situated in cold areas. Ice is formed in the concrete pores which cause internal damage in the concrete and sometime cause major structure failure. Freeze thaw durability of concrete has handy affiliation with pore structure. Volume, radius and pore size distribution decide the freezing point of pore solution and the amount of ice formed in the pores of concrete structures. For a definite temperature interval $\left(0^{\circ} \mathrm{C}\right.$ to $20^{\circ} \mathrm{C}$ ) of any frozen concrete pore solution prompts a larger hydraulic pressure which causes severe frost damage. The freezing point and the amount of frozen solution define the durability of concrete. The freezing and thawing of internal frozen solution put hydraulic pressure and distress on the microstructure of concrete which cause deterioration (Cai \& Liu, 1998).

Cycles of freeze and thaw in humid atmosphere result in frost damage of concrete. If concrete is provided with entrainment of air, it has increase resistance to freeze and thaw because discrete bubble can release internal pore pressure caused by ice formation. One can expect that controlled permeability formwork which densify the surface may not be perfect for the repetitive cycles of freeze and thawing. However literature suggest that irrespective of grade, cement type concrete cast with permeable formwork liner has increases resistance to freeze and thaw as compare to impermeable formwork liner. This is because of the liberation action, which causes an increase in the accumulation of entrainment bubbles at the surface (McKenna, 2005). Laboratory and field tests showed that the improvement to the impermeable formwork concrete with the addition of airentrainment agents and application of silanes. It perform as equal to the permeable formwork liner, however, the most improvement was observed when formwork liner was cast with air entrainment admixture and silanes (McKenna, 2005).

Norwegian Institute of Technology in Trondheim conducted a research on the freeze thaw resistance of high strength microsilica cement mixes formed with Zemdrain liner. They investigated that Zemdrain liner showed the minor deterioration after 56 cycles, 
whereas conventionally cases concrete showed an accumulated material loss of over $6 \mathrm{~kg} / \mathrm{m}$ (International Survey, 1992).

Laboratory experiment showed by the application of formwork liner with different cement, the freeze-thaw resistance was increased by 50\%. When the same formwork liner was used with different concrete grades, the freeze-thaw resistance was increased by $65 \%$. Old construction sites where formwork liner was used showed $60 \%$ more resistance of freeze- thaw as compare to concrete section cast with conventional formwork. (Philip \& Chirag, 2008)

By the use of formwork liners surface density is increased which make concrete more strong for freezing and thawing conditions. No. of researchers have done on the effect of formwork liner on the freeze thaw durability of concrete. Irrespective of the design mix and methodology formwork liner improves the freeze thaw property of concrete. However, results varied by the change in mix and test method. The degree of damage to concrete cast with permeable formwork liner was less than one fifth the damage to concrete cast with conventional formwork (Malone, 1999).

Skjolsvold (1991) compared the efficiency of Zemdrain formwork liner with conventional formwork by mixing $384 \mathrm{~kg} / \mathrm{m}^{3}$ of cement in proportion of 0.42 ratio of water-cement ratio with $4.7 \%$ of silica fumes. He found that after 28 cycles concrete cast with permeable formwork liner has mass reduction of $0.02 \mathrm{~kg} / \mathrm{m}^{3}$ and conventional formwork shows the reduction of $2.54 \mathrm{~kg} / \mathrm{m}^{3}$ (Skjolsvold, 1991).

Beddoe (1991) also compared the conventional formwork with conventional form work at 28 and 50 cycles of freezing and thawing he found that the concrete cast with conventional formwork have the mass reduction of $6.2 \mathrm{~kg} / \mathrm{m}^{3}$ and $7.87 \mathrm{~kg} / \mathrm{m}^{3}$ at 28 and 50cycles, whereas for the same concrete cast with formwork liner have mass reduction of $0.10 \mathrm{~kg} / \mathrm{m}^{3}$ and $0.17 \mathrm{~kg} / \mathrm{m}^{3}$ at 28 and 50 cycles. The mix design he used include 355 $\mathrm{kg} / \mathrm{m}^{3}$ of cement with 0.55 water to cement ratio. 
Karl \& Solacol (1993) investigated the performance of formwork liner on two different design mixes. First mix had 0.49 w/c containing $13 \%$ flyash with OPC cement and another mix with 0.65 water to cement ratio with OPC cement. He found after 5 repetitions of freezing and thawing cycles formwork liner with 0.49 w/c mix has $19 \%$ loss in control. Whereas formwork liner with $0.65 \mathrm{w} / \mathrm{c}$ mix had 3\% loss in control.

David (2004) used two different mix with formwork liner and conventional control formwork. Mix 1 was composed of 0.57 w/c with OPC and mix 2 was made from 0.44 w/c with OPC. He found after 28 cycles the mass loss for mix 1 with formwork liner was $0.06 \mathrm{~kg} / \mathrm{m}^{3}$ and conventional has mass loss of $1.12 \mathrm{~kg} / \mathrm{m}^{3}$. Mix 2 has the mass loss of 0.01 $\mathrm{kg} / \mathrm{m}^{3}$ and $0.79 \mathrm{~kg} / \mathrm{m}^{3}$ for formwork liner and conventional formwork respectively (David, 1994).

\subsection{INFULENCE OF FORMWORK LINER ON SALT SCALING RESISTANCE}

Salt scaling is the major durability concern of concrete. In cold areas the concrete is subjected to freezing and thawing in the present of de-icers, which cause damage on the surface of concrete termed as "Salt Scaling”. Scaling can cause progressive removal of small chips and flakes from the surface and making it vulnerable to water and other chemicals which cause the severe durability issues (Scherer \& Valenza, 2006).

When a saline solution freezes on the cementitious surface composite material of ice and concrete is formed. Due to this composite action there is a thermal expansion imbalance. According to this mechanism, scaling occurs when stress in the freezing ice layer rises. Ice layer contracts 4-5 times as much as concrete surface inducing tensile stresses on the concrete, which results in cracking (Scherer \& Valenza, 2006).

Tests indicate that the formwork liners could produce enhances surface characteristics with increased density and increased strength with all varieties of mix and w/c ratio of 0.40 to 0.65 . Type of Portland cement, slag, flyash and silica fumes did not change the action of formwork liner. Research proved that the use of formwork liner gave better 
resistance to de-icing chemicals as compare to concrete cast with OPC (replaced with 75 \% GBBS) with air entrainment admixture. (Stark \& Knaack, 1997).

Permeable formwork offers the greatest cost benefits in areas where concrete will experience severe conditions such as on roadways treated with de-icing salts (Stark \& Knaack, 1997; Malone, 1999).

\subsection{PAPERBOARD MATERIALS PROPERTIES}

Paperboard tube which are also known as cores are highly engineered and optimized structures. They consist of piles of orthotropic paperboard materials of different strengths and stiffness, which are produced in a continuous automated fashion by a processing technology called spiral-winding (QuickStrip). The strength and stiffness properties of paperboard materials are nonlinear and vary with moisture content (Gerhardt, 1990).

Andrew et al., (2012) found the axial stiffness (Modulus o elasticity) of paper based tube material to be $2390 \mathrm{MPa}$. In addition, they also found that that specimen size and temperature have little effect on the equilibrium moisture content of paperboard at a given relative humidity. To improve the water resistance of paperboard tubes they suggested that a water resistant polymer coated ply can be added in the winding process or a polyurethane coating can be applied to the surface during manufacturing process. 


\subsection{REVIEW OF LITERATURE}

Numerous researches have been conducted on the permeable and impermeable formwork liners. Investigations showed that concrete visual, durability and mechanical properties can be enhanced by using permeable formwork liner. Permeable formwork can extract excess water and air from concrete and hence, concrete surface is densified with lower water to cement ratio. These formwork liners have been used in structures from decades. Without changing the mix design, high surface strength and durable concrete can be achieved. There practical applications can be seen in bridges, water treatment plants and other concrete structures. The formwork liners which are selected for this research project are Weather Shield, Poligloss and Zemdrain manufactured by the Newark Group. Lots of research is done on Zemdrain formwork liner, however Poligloss and Weather Shield are new products which are introduced by Newark Group in construction world. Fresh, visual, mechanical and durability properties of cast concretes (four commercial concretes supplied by King Package Materials) using these formwork liners will be conducted to assess performance. 


\section{CHAPTER 3: EXPERIMENTAL INVESTIGATION}

\subsection{INTRODUCTION}

Considering formwork as an important cost feature in the construction, NEWARK GROUP is manufacturing Forming Tubes from recycled paper products. To find the influence of these tubes on fresh state properties of concrete, long and short term mechanical properties, and durability characteristics of various cast commercial concretes, a comprehensive series of experimental investigation was conducted at Concrete, Structures and Non- Destructive laboratories at Ryerson University. Four different types of commercial concretes were selected on the basis of strength and workability properties, these concretes were the products of KING Package Materials - a well-known ready-mix concrete Manufacturer. The composition and properties of these concretes were provided by the Company.

In the first phase of the investigation, tests were conducted to determine the fresh state properties of cast concrete in forming tubes such as slump flow, fresh density and its variation with time, and pressure development on forming tubes during casting. To monitor pressure distribution due to fresh concrete on forming tubes, pressure transducers were installed at top, middle and bottom of the forming tubes. Lateral pressure developments on the forming tubes were monitored with time. Temperature (due to heat of hydration) development in cast fresh concrete was also monitored by thermocouples installed at the center and close to the side of the tube surface.

In the second phase, Tests were conducted to determine the Surface characteristics through visual observation and compressive strength using non-destructive test (NDT) "Rebound Hammer" of cast concretes in various Newark forming tubes in order to analyze the tube performance. In the third phase, mechanical properties, such as compressive strength and density of cast concretes using various forming tubes were evaluated using cylinder specimens as per ASTM Standards. In the fourth and final Last phase, the influence of different forming tubes on durability characteristics of cast 
concretes (performed as per ASTM Standards) such as water absorption, sorptivity and resistance against chloride penetration resistance, freeze-thaw and salt scaling were determined. In third and fourth phases, performance of Newark forming tubes was studied compared to traditional wood, plastic and steel molds. 


\subsection{COMMERCIAL CONCRETES}

Four different KING concretes were provided by Newark Group to evaluate the performance of the Newark forming tubes. Out of four, three were normal density concrete with different compressive strengths and one was self-consolidating concrete (SCC). Compositions, characteristics strength, uses/benefits of each King Concrete are briefly described in the following sections (based on the fact sheets provided by the Manufacturer).

\subsubsection{King Sakrete}

SAKRETE concrete is a pre-blended concrete material. It is designed for new concrete construction projects. It is mainly used to construct footings, sidewalks, slabs, steps and patios, setting deck posts, fence posts, poles, etc. It can also be used where concrete overlays and repairs of a thickness $5 \mathrm{~cm}$ or more is required. Normal 28 day compressive strength of Sakrete concrete can be achieved as $28 \mathrm{MPa}$. Figure 3.1 shows a $30 \mathrm{~kg}$ bag of Sakrete concrete. Each bag required $\quad 2.7 \mathrm{~L}$ of water to yields approximately $0.014 \mathrm{~m}^{3}$ of concrete and the desired compressive strength (http://consumer.kpmindustries.com/Product_Catalogue/ByCategory/SakreteProducts.aspx)

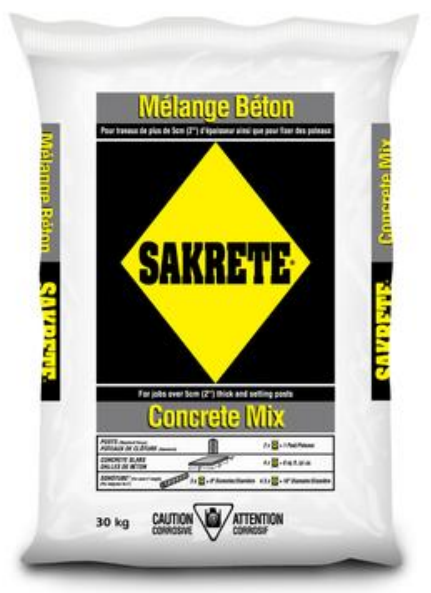

Figure 3.1: Sakrete Concrete Bag 


\subsubsection{King MS-S10}

King MS-S10 concrete is a pre-blended, synthetic fiber reinforced, pre-packaged high performance cementitious concrete repair material containing Portland cement, silica fume, air-entraining admixture, $10 \mathrm{~mm}$ (3/8 inch) stone and other carefully selected components. Air-entrainment in MS-S10 provides superior resistance to freeze-thaw cycling and salt scaling. Properties of this concrete are similar to conventional concrete, thus offering excellent compatibility to parent concrete. It has improved durability, reduced bleeding, improved resistance to sulphate attack, very low permeability, and low shrinkage. This is ideal for full depth repair, which does not need to be extended. It has excellent bonding characteristics to parent concrete. It is designed with natural normaldensity non-reactive fine and coarse aggregates to eliminate potential alkali-aggregate reactivity (AAR) .Normal 28 day compressive strength of MS-S10 concrete is 45MPa. Each bag of MS-S10 requires 2.6L of water to yield approximately $0.014 \mathrm{~m}^{3}$ and desired strength. Figure 3.2 shows a $30 \mathrm{~kg}$ bag of MS-S10 Concrete (http://industrial.kpmindustries.com/Product_Catalogue/products/Concrete/MSS10_Concrete.aspx).

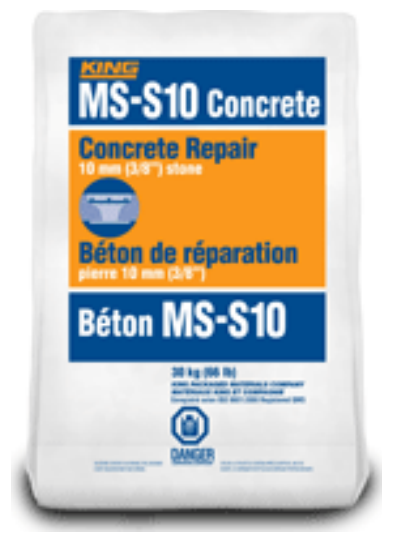

Figure 3.2: MS-S10 Concrete Bag 


\subsubsection{King HP-S10}

King HP-S10 Concrete is a pre-blended, pre-packaged high performance cementitious concrete repair and construction material containing Portland cement, silica fume, airentraining admixture, $10 \mathrm{~mm}$ (3/8 inch) stone and other carefully selected components. This concrete is ideal for full depth repair which does not need to be extended. It provides excellent bond to parent concrete without requiring a bonding agent. It is designed with natural normal-density non-reactive fine and coarse aggregates to eliminate potential alkali-aggregate reactivity (AAR). High early strength can be achieved using HP-S10 concrete for earlier re-opening of traffic lanes on concrete structure. Airentrainment in this concrete provides superior resistance to freeze-thaw cycling and salt scaling resistance. Its properties are similar to conventional concrete, thus offering excellent compatibility to parent concrete. This concrete has improved durability, improved performance in cold temperatures, reduced bleeding, and improved resistance to sulphate attack, very low permeability and low shrinkage. Normal 28 day compressive strength of HP-S10 concrete is $60 \mathrm{MPa}$. Each bag of HP-S10 requires $2.4 \mathrm{~L}$ of water to yield approximately $0.014 \mathrm{~m}^{3}$ and the desired Strength. Figure 3.3 shows the $30 \mathrm{~kg}$ bag of HP-S10 (http://industrial.kpmindustries.com/Product_Catalogue/products/Concrete/HPS10_Concrete.aspx).

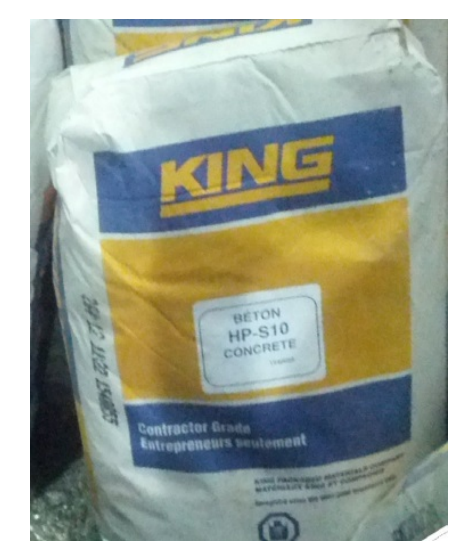

Figure 3.3: HP-S10 Concrete Bag 


\subsubsection{King MS-S10 SCC}

KING MS-S10 Self-Consolidating Concrete (SCC) is a pre-blended, pre-packaged, high performance, flowable concrete material containing Portland cement, silica fume, $10 \mathrm{~mm}$ (3/8 inch) stone and other carefully selected admixtures. MS-S10 has superior plastic properties which provide a fluid mix with self-consolidating characteristics without bleeding or segregation, easily consolidated without rodding or vibrating. Airentrainment provides superior resistance to freeze-thaw cycling and salt scaling in the presence of de-icing salts. It has excellent pump-ability. Properties of MS-S10 concrete are similar to conventional concrete, thus offering excellent compatibility with existing concrete. It also provides improved resistance to sulphate attack, very low permeability, low shrinkage and it is designed with natural normal-density non-reactive fine and coarse aggregates to eliminate potential alkali-aggregate reactivity (AAR). Normal 28 day compressive strength of MS-S10 SCC concrete is $40 \mathrm{MPa}$. Each bag of MS-S10 SCC requires $3.4 \mathrm{~L}$ of water to yield approximately $0.014 \mathrm{~m}^{3}$ and the desired Strength. Figure 2.4 shows a 30 kg bag of MS-S10 SCC Concrete (http://industrial.kpmindustries.com/Product_Catalogue/products/Concrete/MS-S10_SelfConsolidating_Concrete.aspx).

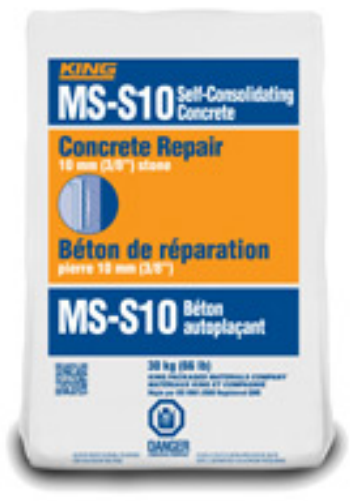

Figure 3.4: MS-S10 SCC Concrete Bag 


\subsection{NEWARK FORMING TUBES}

Three different types of forming tubes were provided by The Newark Group. These forming tubes are manufactured from waste paper Products and are widely used in North America. Newly introduced Weather Shield, Poligloss and Zemdrain forming tubes produced by the Newark Group is an emerging technology. The application of these tubes as formwork can produce quality concretes through improved water resistance, handling extensive vibration/hydrostatic pressure during casting, better surface finish and enhancing concrete durability. Over all, such engineered tubes as formwork can lead to efficient and speedy construction, extend the service life of structures due to better durability and promote sustainable construction through the use of recycled products. The forming tubes provided by the Newark Group for experimental program was $300 \mathrm{~mm}$ (dia) x $900 \mathrm{~mm}$ (height). However, tubes of varying dimensions are used by the Newark in the field. A brief introduction of each forming tubes are provided in the following section as per the NEWARK Technical publication. 


\subsubsection{Weather Shield}

Weather Shield provides protections against moisture and adverse weather conditions to help keep the elements from impacting your construction schedule. These tubes are built to withstand the rigors of construction. These are designed to hold the full hydrostatic pressure load of concrete in a single continuous pour. Newark Weather Shield tubes have earned their mark in the North America industry for the most demanding construction projects. This tube has Weather Shield Technology which improved water resistance that minimizes schedule changes due to inclement weather and provides increased strength and durability vs. regular column forms. It is economical with one-time use and with easy placement, pouring and stripping. These tubes manufactured with $100 \%$ recycled paperboard can handle extensive concrete vibrations and are also LEED® Qualified. The Poly inside Ply of this tube ensures easy stripping without form release agents and can easily be placed manually or by crane in the field. Figure 3.5 shows the Weather Shield Material and the Weather Shield forming tube respectively (http://www.newarkgroup.com/products/newark-construction-products.aspx).

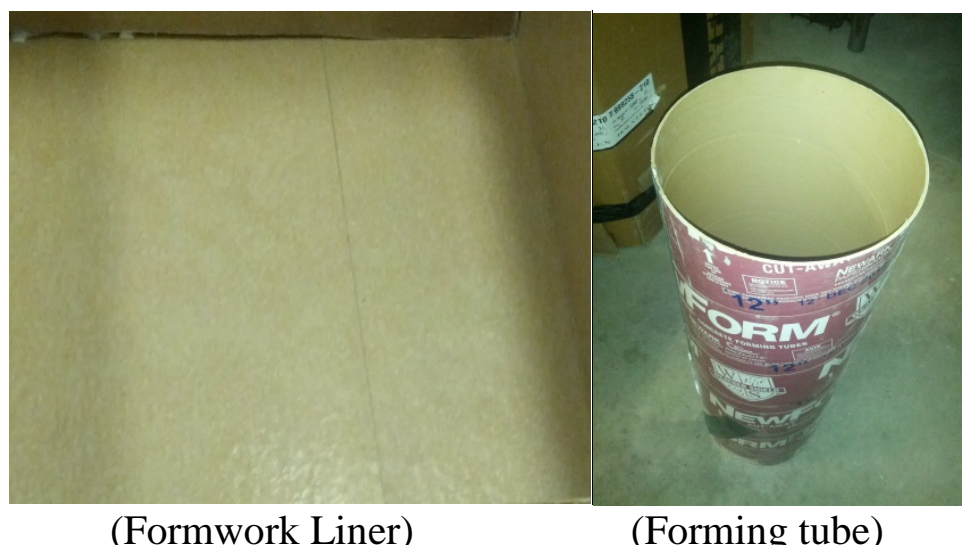

Figure 3.5: Weather Shield Material and Weather Shield Tube 


\subsubsection{Poligloss}

Newark Poligloss forming tubes can be used for jobs that demand aesthetically smooth and high gloss concrete columns without seam markings. It provides superior aesthetics with a unique high gloss finish. It is installed with inner Poly lining which produces a smooth concrete finish without spiral seams, eliminating the need for extensive manual finishing. Its Weather Shield improves water resistance and minimizes schedule changes due to inclement weather. Poligloss has QuickStrip ${ }^{\mathrm{TM}}$ Technology which provides a quick and convenient method for the removal of forms. QuickStrip ${ }^{\mathrm{TM}}$ eliminates the need to cut the form with a saw, creating a safe and cost-effective means to completely strip the form within minutes. These tubes are one-time use which allow for faster setup for multiple column pours with no cleaning or return shipping. It can easily be placed manually or by crane in the field. It is engineered to withstand the full hydrostatic pressure of a continuous pour (http://www.newarkgroup.com/products/newarkconstruction-products.aspx). Figure 3.6 shows the Poligloss material and the Poligloss forming tube respectively.

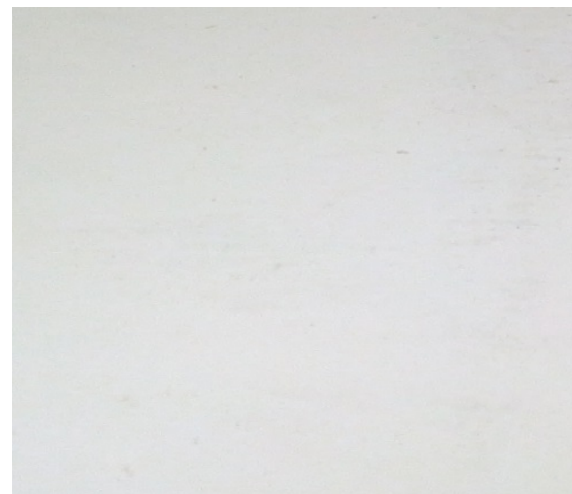

(Formwork Liner)

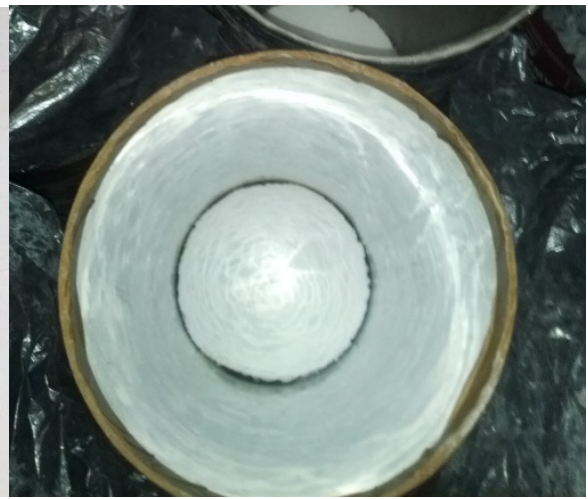

(Forming tube)

Figure 3.6: Poligloss Material and Poligloss Tube 


\subsubsection{Zemdrain}

Newark Zemdrain liner offers superior surface hardness. Blow hole and porous free surface of Zemdrain tube significantly limits the ingress of salt and insects. This tube has Weather Shield Technology which Improves water resistance and minimizes schedule changes due to inclement weather. Unique DuPont ${ }^{\mathrm{TM}}$ Zemdrain ${ }^{\circledR}$ Liner provides the controlled evacuation of excess water and air away from the freshly poured concrete. It can improve concrete cement to water ratio, creates a higher density surface for greater longevity and minimize the effect of carbonation, increase surface hardness and abrasion resistance in finished concrete column. The QuickStrip ${ }^{\mathrm{TM}}$ technology provides a quick and convenient method for the removal of forms. QuickStrip ${ }^{\mathrm{TM}}$ eliminates the need to cut the form with a saw, creating a safe and cost-effective means to completely strip the form within minutes. It has faster curing which can improve drying time, via DuPont ${ }^{\mathrm{TM}}$ Zemdrain ${ }^{\circledR}$ liner wicking properties at surface of concrete. This product is extensively used in water infrastructure projects where concrete is in direct contact with water. It is engineered to withstand the full hydrostatic pressure of a continuous pour. It can be placed readily, either manually or by crane, for large diameters and longer lengths. Figure 3.7 shows the Zemdrain material and Zemdrain forming tube respectively (http://www.newarkgroup.com/products/newark-construction-products.aspx). .

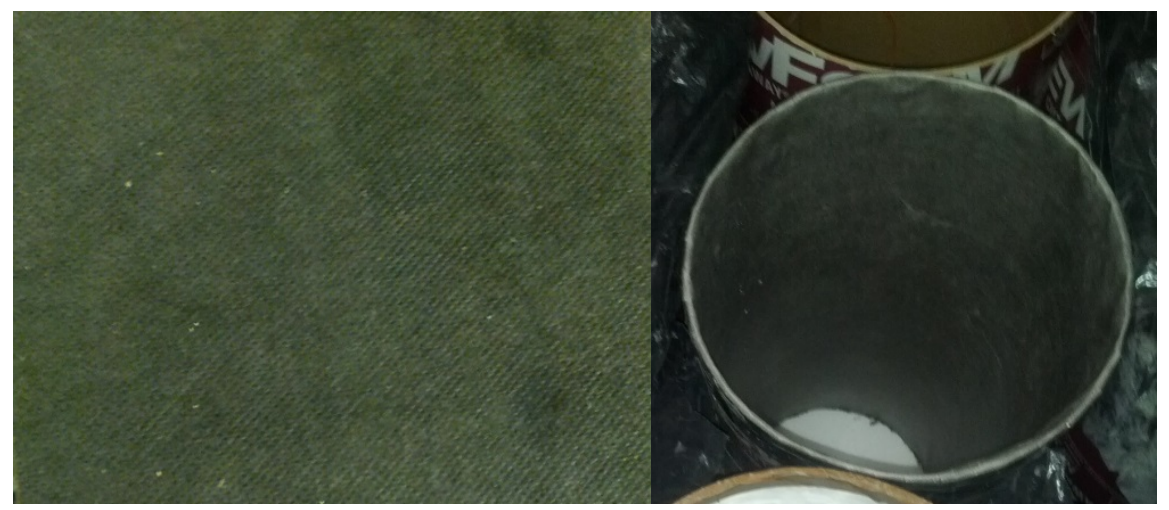

(Formwork Liner)

(Forming tube)

Figure 3.7: Zemdrain Material and Zemdrain Tube 


\subsection{CASTING CONCRETE IN FORMUNG TUBES}

\subsubsection{Mixing}

All concretes were cast as per Manufacturer Guidelines using Sicoma commercial mixer which has maximum capacity of 300 liters. The capacity was large enough to cast all the tubes and test specimens in single batch. Figure 3.8 shows the commercial mixture used for casting. After mixing, crane was used to transport the bucket of fresh concrete to the pour in the forming tube specimens and cast other specimens associated with for fresh, mechanical and durability tests.

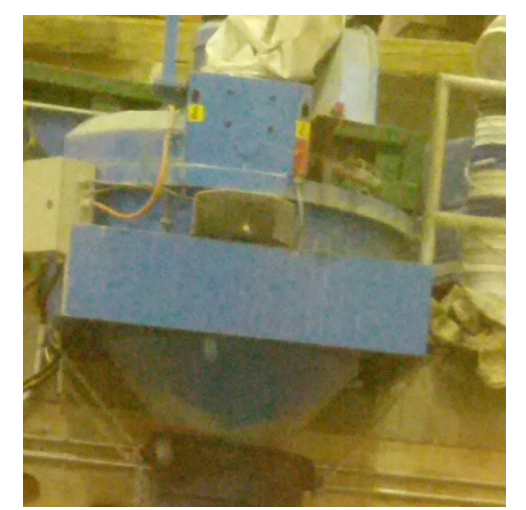

Figure 3.8: Commercial mixture used for all casting

\subsubsection{Slump and slump flow tests on fresh concretes}

Immediately after concrete mixing, slump test was conducted as per ASTM C143 for normal density concrete and slump flow test was conducted as per ASTM C1611 for SCC. Slump flow test shows the consistency, workability and concrete capacity to deform under its own weight. Figure 3.9 shows the slump flow test performed during experimental program. 


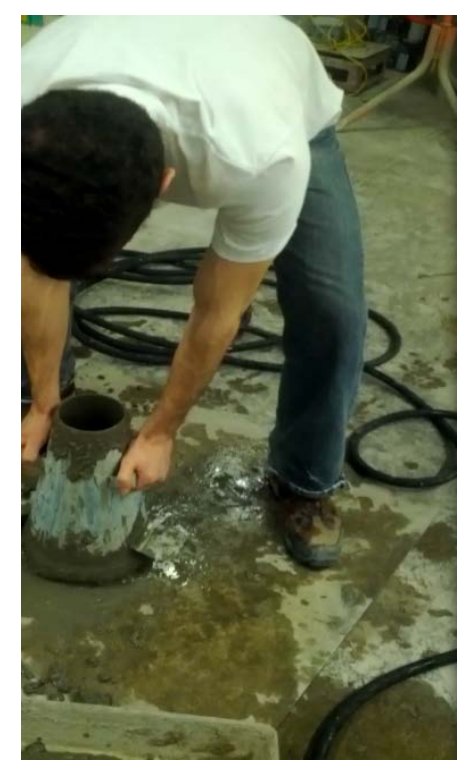

Figure 3.9: Slump flow test

\subsubsection{Fresh density test of concrete}

In order to calculate pressure created by concrete on walls of forming tubes from fundamental theories, we need to calculate a factor named "Cw”, which depends on fresh density of concrete. Figure 3.10 shows the typical wet density monitoring setup of concrete. Typical cylinder of $100 \mathrm{~mm}$ x 200mm was cast from each concrete mix and its weight was continuously monitored for several hours depending upon the type of concrete and final setting time. Fresh density with time was calculated based on mass and volume.

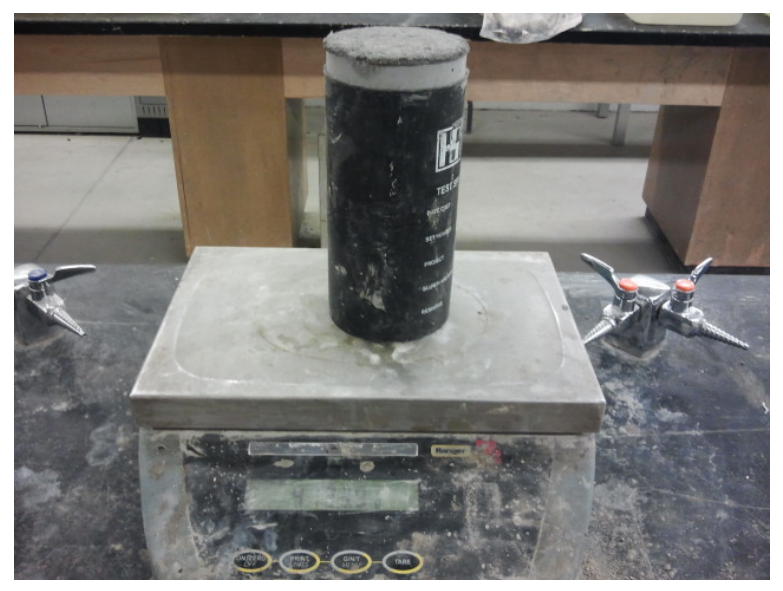

Figure 3.10: Fresh density monitoring setup 


\subsubsection{Curing of specimens}

To prevent evaporation of water from unhardened concrete all specimens were cured according to ASTM C192. Immediately after casting and finishing, all the specimens were placed in a curing room for 28 days. Specimens were released from the moulds after 21 days to catch the influence of Newark forming tubes on the surface of concrete. However, the big forming tube specimens were cured in normal curing conditions in the lab at room temperature. Figure 3.11 shows the mechanical and durability testing specimens placed in humidity room.

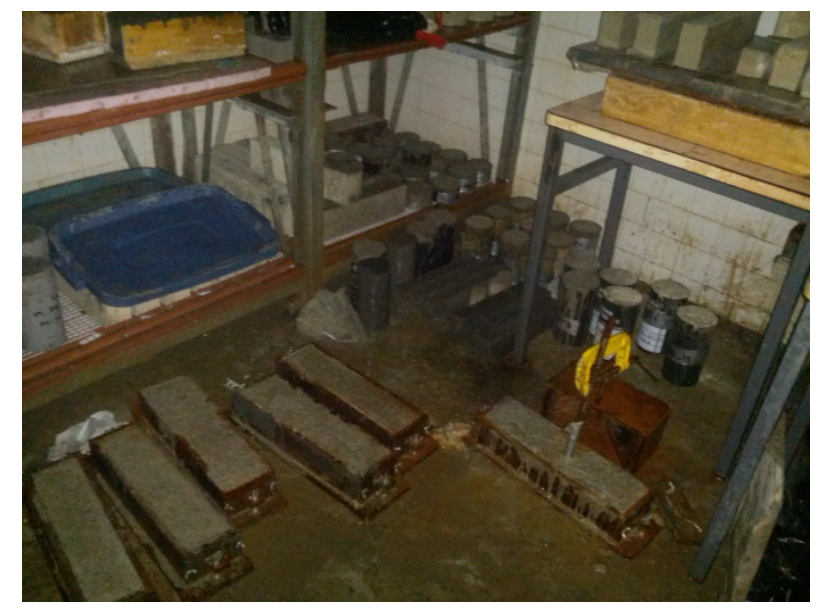

Figure 3.11 Specimen in curing room

\subsection{MONITORING PRESSURE DEVELOPMENT DURING CASTING}

As per consultation with Newark Group, Weather Shield tube was selected to monitor the lateral pressure development due to fresh concrete. The lateral pressure development at various heights was monitored using pressure transducers with time from fresh state to the hardened state during setting time of concrete. Pressure data with time was recorded by using a computer aided data acquisition system. Figure 3.12 shows the typical pressure monitoring schematic diagram for all the concrete mixtures. Pressure transducers were installed at top, middle and bottom of Weather Shield tube. The basic purpose of this test (in addition to determining the pressure data) was to observe the impact of concrete pressure created on the walls of form; either they can bear the pressure without any 
bulging or some amendments should be made in the manufacturing of tubes. The pressure exerted on the forming tube was theoretically verified from Garnet (E.q. 2.1) and ACI (E.q 2.2) models. The percentage change in theoretical and experimental values were also calculated Figure 3.13 (Scale 1:150) shows the pressure transducers installed at the top, middle and bottom of the Weather Shield tube.

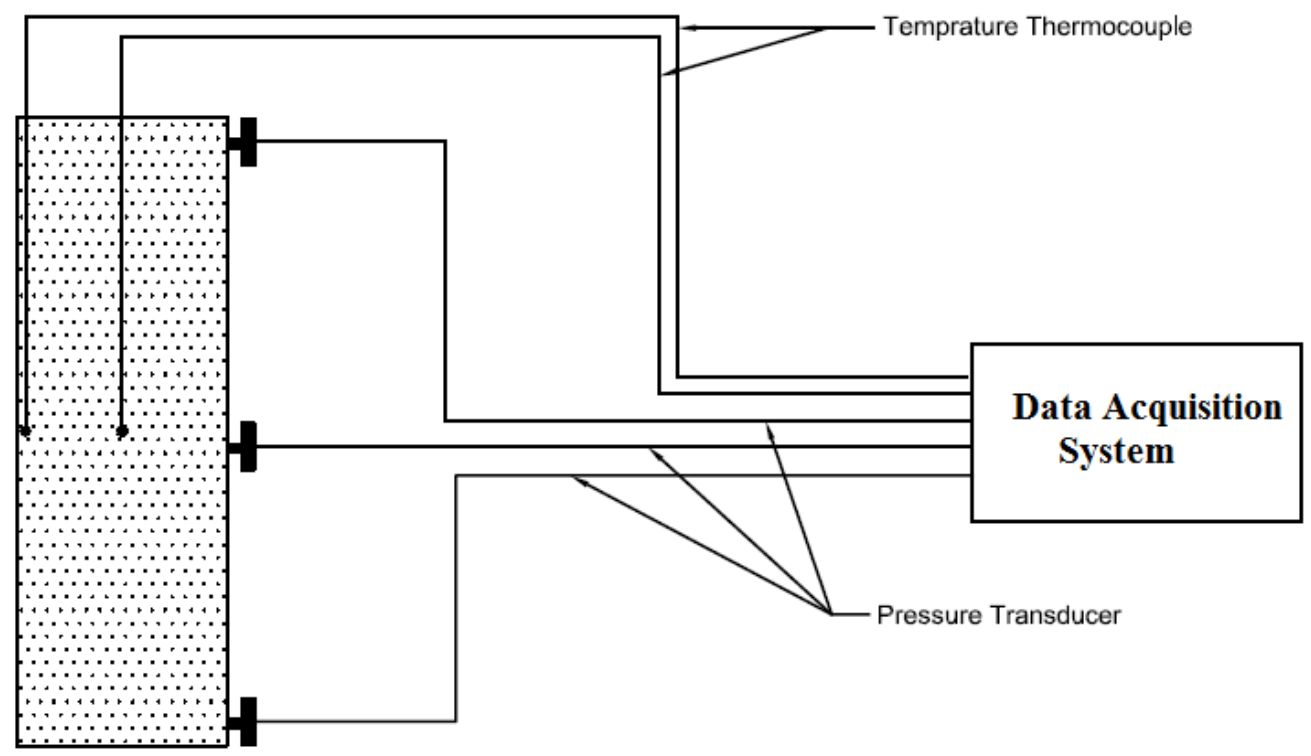

Figure 3.12: schematic diagram for pressure and heat of hydration monitoring

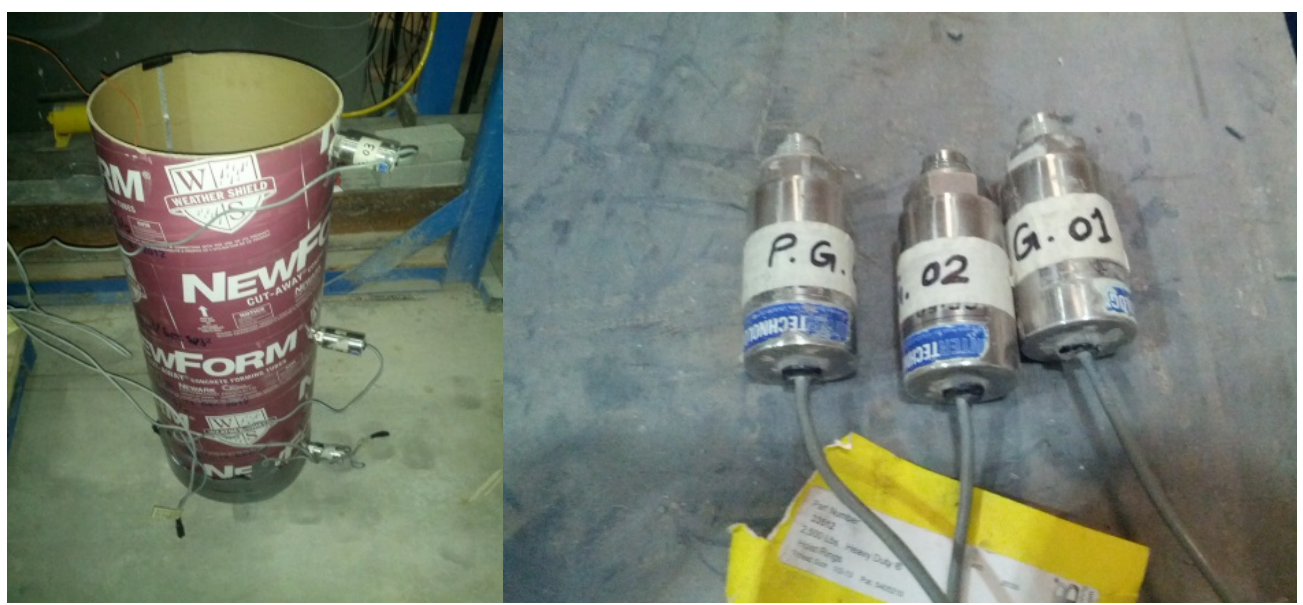

(Pressure transducers 19mm dia)

Figure 3.13: Pressure transducers installed in the Weather Shield tube 


\subsection{MONITORING OF TEMPERATURE DEVELOPMENT IN CAST FORMING TUBES}

Temperature thermocouples were introduced inside the cast concrete at near the surface and at the core of Weather Shield tube during casting when concrete was is filled half way in the tube. Figure 3.12 shows the typical temperature monitoring schematic diagram for all the concrete mixture showing location of thermocouples.. Figure 3.14 shows thermocouples installed at core and at the surface of Weather Shield tube for all concretes.

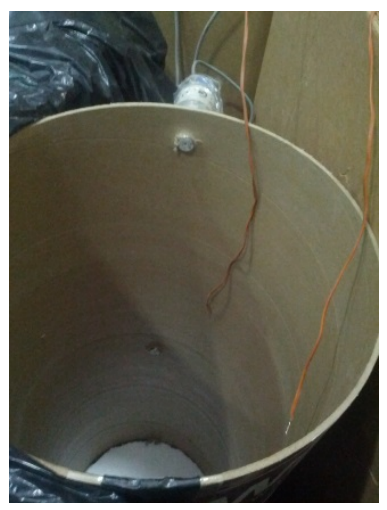

Figure 3.14: Temperature thermocouple introduced at core and at surface of Weather Shield tube for all concretes.

\subsection{OBSERVATION OF SURFACE CHARACTERSITICS}

The Newark forming tubes were stripped off from the surface of the cast tube column specimens after 21 days of room curing to observe the influence of different forming tube liners on the concrete surface (Fig, 3.15). It should be noted that this tubes were not put in a curing room and was covered with polythene bags during the duration of normal room curing condition. Surface characteristics developed by each of the Newark tubes for different concretes were inspected visually and physically. In addition, tube concrete surface strength was monitored at various heights by Schmidt rebound hammer. 
After removing the Newark tubes from harden concrete, the surface of concrete was inspected visually and surface characteristics like surface texture, honeycombing, cracks, joints etc. were identified.

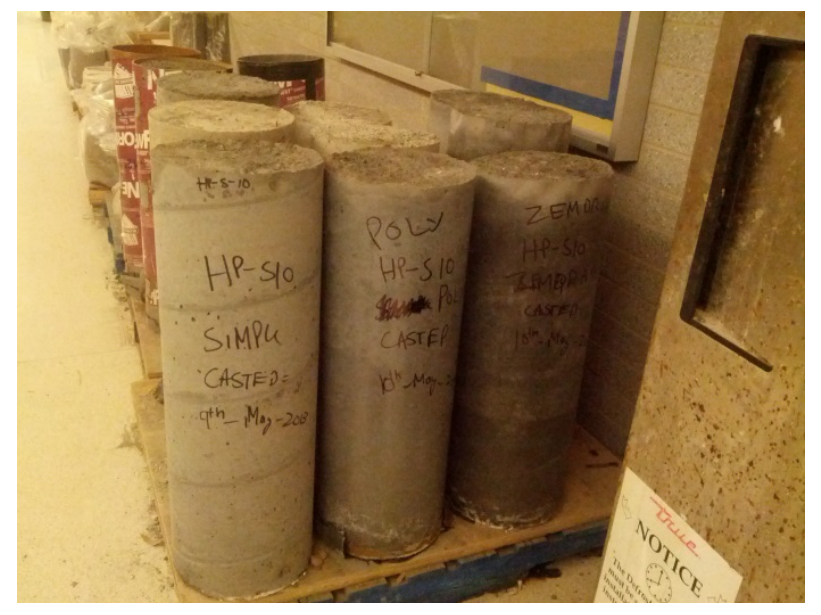

Figure 3.15: Tubes after removal of forms

The surface strength was measured using a Schmidt hammer at various heights of cast tubes column specimens at different ages of 7, 14, 21 and 28 days. A comparative study for strength development was conducted on Weather Shield, Poligloss and Zemdrain tube effects. Holes of $75 \mathrm{~mm}$ x $75 \mathrm{~mm}$ was made in the forming tubes at the top, bottom and middle to expose the cast concrete for measuring the strength by Schmidt hammer as forms were removed after 21days. Figure 3.16 Shows the Schmidt hammer test on a typical tube.

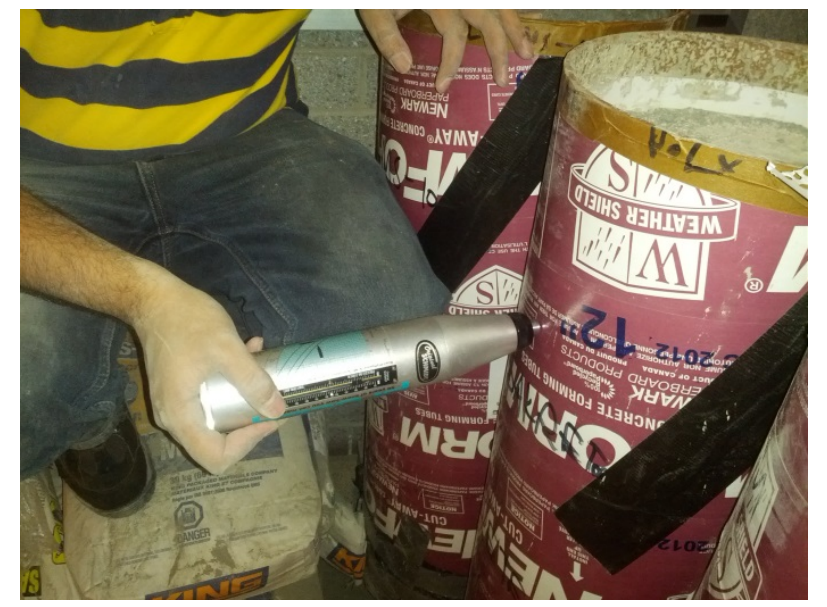

Figure 3.16: Schmidt hammer test on a typical tube 


\subsection{ABSORPTION OF FORMWORK LINER}

Water absorption of formwork liner was checked to investigate the change in concrete properties caused by absorption of formwork liner. Water absorb by formwork liner can affect the water-cement ratio near the surface of formwork and can influence the mechanical and durability properties. Figure 3.17 shows the setup for finding the water absorption of formwork liner. A piece of Weather Shield, Poligloss and Zemdrain was initially weighted, they were immersed in water after $24 \mathrm{~h}$ of immersion their final weight were recorded.

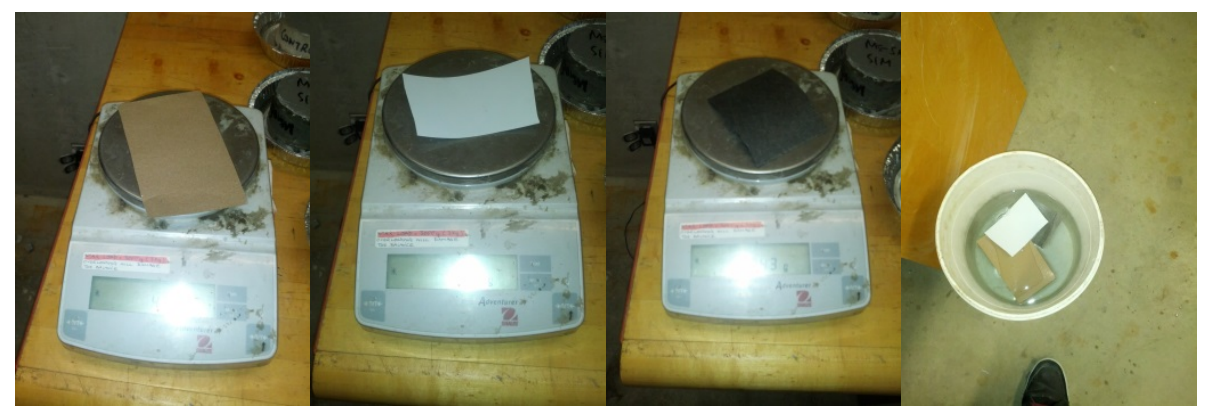

Figure 3.17: Setup for water absorption of formwork liners.

\subsection{COMPRESSIVE STRENGTH FROM CYLINDERICAL SPECIMENS}

Cylindrical molds of $100 \mathrm{~mm}$ diameter and $150 \mathrm{~mm}$ height for all types of Newark forming tube liner were cast and prepared for the compressive strength test. At least three cylinders were cast for each Weather Shield, Poligloss and Zemdrain tubes with each concrete mixture and their compressive strength was determined as per ASTM C39 standard testing procedure. In addition, 100 x 200 mm cylinders using conventional plastic moulds were also cast (as control) to compare performance compared with Newark form's cylinder strength. Figure 3.18 shows the molds prepared for compressive strength of Weather Shield, Poligloss and Zemdrain, respectively. 


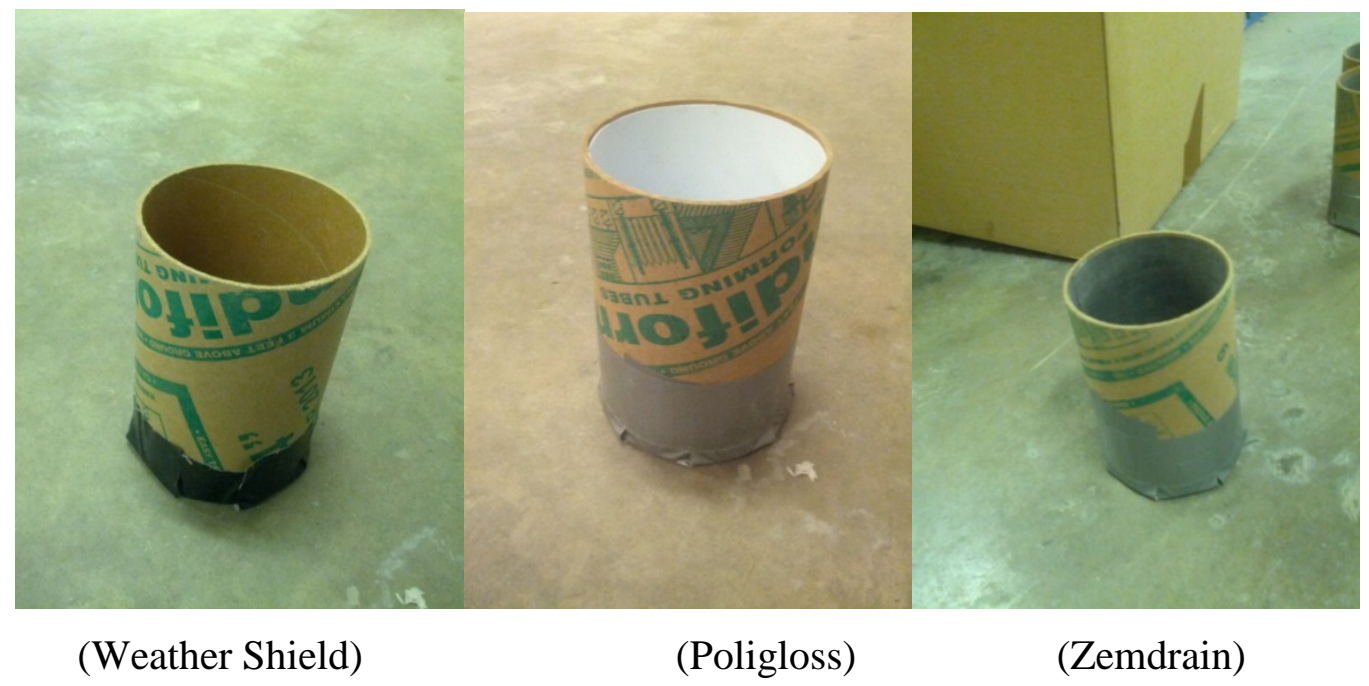

Figure 3.18: Compressive Strength molds for Weather Shield, Poligloss and Zemdrain

Compressive strength of cylinders for all concrete cast in control (plastic mould), Weather Shield, Poligloss and Zemdrain tube moulds was tested after 28 days of casting. Figure 3.19 shows the typical testing of compressive strength using compressive testing machine. Figure 3.20 shows the crushed concrete specimens of Newark form's concrete.

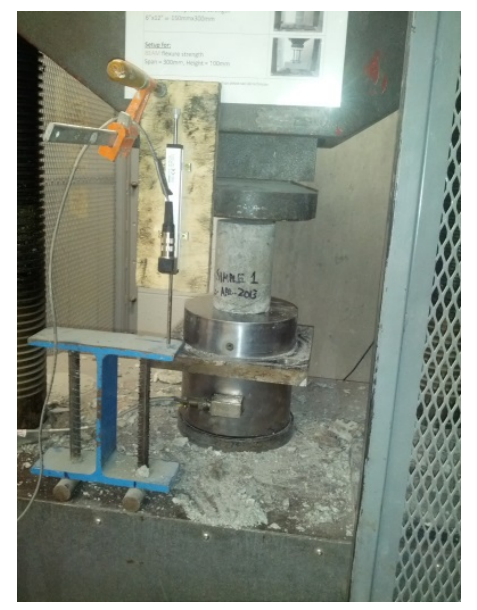

Figure 3.19: Typical experimental setup of Compressive testing machine. 


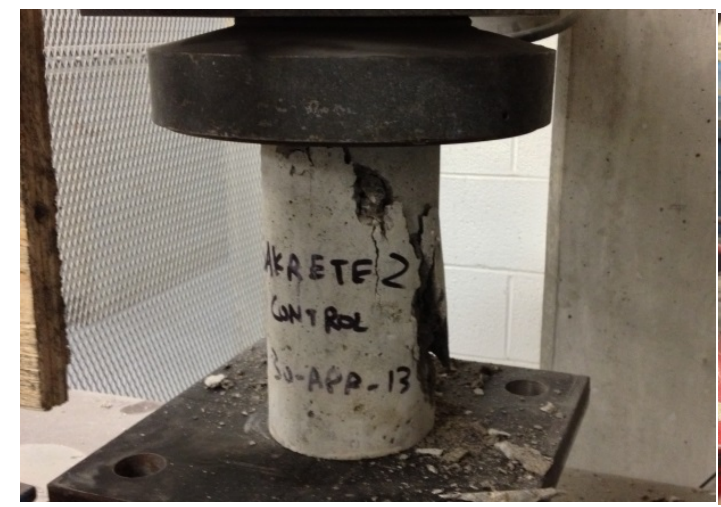

(a-Control)

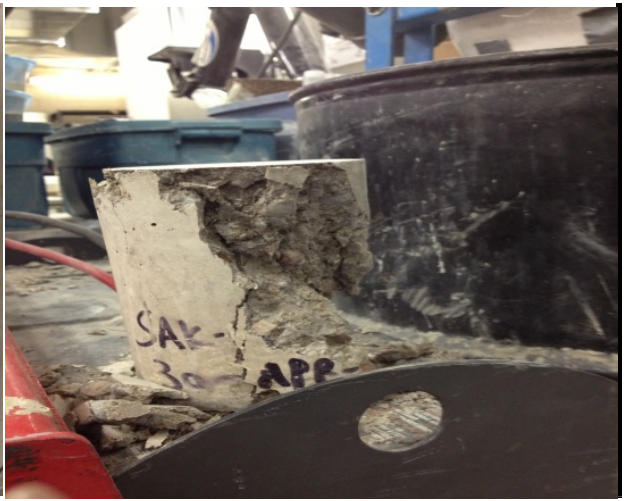

(b-Weather Shield)

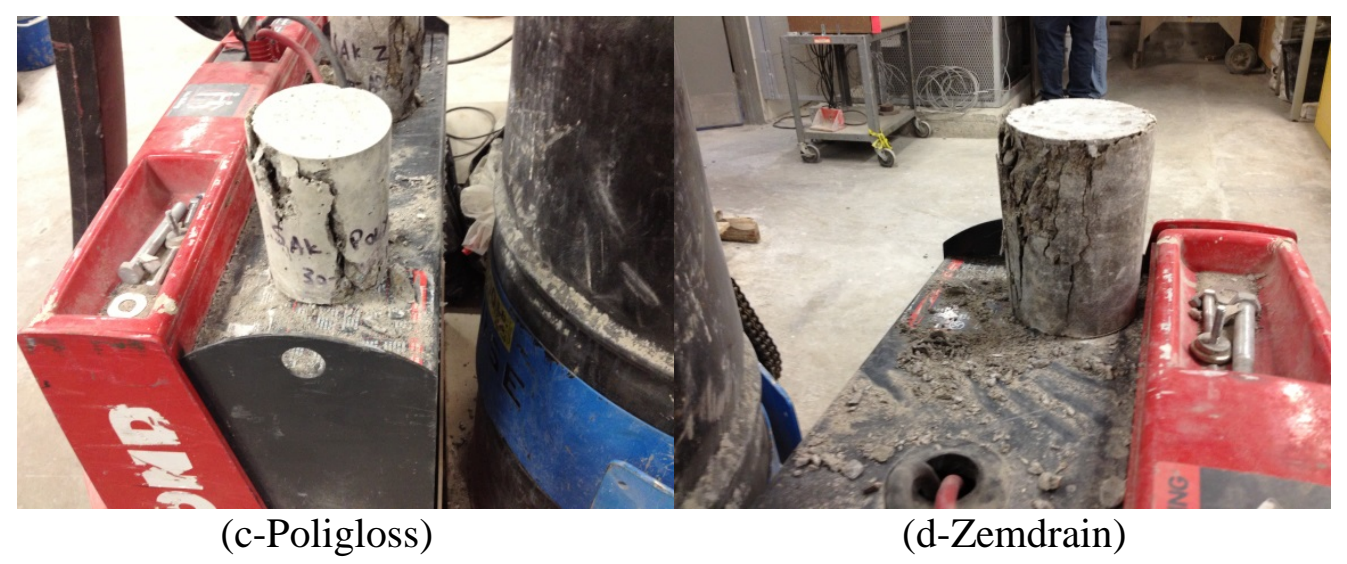

Figure 3.20: Specimen after Compressive Strength 


\subsection{WATER ABSRORTION AND DENSITY TESTS}

Cylindrical mold for all types of Newark form liners with $100 \mathrm{~mm}$ diameter and $50 \mathrm{~mm}$ height were prepared for water absorption and density tests. Figure 3.21 shows the molds prepared for water absorption test of Weather Shield, Poligloss and Zemdrain forms, respectively.

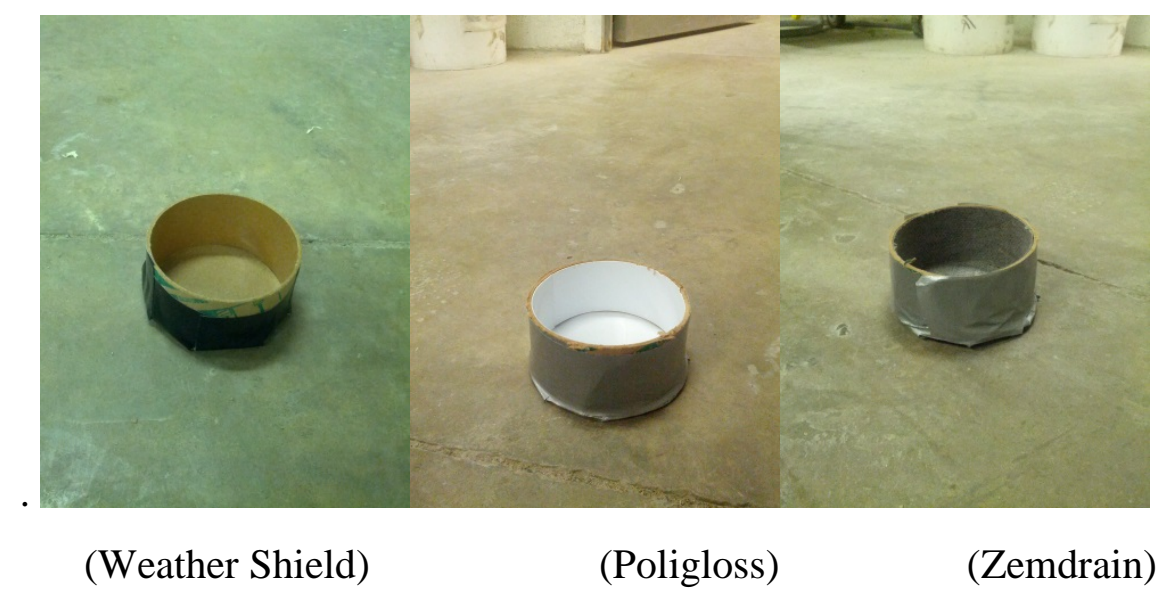

Figure 3.21: Water Absorption molds

At least three cylinders of Weather Shield, Poligloss and Zemdrain were cast from all concrete mixtures. Three cylinders of each concrete was also cast using conventional 100 mm x 200 mm plastic moulds. After curing, they were sliced into $100 \mathrm{~mm}$ x $50 \mathrm{~mm}$ cylinders. The specimens from conventional plastic moulds called "control specimens" were used to compare the performance of Newark forming tube specimens.

Water Absorption and density of all the specimens were determined as per ASTM C642. This test was conducted in 4 steps: 1. measuring weight after oven drying of samples, 2. Taking weight after immersion in water, 3. weighting after boiling and, 4. weighting in water. After these four steps. Absorption after immersion, absorption after boiling, bulk density, apparent density and volume of permeable pores of all the cylinder specimens 
were calculated. Figure 3.22 shows the experimental setup of the test as per ASTM C642 standard.

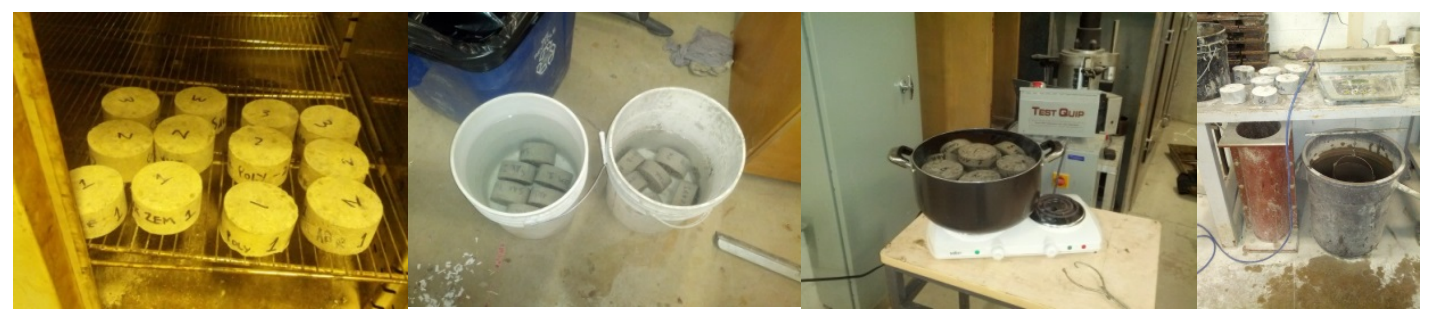
(a) Oven Dry,
(b) Immersion in water,
(c) Boiling
(d) Weight in water

Figure 3.22 Pictures of water absorption test

\subsection{SORPTIVITY}

Cylindrical moulds of dimension $100 \mathrm{~mm}$ diameter and $50 \mathrm{~mm}$ height with Weather Shield, Poligloss and Zemdrain were prepared for sorptivity test. At least two cylinders of each type of molds were cast for all four types of concrete mix. One cylinder of each concrete was also cast in conventional plastic $100 \mathrm{~mm}$ x $200 \mathrm{~mm}$ moulds and after curing they were sliced into $100 \mathrm{~mm}$ x 50mm cylinders. Figure 3.23 shows the moulds prepared for sorptivity test.

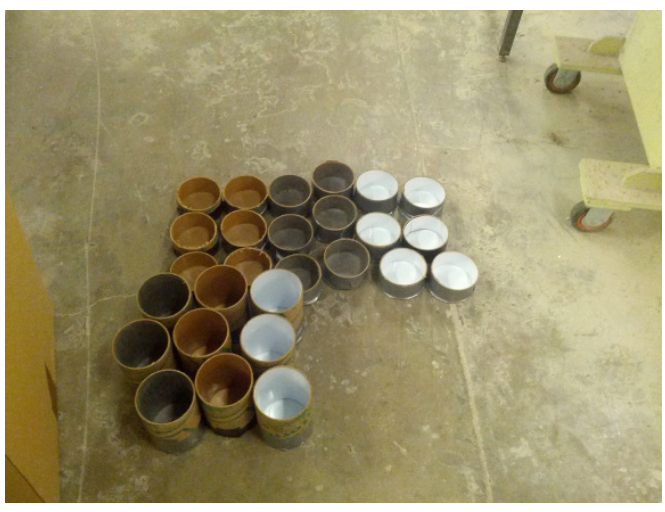

Figure 3.23: Sorptivity molds for Weather Shield, Poligloss and Zemdrain

Sorptivity test was conducted according to ASTM C1585 standard. Sides and the top of each cylinder were covered by epoxy, only the side cast with the face of formwork liner was remain original. The samples were put in aluminum plates, with original facing the 
bottom. Poured water in the plate until 3mm higher than the surface. Removed samples out from the water at $1 \mathrm{~min}, 5 \mathrm{mins}, 10 \mathrm{mins}$, 20mins, 30mins, $60 \mathrm{mins}$, 2h, 3h,4h,5h,6h and $48 \mathrm{~h}$, wiped the surface and marked the weight. Figure 2.24 shows the experimental setup for sorptivity test. The absorption I can be calculated as follows (Eq. 3.1).

$$
I=\frac{m_{t}}{a * d}
$$

Where: $m_{t}$ is the change in specimen mass in grams, at the time $t, a$ is the exposed area of the specimen, in $\mathrm{mm}^{2}$, and $d$ is the density of the water in $\mathrm{g} / \mathrm{mm}^{3}$.

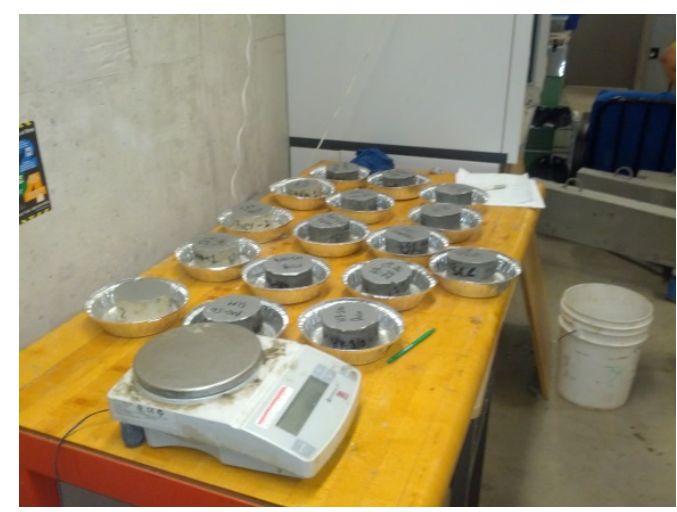

Figure 3.24: Experimental setup for sorptivity test

The initial sorptivity $\left(\mathrm{mm} / \mathrm{s}^{1 / 2}\right)$ of the specimens were calculated by the slope of line (best fit to I plotted against the square root of time) using all points from 1 minute to 6 hours. 


\subsection{RAPID CHLORIDE PENETRATION (RCP) TEST}

Cylindrical mould for all types of forms with $100 \mathrm{~mm}$ diameter and $50 \mathrm{~mm}$ height were prepared for rapid chloride penetration test. At least three cylinders of Weather Shield, Poligloss and Zemdrain molds were cast from all concrete mixtures. Three cylinder of each concrete was also cast in conventional plastic $100 \mathrm{~mm}$ x $200 \mathrm{~mm}$ moulds and after

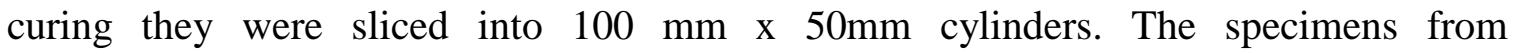
conventional plastic moulds are called control specimens with which Newark's Specimens were compared. Figure 3.25 shows the molds prepared for rapid chloride penetration test.

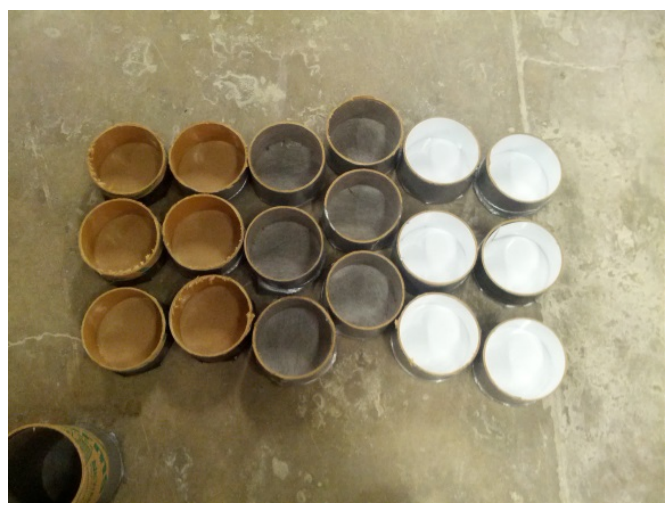

Figure 3.25: Chloride penetration molds for Weather Shield, Poligloss and Zemdrain

Chloride penetration tests according to ASTM 1202 standard were performed on all types of concrete cast in different forms. Figure 3.26 shows the typical experimental setup for chloride penetration test and specimens after chloride penetration tests. 


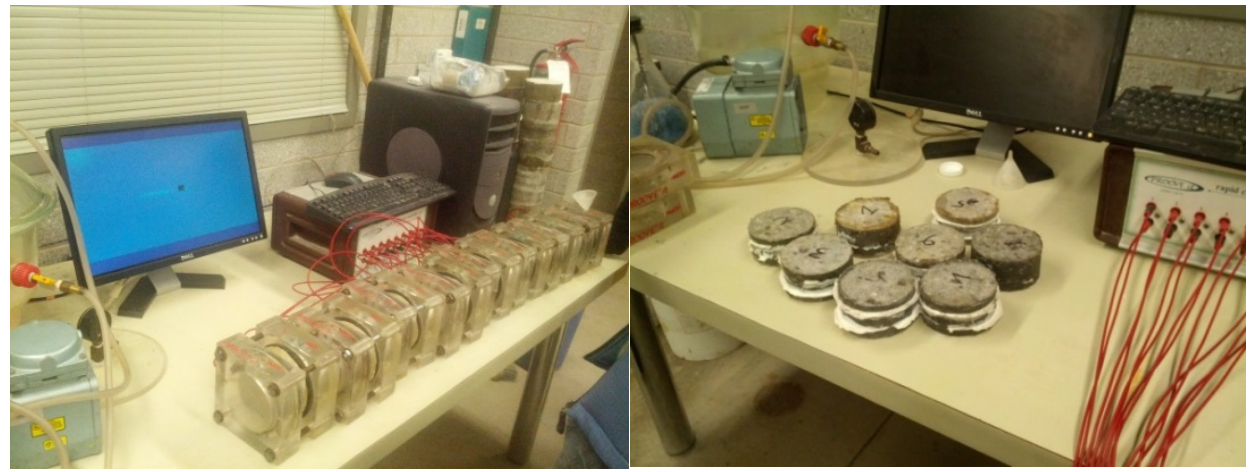

Figure 3.26: Experimental Setup of chloride penetration test

Qualitative indications of the chloride ion penetrability of concrete based on the measured values from ASTM Standards are provided in Table 3.1

Table 3.1: Qualitative indication of chloride ion penetration

\begin{tabular}{|l|l|}
\hline \multicolumn{2}{|c|}{ Chloride ion Penetrability based on charge passed } \\
\hline Charge passed (Coulombs) & Chloride Ion penetrability \\
\hline$>4000$ & High \\
\hline $2000-4000$ & Moderate \\
\hline $1000-2000$ & Low \\
\hline $100-1000$ & Very Low \\
\hline$<100$ & Negligible \\
\hline
\end{tabular}




\subsection{FREEZE THAW RESISTANCE}

King Sakrete concrete was selected for freeze that test with the consultation of Newark Group. Prisms for all types of forms with $400 \mathrm{~mm}$ length, $100 \mathrm{~mm}$ width and $75 \mathrm{~mm}$ height were prepared for the freeze thaw test. Newark's form liner was glued to typical steel molds to cast the specimens. At least two prisms for each of Newark's forms were cast from Sakrete concrete and MS-S10 Concrete. Two Prisms for selected concrete in conventional steel molds were also cast to compare performance of Newark forming tube prisms. Figure 3.27 shows the molds prepared for Freeze thaw test specimens.

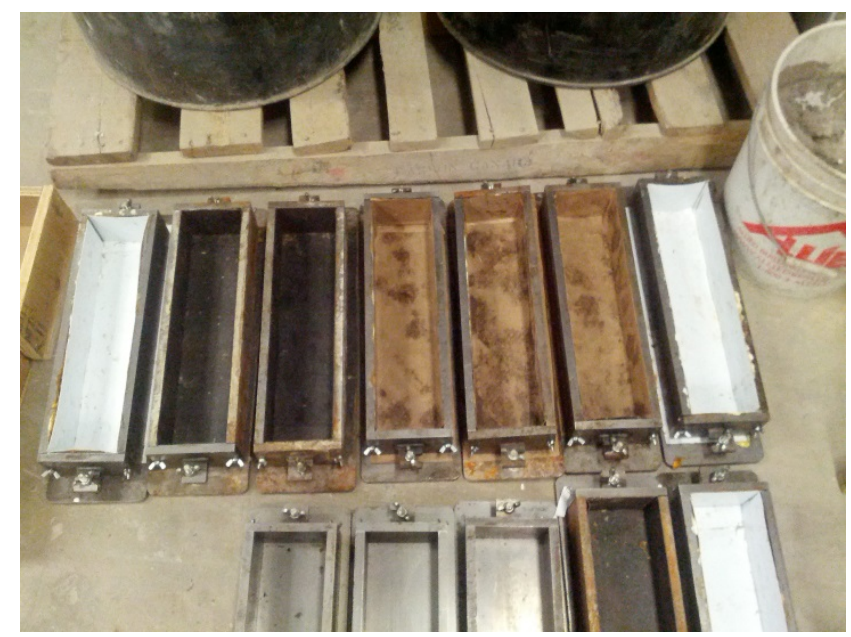

Figure 3.27: Freeze Thaw molds for Weather Shield, Poligloss and Zemdrain

Freeze thaw tests were performed according to ASTM C666 standard on all types of concrete prism specimens cast in different forms. Relative dynamic modulus of elasticity and durability factor (DF) are the two important factors were found by using ASTM C666 standard.

Relative Dynamic Modulus of Elasticity - the numerical value of relative dynamic modulus of elasticity is calculated as follows (Eq. 3.2):

$$
\mathrm{p}_{\mathrm{c}}=\left(n_{1}{ }^{2} / n^{2}\right) * 100
$$


Where $P c$ is the relative dynamic modulus of elasticity, after $c$ cycles of freezing and thawing, percent , $n$ is the fundamental transverse frequency at 0 cycles of freezing and thawing, and $n 1$ is fundamental transverse frequency after $c$ cycles of freezing and thawing.

Durability Factor (DF) can be calculated as follows (Eq. 3.3):

$$
D F=\frac{P N}{M}
$$

Where, $D F$ is the durability factor of the test specimen, $P$ is the relative dynamic modulus of elasticity at $N$ cycles, \%, $N i$ number of cycles at which $P$ reaches the specified minimum value for discontinuing the test or the specified number of cycles at which the exposure is to be terminated, whichever is less, and $M$ is the specified number of cycles at which the exposure is to be terminated.

Figure 3.28 shows the typical experimental set-up for Freeze Thaw test and the test setup for identifying fundamental traverse frequency of samples using ultrasonic pulse velocity instrument (UPVI). Figure 3.29 shows the specimen after freeze thaw cycle test.

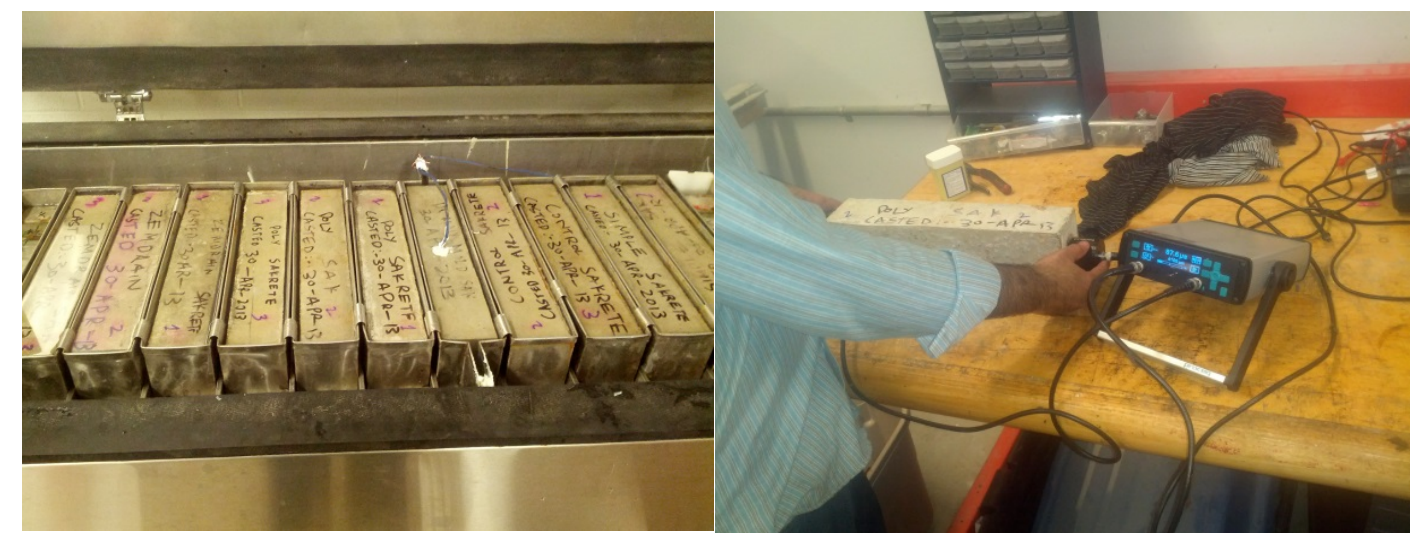

Figure 3.28: Experimental setup for freeze thaw test and UPVI 


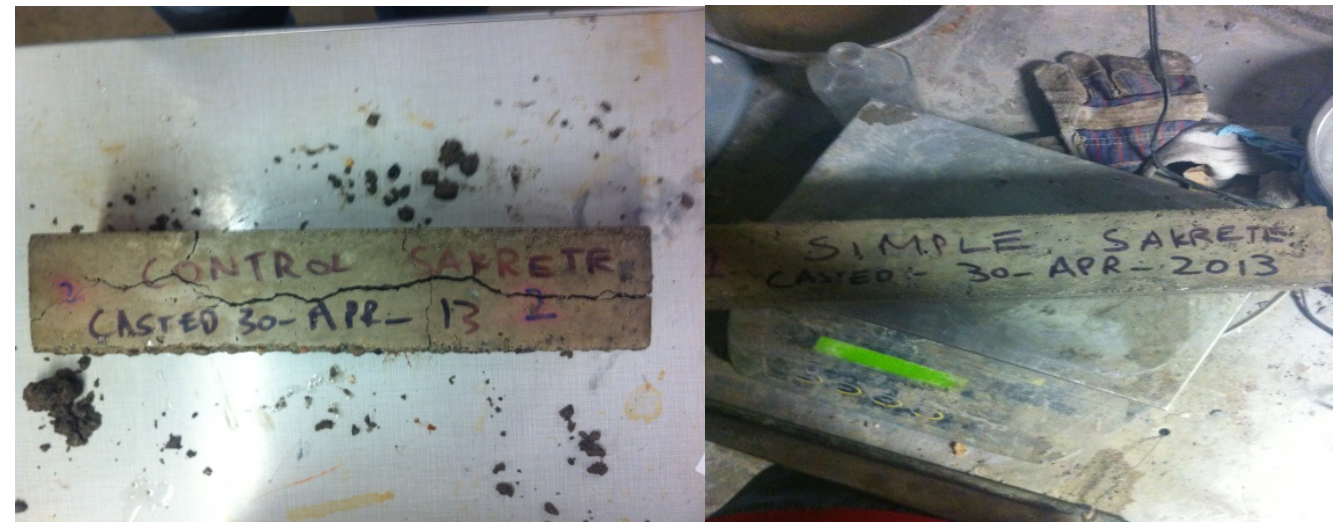

(a-Control steel)

(b-Weather Shield)

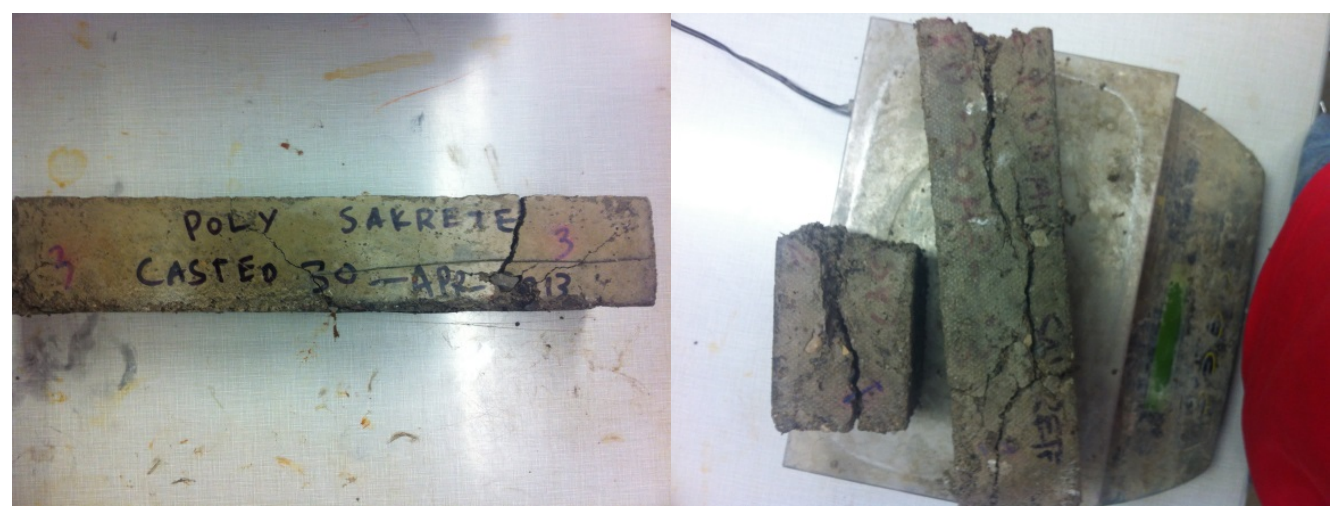

(c-Poligloss)

(d-Zemdrain)

Figure 3.29: Sakrete specimens after 65 Cycles of freezing and thawing 


\subsection{SALT SCALING}

Sakrete and MS-S10 concrete were selected for salt scaling test with the consultation of Newark Group. Moulds for all types of Newark forms including a conventional steel form (for comparison purpose) with $225 \mathrm{~mm}$ length, $225 \mathrm{~mm}$ width and $100 \mathrm{~mm}$ height were prepared for the test. One slab specimen for each of Newark's form and control steel form was cast with Sakrete and MS-S10 concrete. Figure 3.30 shows the molds prepared for salt scaling tests.

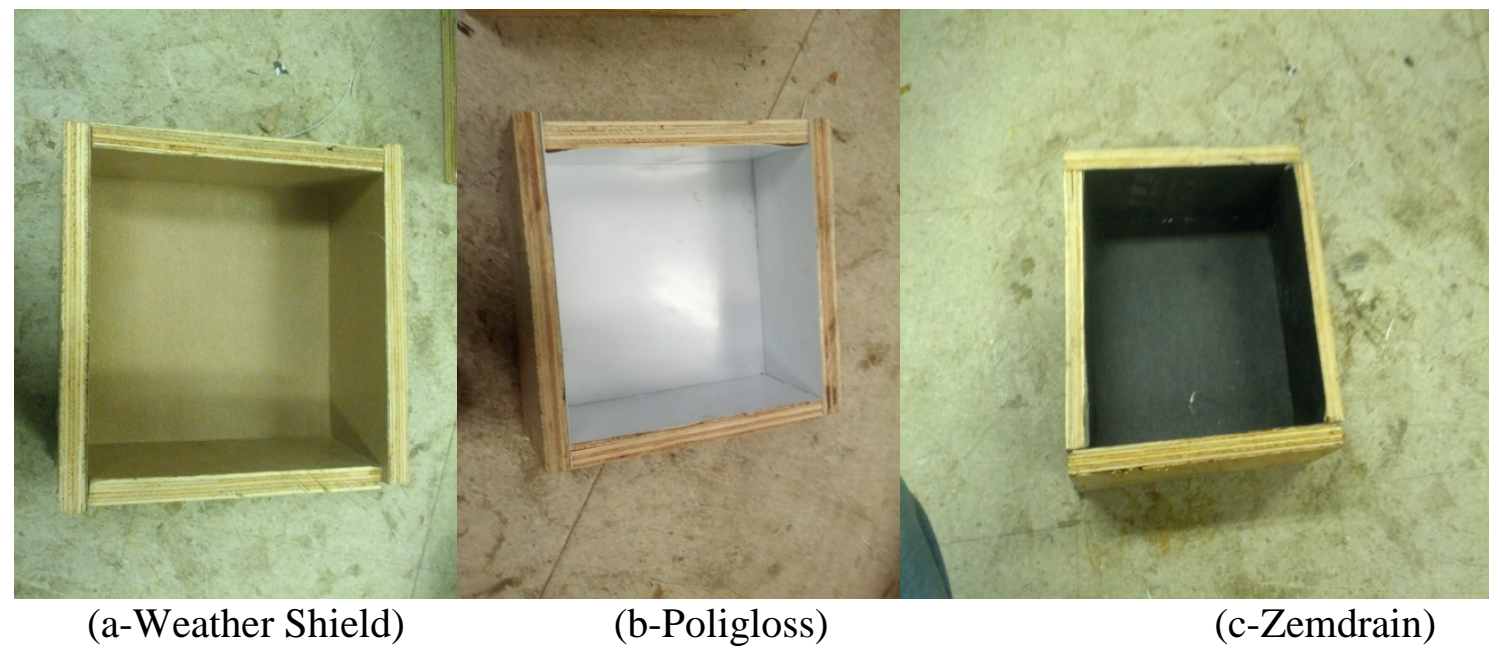

Figure 3.30: Salt scaling molds for Weather Shield, Poligloss and Zemdrain

Salt Scaling test according to ASTM C672 was performed. Figure 3.31 shows the salt scaling slab specimens placed in freezer with $\mathrm{CaCl}_{2}$ solution ponded in it. Figure 3.32 shows the specimens after 50 cycles of freeze-thaw. 


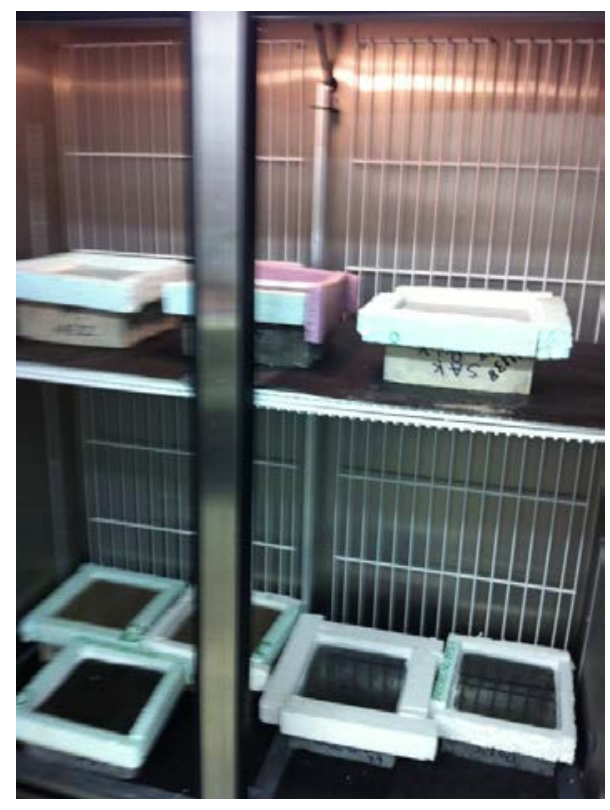

Figure 3.31 Salting scaling samples placed in freezer

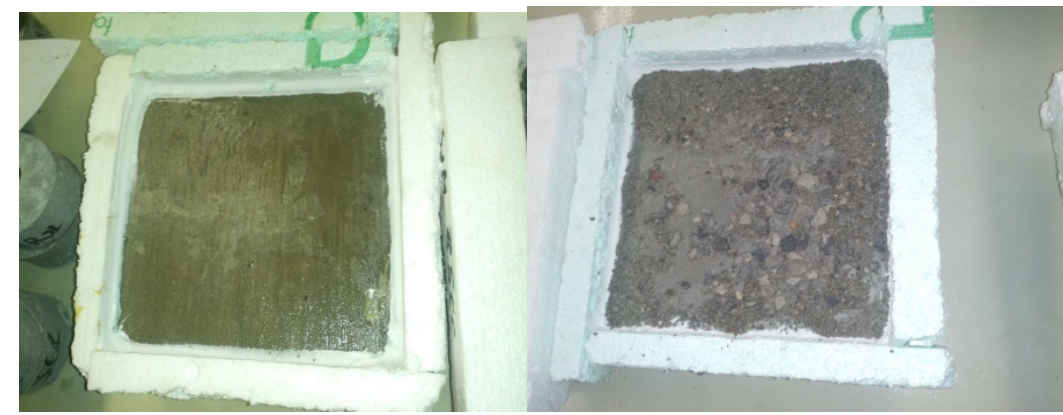

(a-Control steel)

(b-Weather Shield)

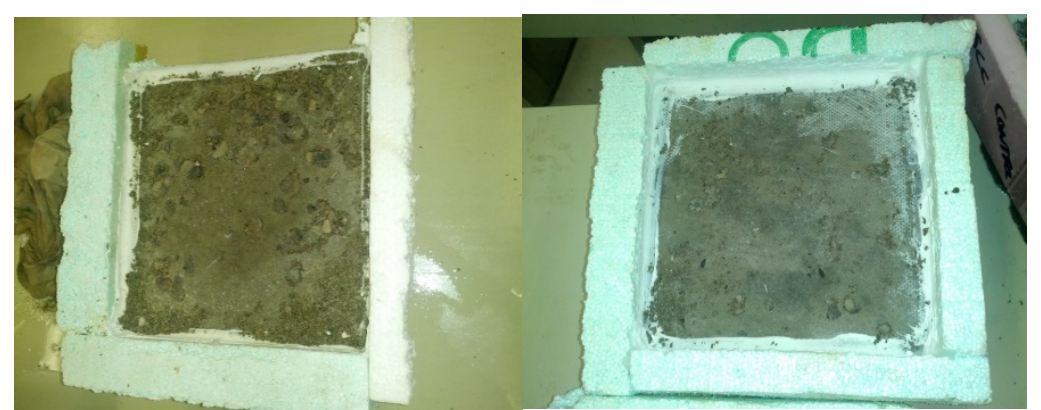

(c-Poligloss)

(d-Zemdrain)

Figure 3.32: Condition of Sakrete concrete specimen surface after 50 cycles 


\subsection{AXIAL COMPRESSIVE STRENGTH OF FORMING TUBE}

Axial compressive strength of Weather Shield forming tube (100mm diameter and 150 mm height) was checked. Figure 3.33 shows the experimental setup for the compressive strength of Weather Shield forming tube. Strain gauges were installed vertically on the surface of tube, stress strain curve of forming tube was also plotted to find the total compressive strength of the tube. The ultimate strength of forming tube was added to typical strength of concrete (assuming fully composite action) to find the total composite compressive strength of cast tubes. Figure 3.34 shows the deformed shape of forming tube.

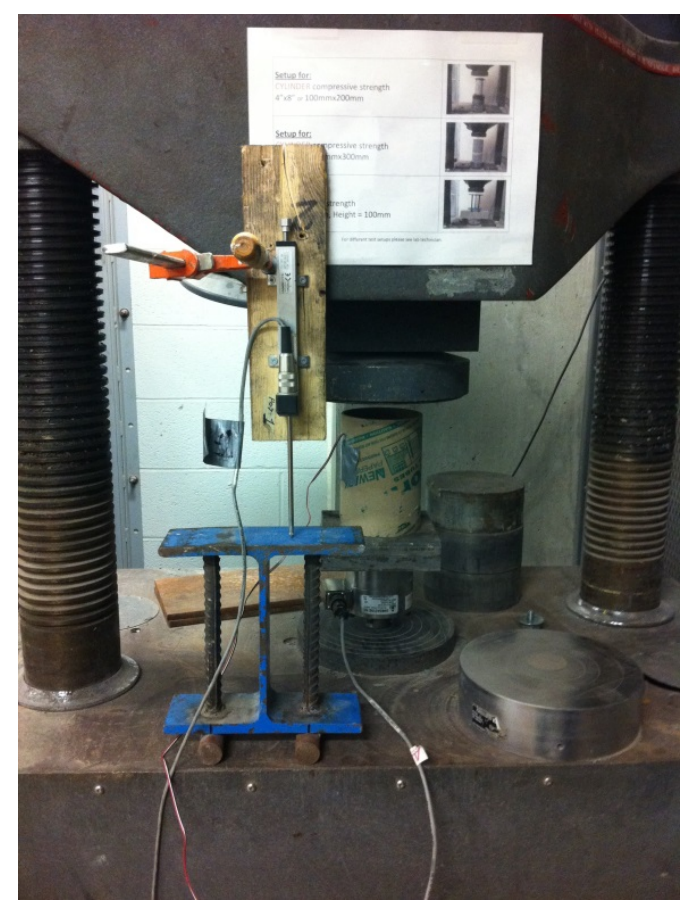

Figure 3.33: Experimental setup for compressive strength of Weather Shield forming tube 


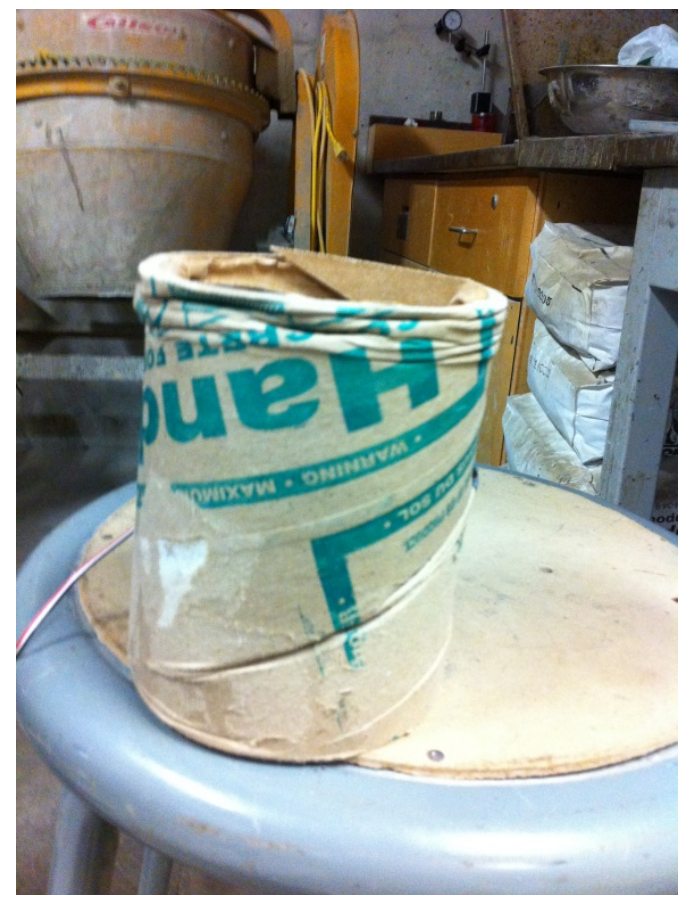

Figure 3.34: Weather Shield forming tube after compressive test 


\section{CHAPTER 4: RESULTS AND DISCUSSION}

\subsection{INTRODUCTION}

In this chapter, result covering fresh state properties (Slump/slump flow, fresh Density), Pressure development on forming tubes, temperature development), mechanical properties (tube surface strength using Schmidt Hammer, tube surface characteristics, cylinder compressive strength) and durability characteristics (Water absorption, sorptivity and resistance to chloride penetration, salt scaling and freeze thaw) are presented. Influence of forming tubes on these properties are described based on four different types of concrete are presented. Comparative analysis of all forming tubes with conventional steel and wooden form work is also presented.

\subsection{FRESH STATE PROPERTIES}

\subsubsection{Slump/Slump flow test results}

The results of slump/slump flow test for all the concrete mixtures are presented in table 4.1. Among normal concrete, Sakrete showed the highest slump with a value of $150 \mathrm{~mm}$ followed by MS-S10 and HP-S10. MS-S10 self-consolidating concrete showed a slump flow value of $700 \mathrm{~mm}$.

Table 4.1 Slump Flow Results

\begin{tabular}{|c|c|}
\hline Concrete & Slump (mm) \\
\hline Sakrete & 150 \\
\hline MS-S10 & 120 \\
\hline HP-S10 & 90 \\
\hline MS-S10 SCC & 700 \\
\hline
\end{tabular}




\subsubsection{Fresh density test results}

Fresh density results for all King concretes are presented in table 4.2. HP-S10 exhibited highest density of $2647 \mathrm{~kg} / \mathrm{m}^{3}$ followed by Sakrete, MS-S10 and SCC.

Table 4.2 Fresh Density Results

\begin{tabular}{|c|c|}
\hline Concrete & $\begin{array}{c}\text { Wet Density } \\
\left(\mathbf{K g} / \mathbf{~ m}^{\mathbf{3}} \mathbf{)}\right.\end{array}$ \\
\hline Sakrete & 2588.498 \\
\hline MS-S10 & 2582.29 \\
\hline HP-S10 & 2646.43 \\
\hline MS-S10 SCC & 2505.419 \\
\hline
\end{tabular}

Fig 4.1 shows the variation of fresh density with time for Sakrete e, MS-S10, HP-S10 and SCC concretes, during several hours of monitoring. As time increases, the concrete harden due to hydration process and density decreased. The maximum density observed for each concrete is used in calculating the theoretical pressure exerted on the face of the walls of forming tubes.
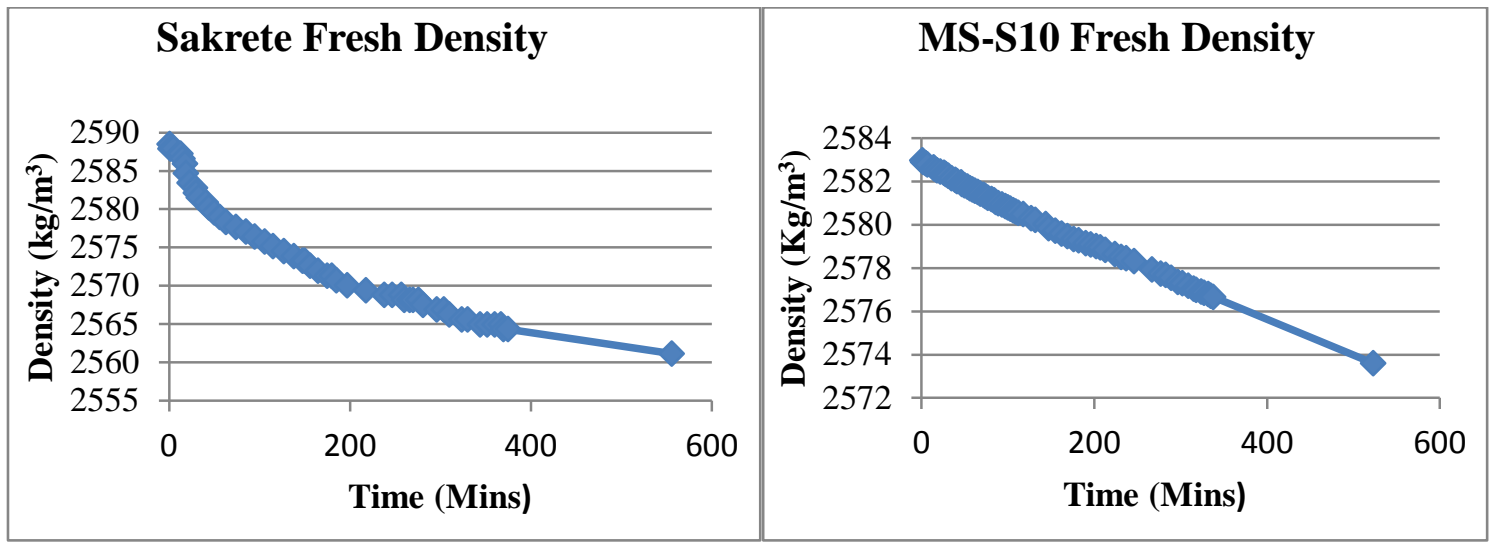


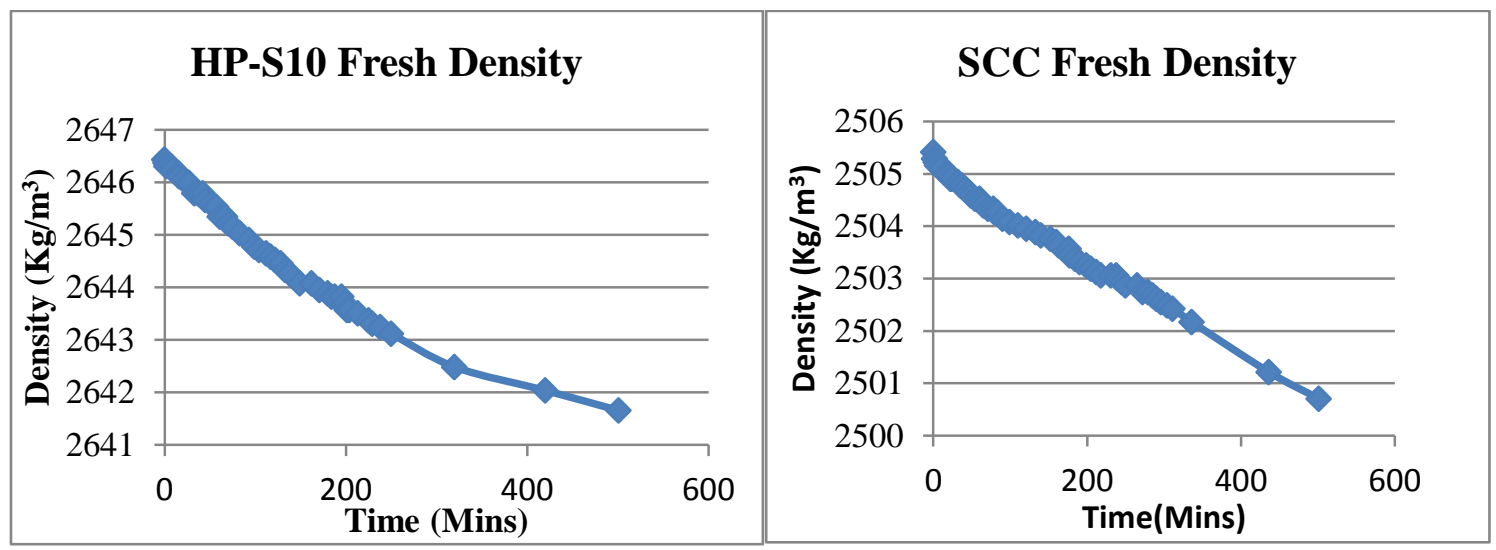

Figure 4.1: Variation of fresh Density with time for various concretes

\subsection{TEMPERATURE MONITORING RESULTS}

Table 4.3 summarizes the max temperature developed by each concrete near the surface of forming tube wall and the concrete core of the Weather Shield tube. HP-S10 developed the highest temperature of $57.51^{\circ} \mathrm{C}$ followed by MS-S10, SCC and Sakrete. The \% difference of surface temperature and core temperature is found to be less than $3 \%$. Due to temperature rise, no harmful effect was observed for any concrete which suggested that for all the concretes heat of hydration did not affect the tube performance.

Table 4.3 Maximum temperature developed by concretes

\begin{tabular}{|c|c|c|c|}
\hline Concrete & $\begin{array}{c}\text { Temperature Surface } \\
\left({ }^{\circ} \mathrm{C}\right)\end{array}$ & $\begin{array}{c}\text { Temperature Core } \\
\left({ }^{\circ} \mathrm{C}\right)\end{array}$ & \% Difference \\
\hline Sakrete & 38.04 & 38.34 & 0.782 \\
\hline MS-S10 & 51.41 & 52.5 & 2.076 \\
\hline HP-S10 & 57.51 & 57.48 & -0.052 \\
\hline MS-S10 SCC & 51.96 & 50.2 & -3.506 \\
\hline
\end{tabular}


Figure 4.2 illustrates the temperature development with time in all four concretes at the core and surface of Weather Shield Tube. It can be seen from the graphs that initially the temperature increased with time until reached a peak and then deceased as time increased. . This is due to the initial faster hydration process of the concrete. For calculation of max pressure using theories, temperature at the time of max pressure was also interpolated from data which is summarized in table 4.4.

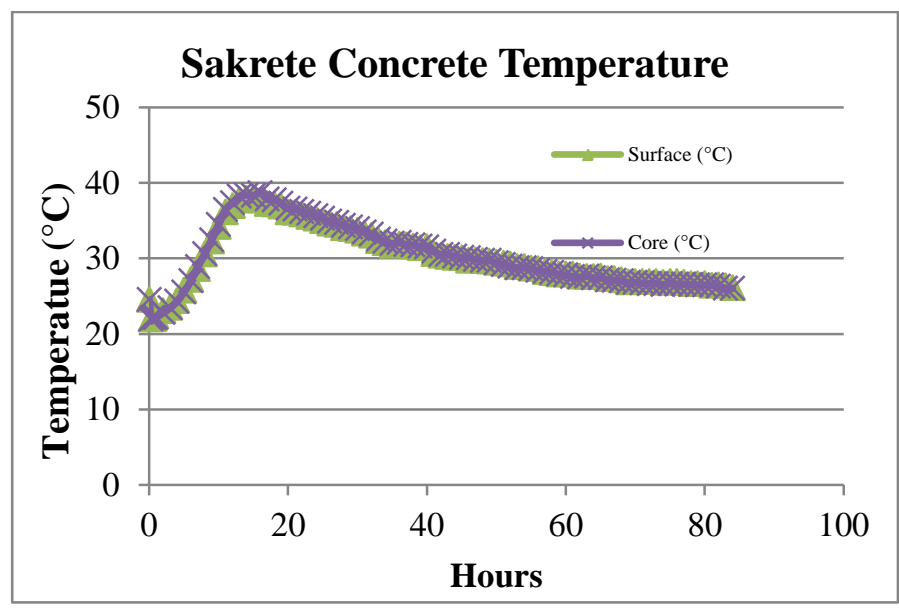

Figure 4.2a Temperature -time history of fresh cast concrete (Sakrete)

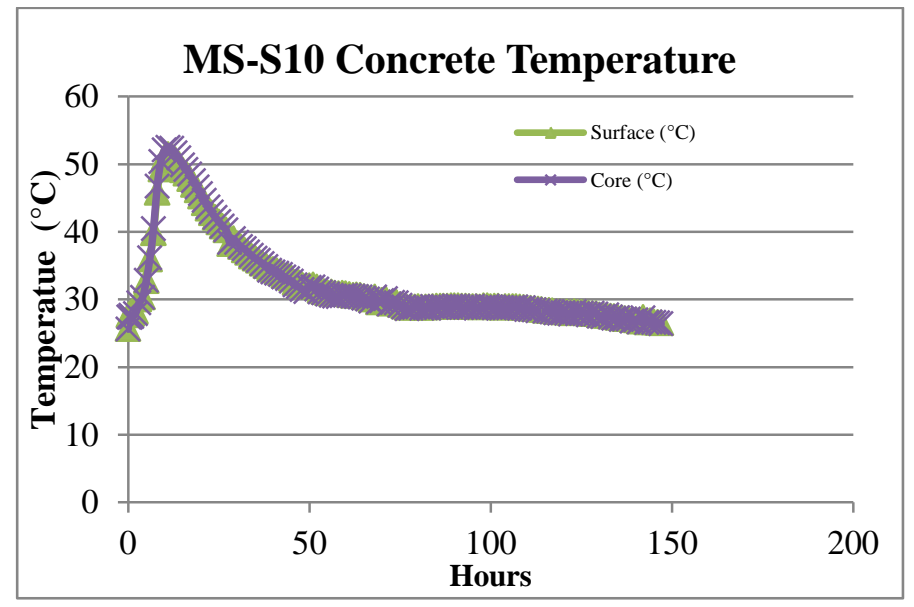

Figure 4.2b Temperature -time history of fresh cast concrete (MS-S10) 


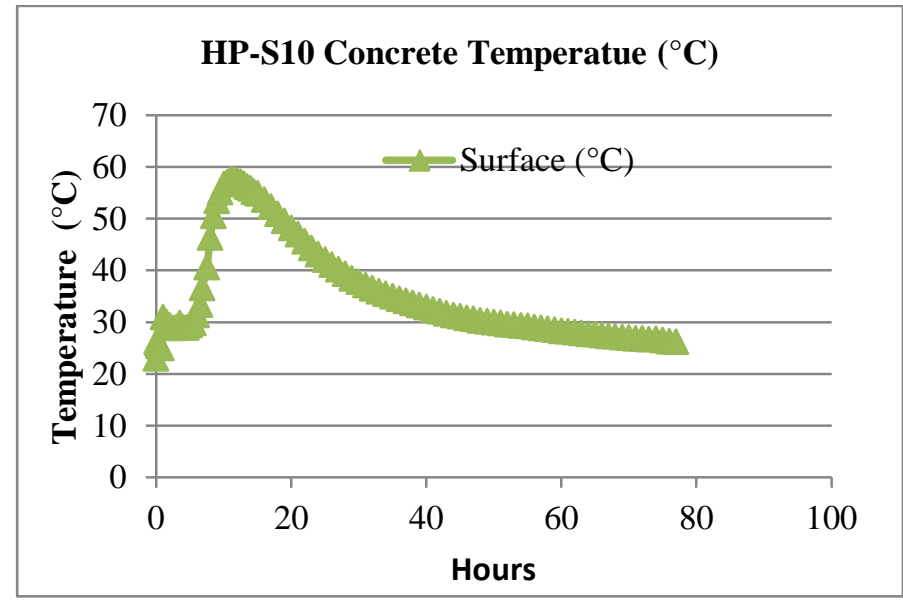

Figure 4.2c Temperature -time history of fresh cast concrete (HP-S10)

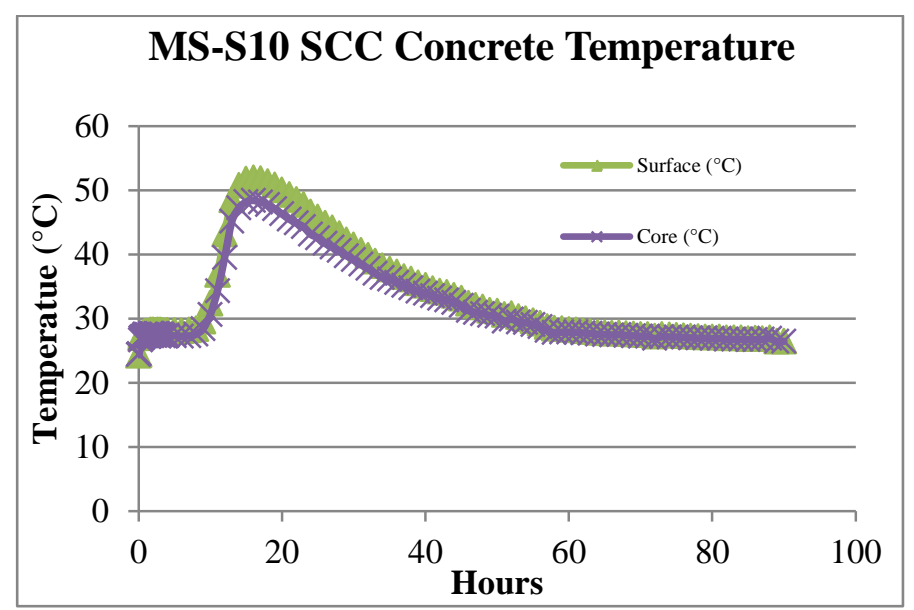

Figure 4.2d Temperature -time history of fresh cast concrete (MS-S10 SCC)

Table 4.4 Temperatures at max pressure for all concrete

\begin{tabular}{|c|c|}
\hline Concrete & $\begin{array}{r}\text { Temperature at maximum } \\
\text { pressure }\left({ }^{\circ} \mathrm{C}\right)\end{array}$ \\
\hline Sakrete & 24.55 \\
\hline MS-S10 & 25.6 \\
\hline HP-S10 & 30.01 \\
\hline MS-S10 SCC & 27.04 \\
\hline
\end{tabular}


Zemdrain liner is composed of a textile liner which allow air bubbles and surface water to drain out but holding the cement particles on the surface; which enables the surface near the liner to become very dense and make concrete to hydrate optimally (Coutinho. 2001).

\subsection{PRESSURE DEVELOPMENT}

\subsubsection{Experimental results}

Figure 4.3 illustrates the variation of pressure with time for all the four concretes at top, middle and bottom of Weather Shield Tube. As expected, maximum pressure for all the concretes was recorded by the bottom transducer. For all the concretes, pressure increased with time until reached at peak. After the peak, pressure decreased with time. Figure 4.4 illustrates the variation of pressure with height for all four concretes.

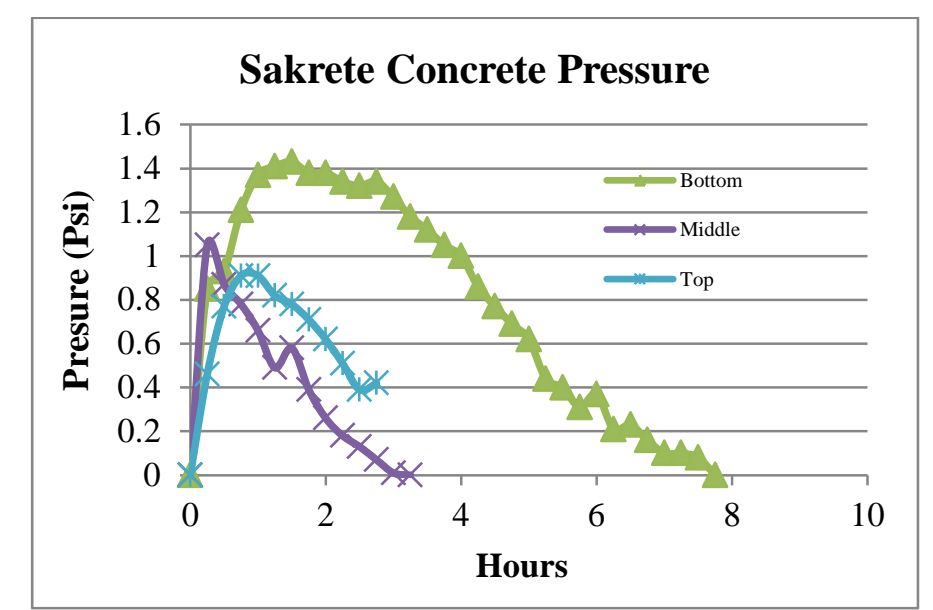

Figure 4.3a Pressure development with time at different heights (Sakrete) 


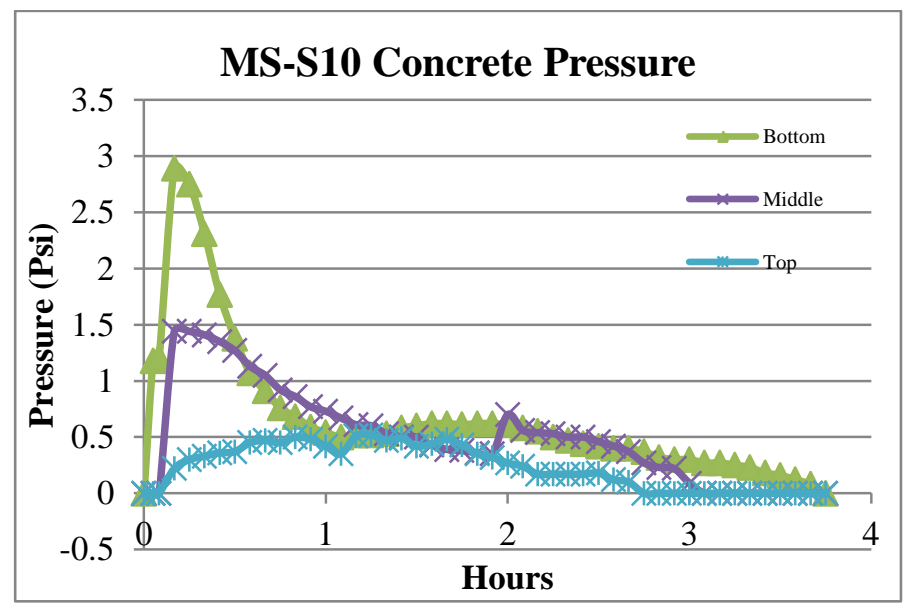

Figure 4.3b Pressure development with time at different heights (MS-S10)

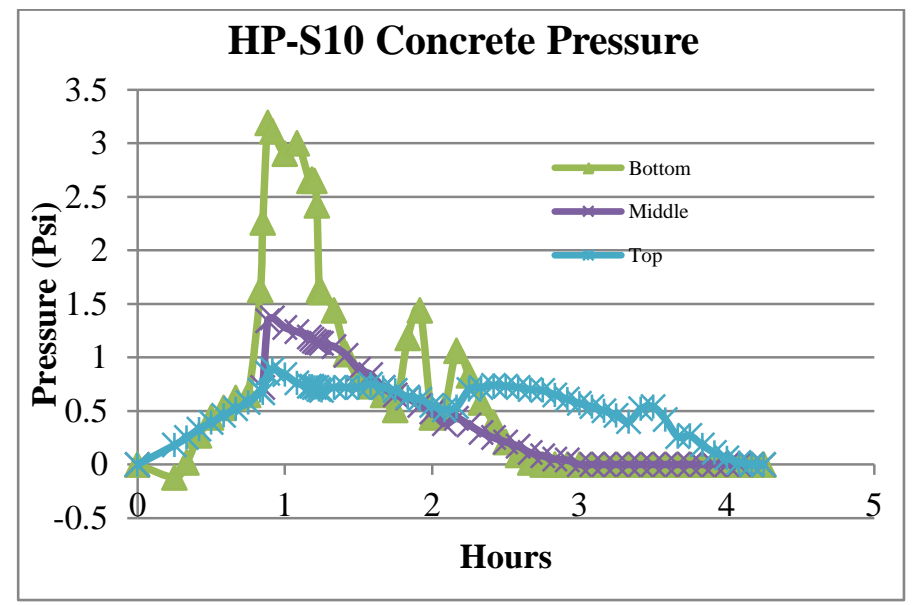

Figure 4.3c Pressure development with time at different heights (HP-S10) 


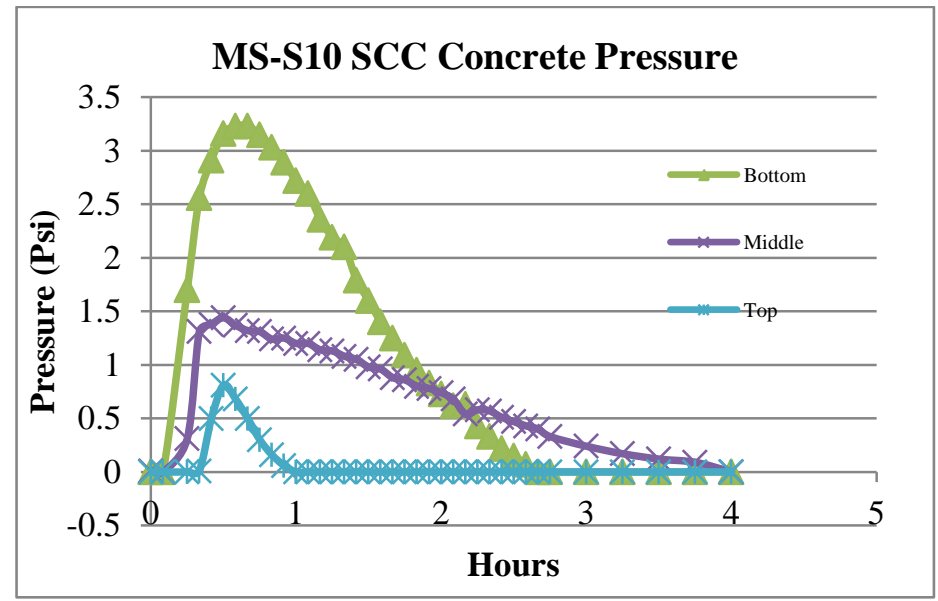

Figure 4.3d Pressure development with time at different heights (MS-S10 SCC)

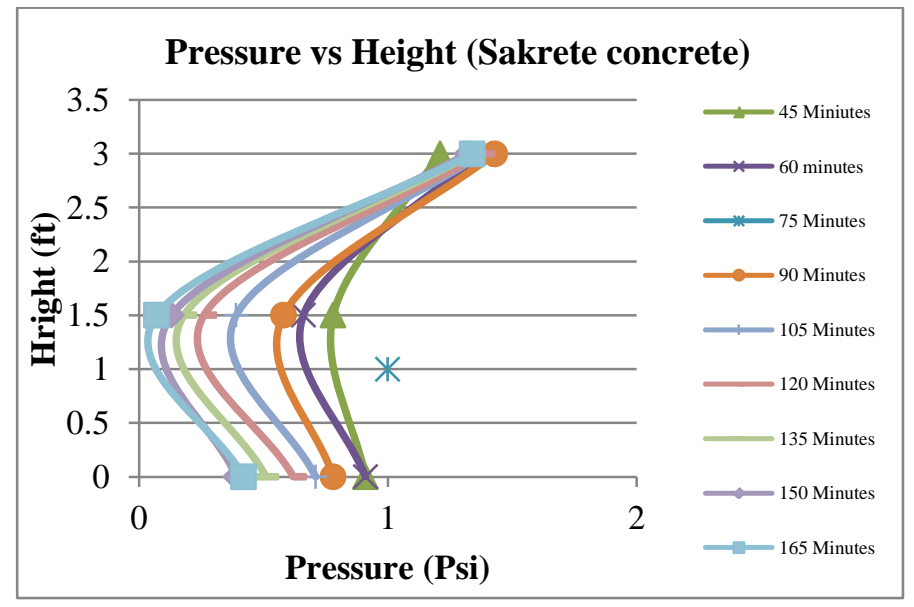

Figure 4.4a Pressure variation with height at different times (Sakrete) 


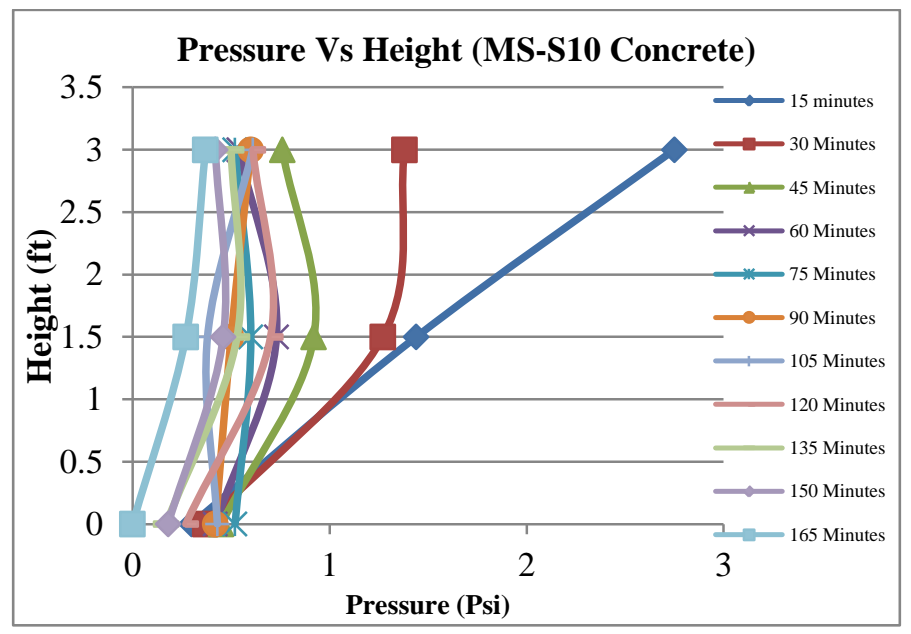

Figure 4.4b Pressure variation with height at different times (MS-S10)

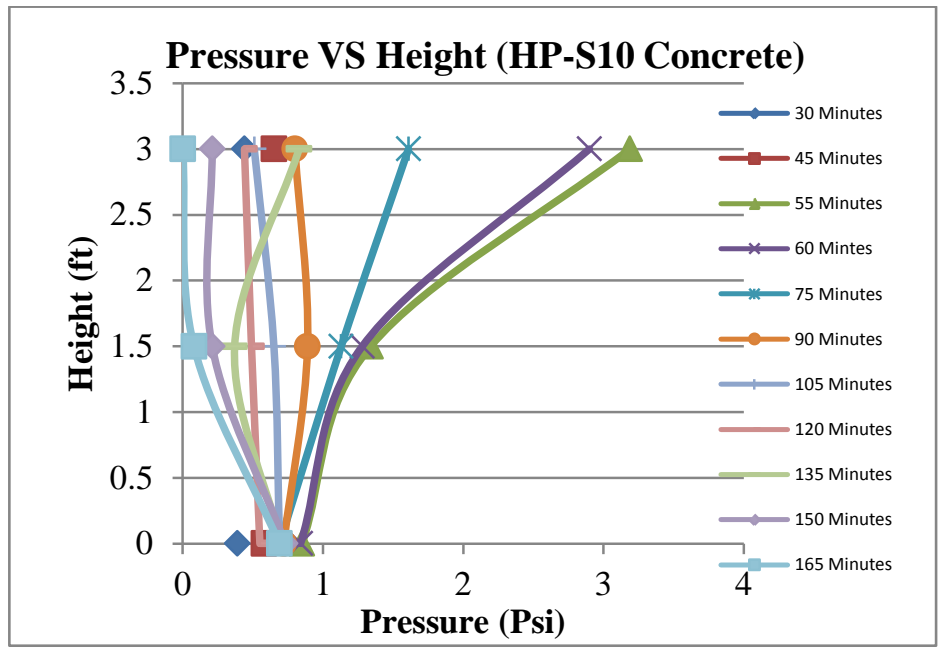

Figure 4.4c Pressure variation with height at different times (HP-S10) 


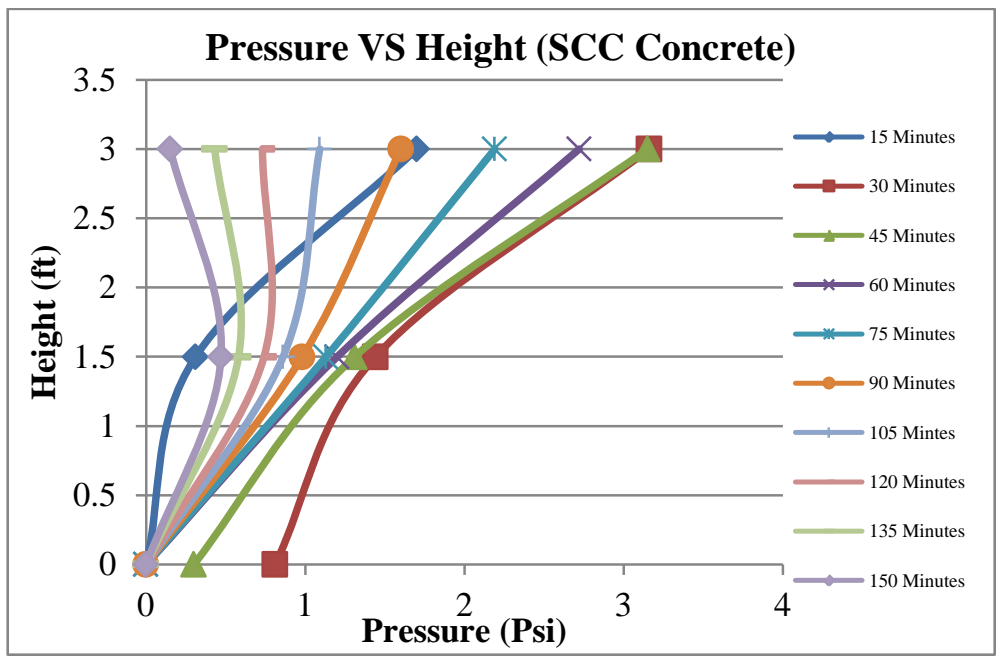

Figure 4.4d Pressure variation with height at different times (MS-S10 SCC)

Table 4.5 summarizes the max pressure developed by each concrete on the wall of the Weather Shield tube. MS-S10 SCC developed the highest pressure of 3.23 psi followed by HP-S10, MS-S10 and Sakrete. Sakrete concrete exerted 56\% less and MS-S10 exerted 10.5\% less pressure as compared to SCC. HP-S10 developed only $1 \%$ less pressure compared to SCC. At the pressure of 3.23 psi no bulging was observed, so the forming tube has sufficient capacity to resist form pressure of such concretes.

Table 4.5: Maximum pressure exerted on the face of wall of Weather Shield Tube

\begin{tabular}{|c|c|c|}
\hline \multirow{2}{*}{ Concrete } & $\begin{array}{c}\text { Maximum Pressure } \\
\text { (Psi) }\end{array}$ & $\begin{array}{c}\text { \% Difference From } \\
\text { SCC }\end{array}$ \\
\hline Sakrete & 1.43 & 55.73 \\
\hline MS-S10 & 2.89 & 10.53 \\
\hline HP-S10 & 3.19 & 1.24 \\
\hline MS-S10 SCC & 3.23 & 0.00 \\
\hline
\end{tabular}




\subsubsection{Comparsion of theoretical and experimental pressure}

Table 4.6 shows the theoretical value of maximum pressure $\left(\mathrm{P}_{\max }\right)$ calculated for each concrete calculated as per Gardner model (Eq.2.1). All the parameters needed for Eq.2.1 in predicting the pressure are tabulated in table 4.6. The experimental values were found to be less than those predicted from theoretical model. The variation is expected due to the fact that theoretical model is based on ideal conditions. Sakrete, MS-S10, HP-S10 and MS-S10 SCC developed lower pressure with experimental to predicted ratio of $0.222,0.51,0.61$ and 0.22 . This suggests that Gardener model is safe in predicting the formwork pressure on the Newark tube

Table 4.6: Lateral Pressure of All concretes using Gardner's model

\begin{tabular}{|c|c|c|c|c|c|c|c|c|c|c|c|}
\hline Concrete & $\begin{array}{c}\text { hi } \\
(\mathbf{m})\end{array}$ & $\begin{array}{c}\mathrm{d} \\
(\mathrm{mm})\end{array}$ & $\mathbf{H P}$ & $\begin{array}{c}\mathbf{R} \\
(\mathrm{m} / \mathrm{h})\end{array}$ & $\begin{array}{c}\mathrm{T} \\
\left({ }^{\circ} \mathrm{C}\right)\end{array}$ & $\begin{array}{c}\text { Slump } \\
(\mathbf{m m})\end{array}$ & $\begin{array}{c}\mathbf{P}_{\max } \\
\text { (kPa) }\end{array}$ & $\begin{array}{l}\mathbf{P}_{\max } \\
\text { (Psi) }\end{array}$ & $\begin{array}{c}\text { Experimental } \\
\text { (kPa) }\end{array}$ & $\begin{array}{l}\text { Experimental } \\
\text { (Psi) }\end{array}$ & Ratio \\
\hline Sakrete & 0.5 & 300 & 1.5 & 2.9 & 24.55 & 150 & 44.51 & 6.45 & 9.86 & 1.43 & 0.222 \\
\hline MS-S10 & 0.5 & 300 & 1.5 & 2.15 & 25.6 & 120 & 38.95 & 5.65 & 19.93 & 2.89 & 0.512 \\
\hline HP-S10 & 0.5 & 300 & 1.5 & 2.61 & 30 & 90 & 35.96 & 5.21 & 22.00 & 3.19 & 0.612 \\
\hline $\begin{array}{c}\text { MS-S10 } \\
\text { SCC }\end{array}$ & 0.5 & 300 & 1.5 & 3.65 & 27 & 700 & 100.48 & 14.57 & 22.28 & 3.23 & 0.222 \\
\hline
\end{tabular}

Table 4.7 compares theoretical pressure for each concrete calculated from ACI committee model (Eq. 2.2) with those derived from experiments.

Table 4.7: Lateral Pressure of All concretes using ACI committee model

\begin{tabular}{|c|c|c|c|c|c|c|c|c|c|c|}
\hline Concrete & $\begin{array}{c}\text { Wet } \\
\text { Density } \\
\left(\mathbf{K g} / \mathbf{m}^{3}\right)\end{array}$ & $\mathbf{C w}$ & $\mathbf{C c}$ & $\begin{array}{c}\mathbf{T} \\
\mathbf{(}\end{array}$ & $\begin{array}{c}\mathbf{R} \\
\mathbf{( m / h )}\end{array}$ & $\begin{array}{c}\mathbf{P}_{\max } \\
\mathbf{( k P a})\end{array}$ & $\begin{array}{c}\mathbf{P}_{\max } \\
\mathbf{( P s i )}\end{array}$ & $\begin{array}{c}\text { Experimental } \\
\mathbf{( k P a )}\end{array}$ & $\begin{array}{c}\text { Experimental } \\
\mathbf{( P s i )}\end{array}$ & Ratio \\
\hline Sakrete & 2588.498 & 1.116 & 1 & 24.55 & 2.9 & 68.01 & 9.86 & 9.86 & 1.43 & 0.145 \\
\hline MS-S10 & 2582.29 & 1.113 & 1.2 & 25.6 & 2.15 & 61.56 & 8.93 & 19.93 & 2.89 & 0.324 \\
\hline HP-S10 & 2646.43 & 1.141 & 1.2 & 30 & 2.61 & 68.53 & 9.94 & 22.00 & 3.19 & 0.321 \\
\hline MS-S10 SCC & 2505.419 & 1.080 & 1.2 & 27 & 3.65 & 92.21 & 13.37 & 22.28 & 3.23 & 0.242 \\
\hline
\end{tabular}


Table 4.7 summarize the maximum pressure exerted by concrete on the walls of forming tubes calculated from ACI model (Eq. 2.2). Sakrete, MS-S10, HP-S10 and MS-S10 SCC developed lower pressure with experimental to predicted ratio of $0.145,0.324$, and 0.321 and 0.242 , respectively.

Both Gardener model and ACI model are found to be safe and conservative in predicting the fresh concrete pressure on all Newark tubes considering Weather Shield to be the weakest (structurally) compared with Poligloss and Zemdrain.

Using the values of $\mathrm{C}_{\mathrm{W}}, \mathrm{C}_{\mathrm{C}}$, temperature, rate of pouring, depth, vibration immersion length and horsepower of vibrator one can find the maximum pressure exerted on the face of wall of any formwork. However, it should be noted that the validity of ACI and Gardener models in predicting concrete pressure on Newark forming tubes should be validated through actual full-scale construction in the field.

\subsection{WATER ABSORPTION OF FORMWORK LINER}

Table 4.8 summarizes the water absorption of Weather Shield, Poligloss and Zemdrain formwork liner. After 24 hours of immersion in water, Weather Shield has the highest absorption of $81 \%$ followed by Zemdrain showed with15 \%, whereas Poligloss is an impermeable formwork liner with water absorption of $0 \%$. This increase in water can decrease water-cement ratio near the surface of formwork liner. By using formwork liner in construction many issues can be solved, the most important among them are, removing of excess air and water which can cause blow holes and other surface defects, avoids surface contamination, increase cement content near surface, acting as a curing membrane. By the use of formwork liner, the durability of first 15-20 mm of surface improved (Wilson et al., 2007). 
Table 4.8: Water absorption of formwork liner

\begin{tabular}{|c|c|c|c|}
\hline Liner & $\begin{array}{c}\text { Dry Weight } \\
\text { (grams) }\end{array}$ & $\begin{array}{c}\text { Weight After 24 h } \\
\text { immersion (grams) }\end{array}$ & \% Absorption \\
\hline Weather Shield & 4.27 & 7.72 & 80.80 \\
\hline Poligloss & 6.18 & 6.19 & 0.16 \\
\hline Zemdrain & 3.43 & 3.92 & 14.29 \\
\hline
\end{tabular}

\subsection{INFULENCE OF TUBES ON SURFACE CHARACTERSITICS AND SURFACE STRENGTH}

\subsubsection{Surface characteristics}

After removing the forms from hardened tubes, the quality of each concrete surface was inspected visually. Figures 4.5 to 4.8 show the concrete surfaces cast with Weather Shield, Poligloss and Zemdrain tubes at 21 days for Sakrete, MS-S10 and HP-S10 SCC columns.

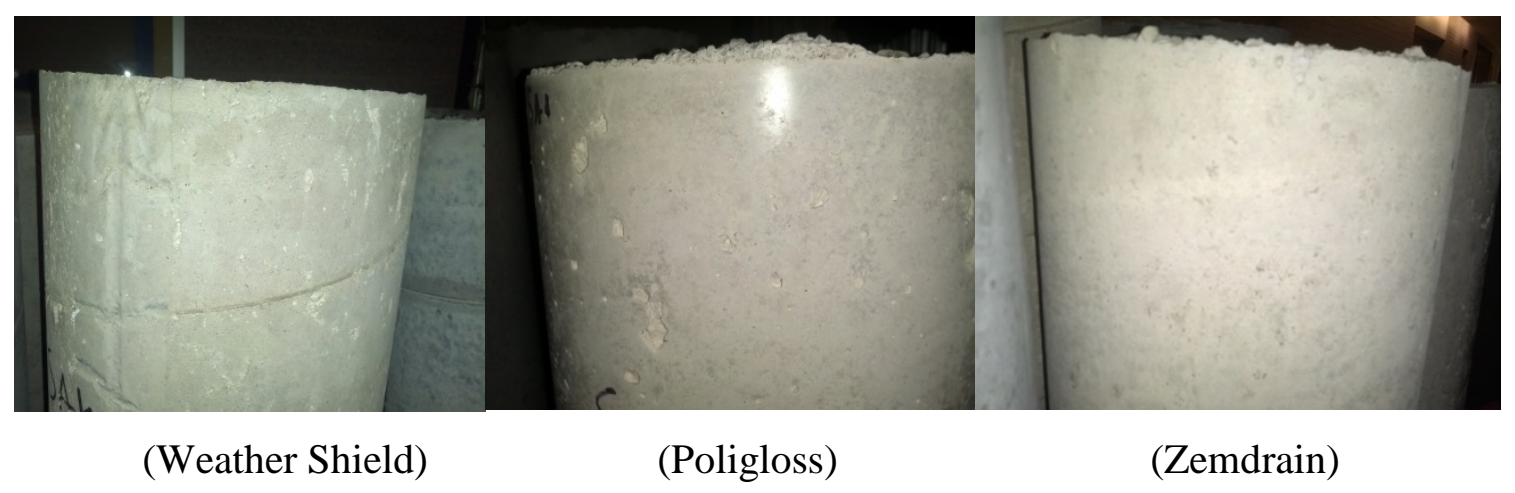

Figure 4.5: Concrete finish after removing formwork for Sakrete 


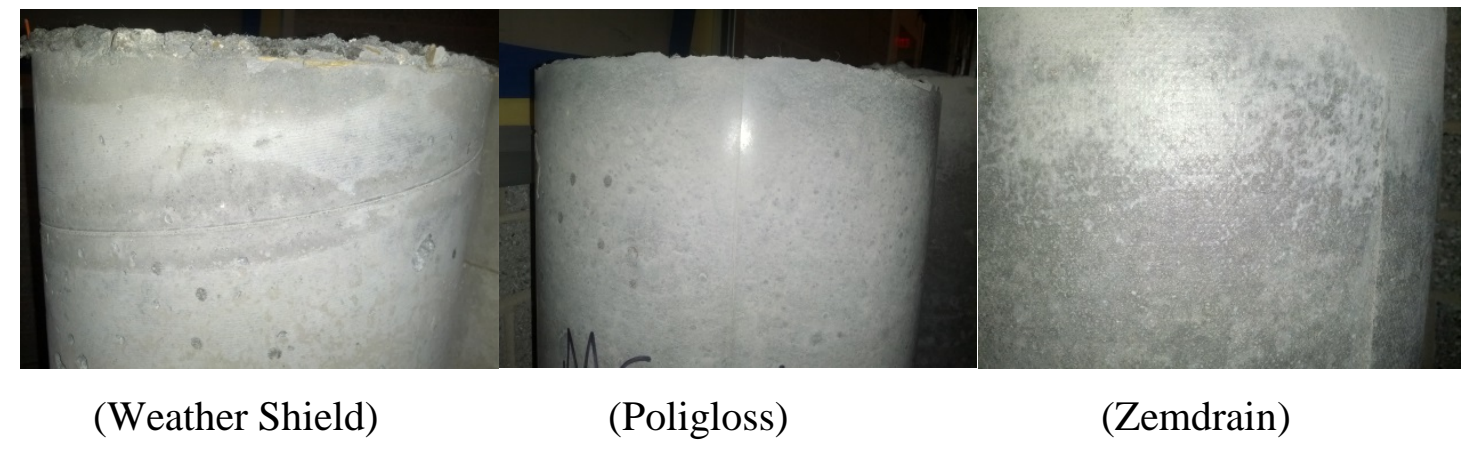

Figure 4.6: Concrete finish after removing formwork for MS-S10

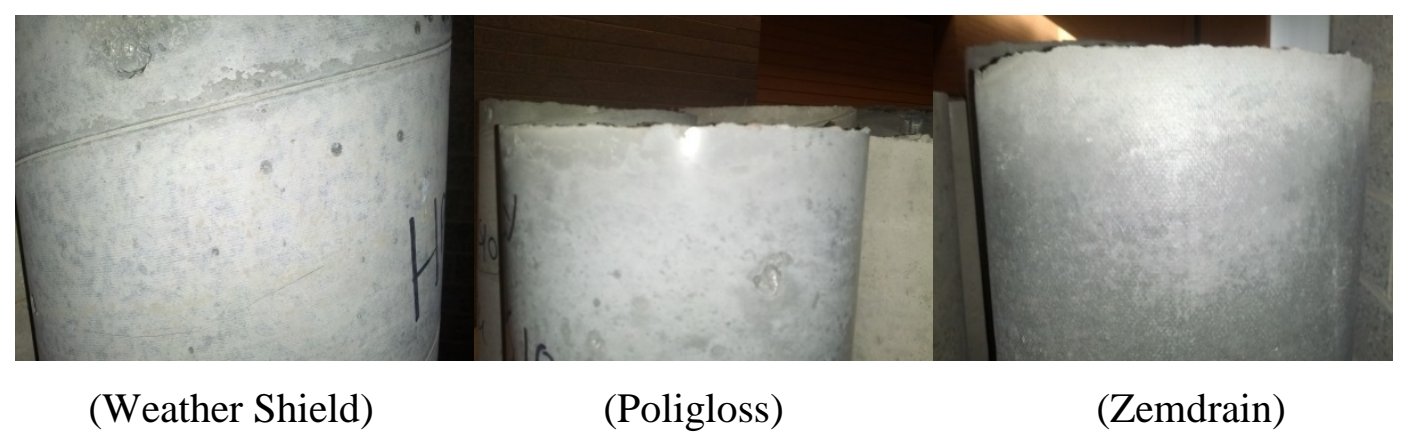

Figure 4.7: Concrete finish after removing formwork for HP-S10

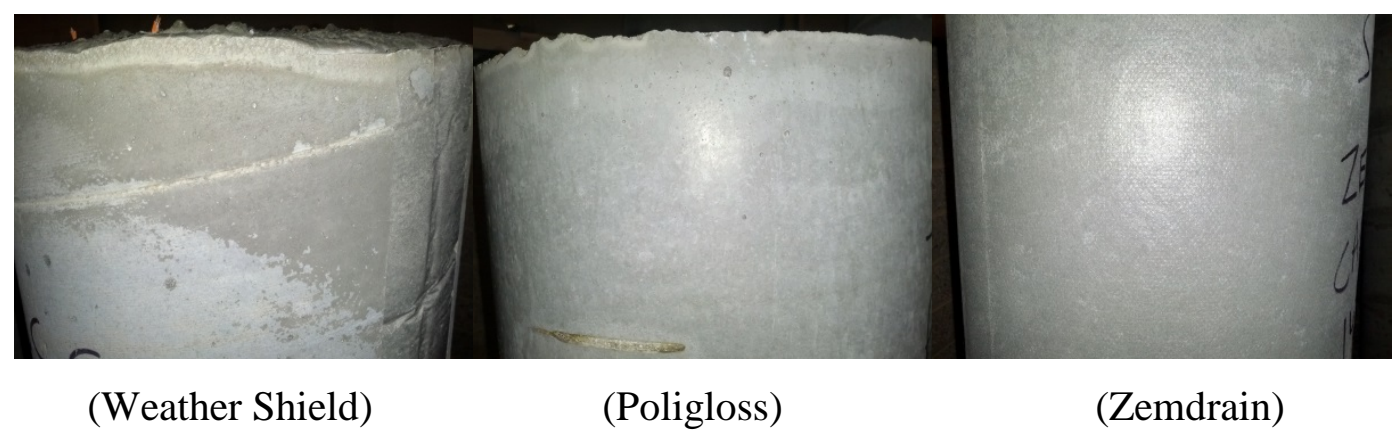

Figure 4.8: Concrete finish after removing formwork for MS-S10 SCC

It can be seen from the picture that for all the concrete Simple Weather Shield gives the surface with the circular lining, Poligloss gives the glossy finish and Zemdrain gives the textured blow hole free surface. In Sakrete and MS-S10, little honeycombing was 
observed in Weather Shield and Poligloss. All the tubes gives desired surface without any honeycombing and defects with HP-S10 and HP-S10 SCC.

Cuicui et. al, (2012) also inspected that many unwanted blowholes on the surface of concrete cast with steel mold, whereas controlled permeability formwork liner has smooth surface without any defects. The reasons for the defects are that the concrete mix the air bubbles break at the surface of steel mold. Bleeding was also noticed at the surface of steel mold.

\subsubsection{Surface strength by Schmidt hammer}

Figures 4.9 to 4.12 show the comparative analysis of surface strength of all the tubes cast with Sakrete, MS-S10, HP-S10 and SCC concrete, respectively.

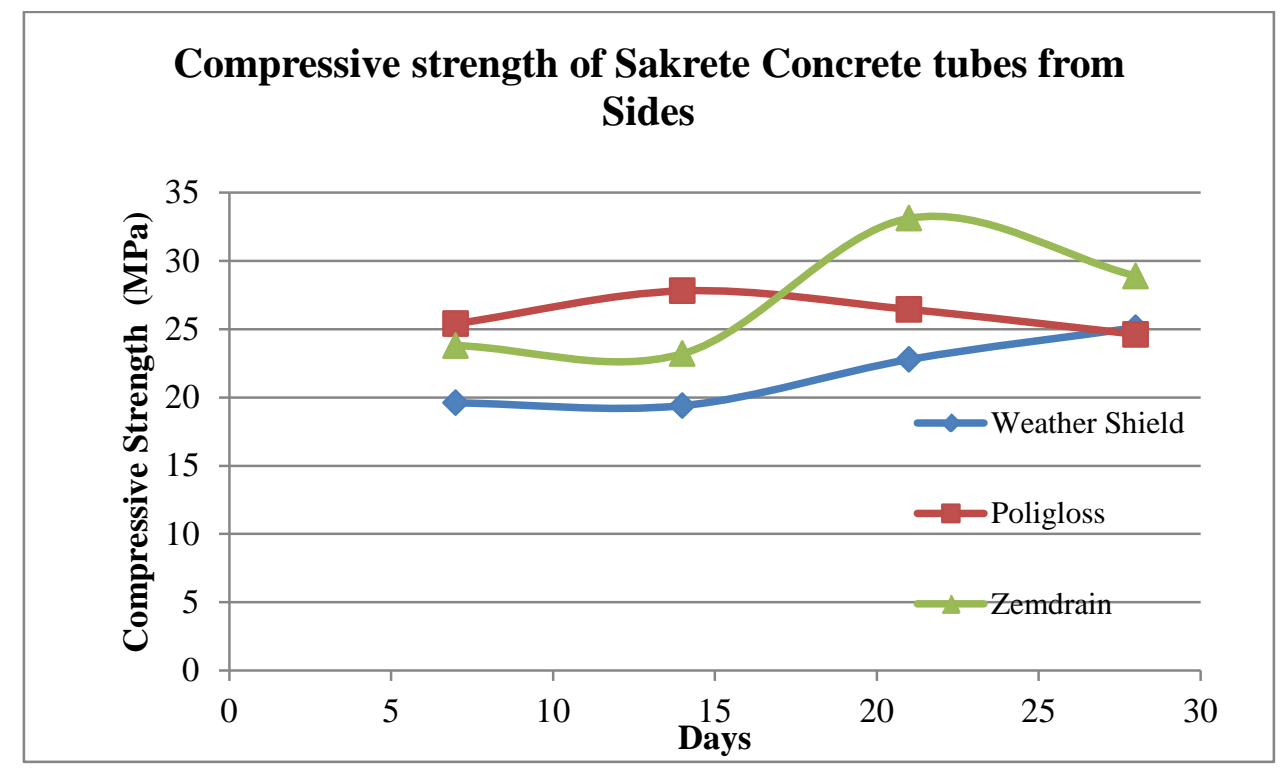

Figure 4.9: Compressive Strength of Sakrete Concrete tubes from sides by Schmidt Hammer 


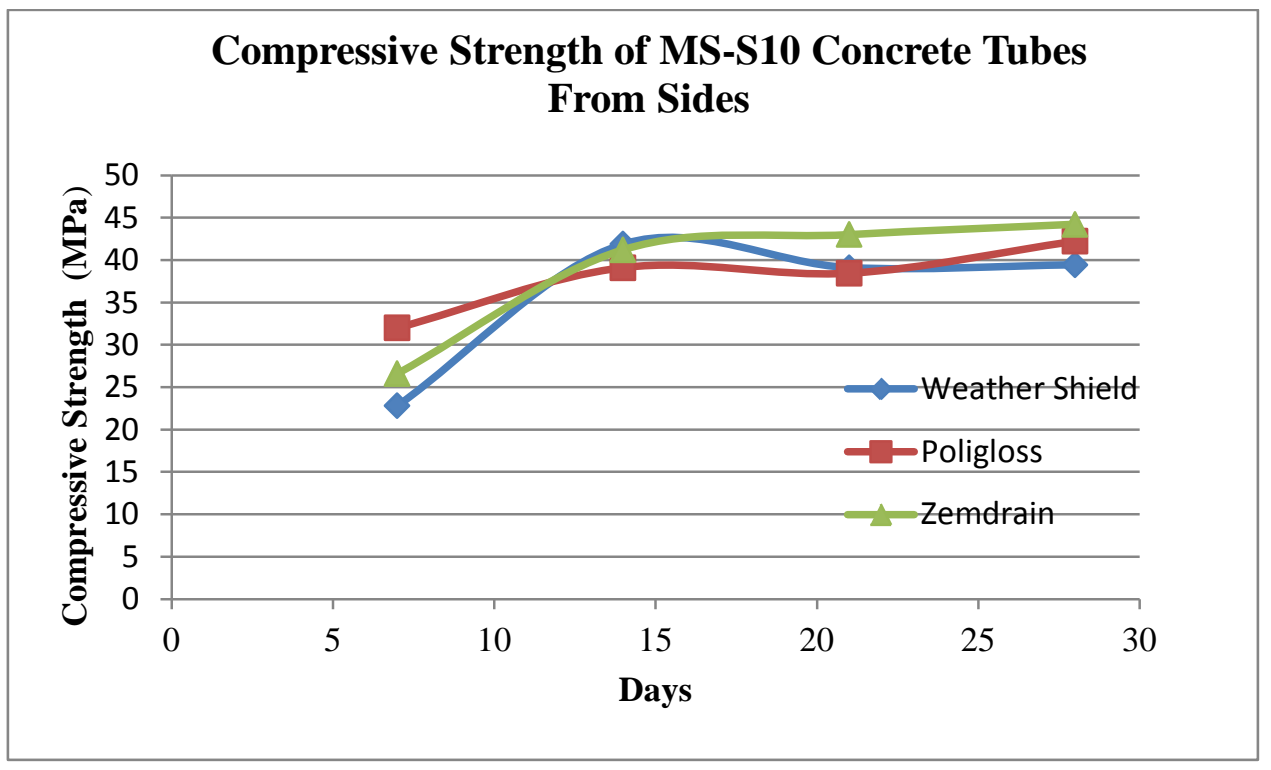

Figure 4.10: Compressive Strength of MS-S10 Concrete tubes from sides by Schmidt Hammer

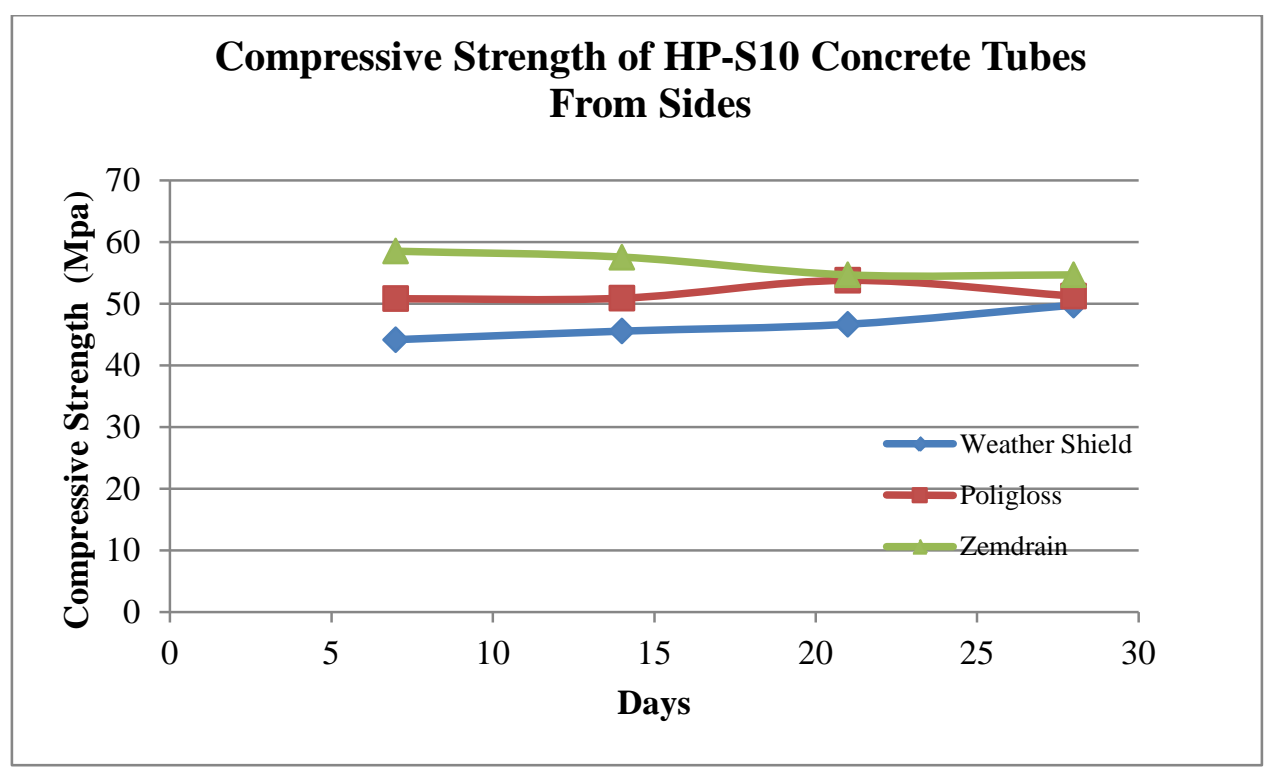

Figure 4.11: Compressive Strength of MS-S10 Concrete tubes from sides by Schmidt Hammer 


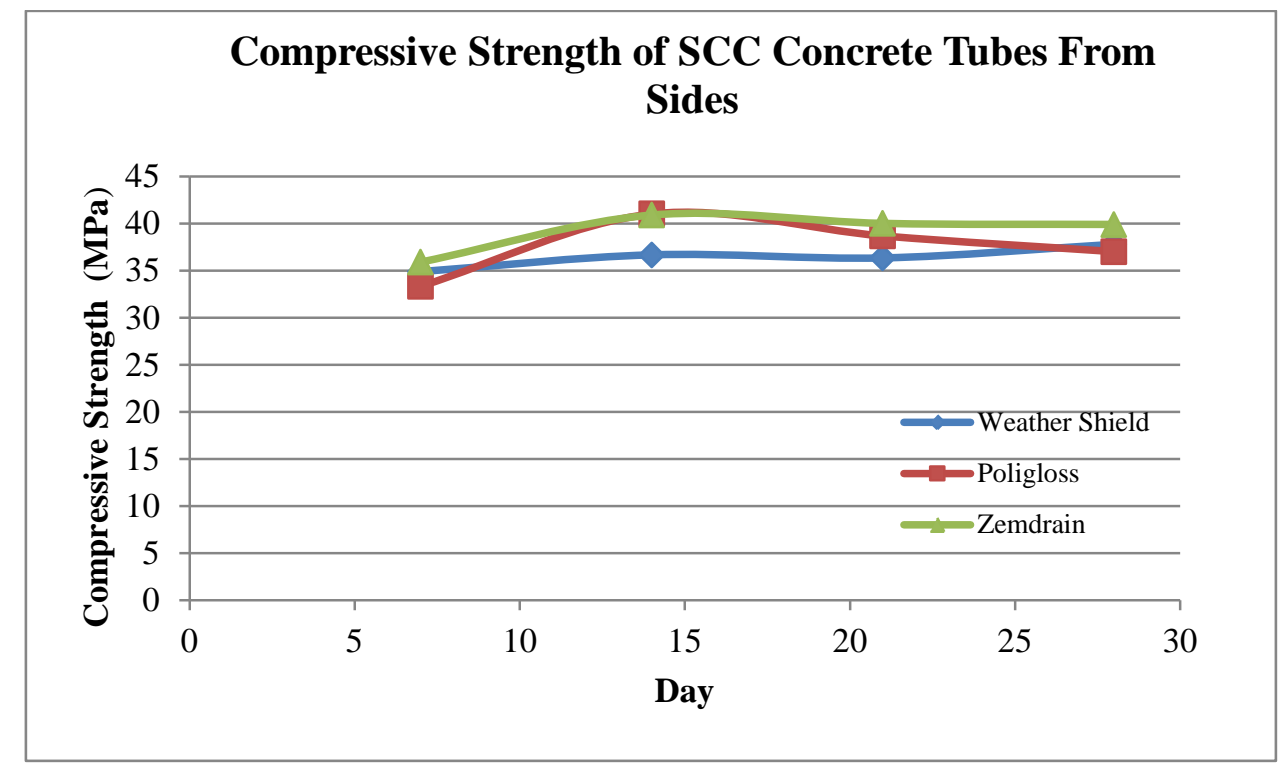

Figure 4.12: Compressive Strength of HP-S10 Concrete tubes from sides by Schmidt

\section{Hammer}

The 28-day surface strength ranges of 25-28 $\mathrm{MPa}$, 40-44 MPa, 50-55 $\mathrm{MPa}$ and 38-40 MPa are observed for Sakrete, MS-S10, HP-S10 and MS-S10 SCC, respectively. For all concretes cast with Zemdrain tubes showed the highest surface strength characteristics. This can be attributed to the better textured compacted surface. In addition, Zemdrain has the affinity to absorb water which causes lower water to cement ratio and increase concrete density near the surface leading to higher surface strength (Coutinho and Joana , 2001). 


\subsection{CYLINDER COMPRESSIVE STRENGTH}

Table 4.9 summarizes the average compressive of at least 3 cylinders for each type forming tubes and each concrete. SCC developed the highest strength followed by HPS10, MS-S10 and Sakrete. . HP-S10 and MS-S10 SCC developed higher cylinder strength followed by MS-S10 and Sakrete, as expected.

Table 4.9: Average compressive Strength of all Specimens and Concrete

\begin{tabular}{|c|c|c|c|}
\hline Concrete & Sample & Strength (MPa) & $\begin{array}{c}\text { \% Change From } \\
\text { Control }\end{array}$ \\
\hline \multirow{4}{*}{ Sakrete } & Control & 33.44 & 0.00 \\
\hline & Weather Shield & 37.04 & 10.77 \\
\hline & Poligloss & 33.39 & -0.14 \\
\hline & Zemdrain & 31.03 & -7.20 \\
\hline \multirow{4}{*}{ MS-S10 } & Control & 51.30 & 0.00 \\
\hline & Weather Shield & 52.43 & 2.20 \\
\hline & Poligloss & 45.44 & -11.42 \\
\hline & Zemdrain & 51.61 & 0.60 \\
\hline \multirow{4}{*}{ HP-S10 } & Control & 64.96 & 0.00 \\
\hline & Weather Shield & 60.25 & -7.25 \\
\hline & Poligloss & 62.94 & -3.11 \\
\hline & Zemdrain & 64.92 & -0.06 \\
\hline \multirow{4}{*}{ MS-S10 SCC } & Control & 67.83 & 0.00 \\
\hline & Weather Shield & 61.88 & -8.77 \\
\hline & Poligloss & 57.41 & -15.36 \\
\hline & Zemdrain & 69.81 & 2.92 \\
\hline
\end{tabular}


Fig 4.13 shows the bar chart comparison of average compressive strength of Weather Shield, Poligloss and Zemdrain with control (plastic mould) for Sakrete. It is clear from chart that Weather Shield showed an increase of $11 \%$, Poligloss almost same and Zemdrain a decrease of $7 \%$ compared to control plastic form.

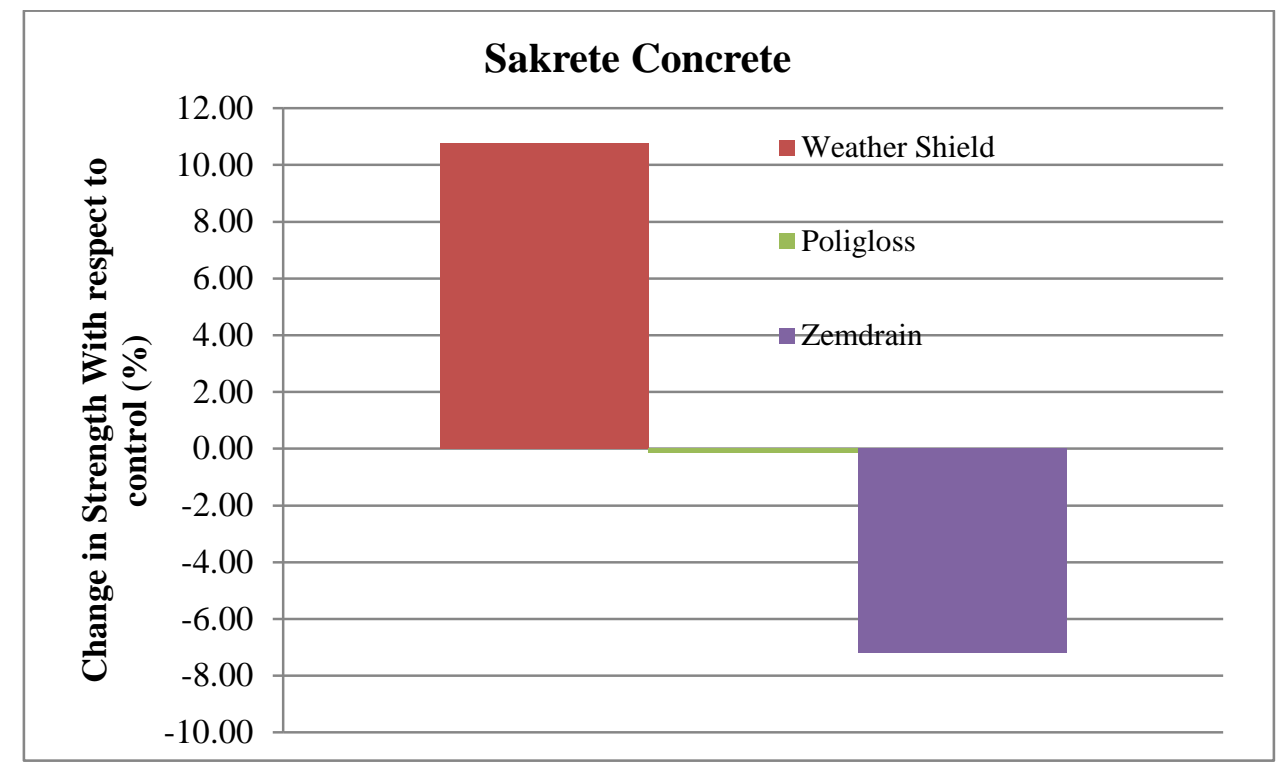

Figure 4.13: Comparison of change in strength from control (Sakrete Mix)

Fig 4.14 shows the bar chart comparison of average compressive g Strength of Weather Shield, Poligloss and Zemdrain with control for MS-S10. It is clear from the chart that simple Weather Shield showed an increase of $2 \%$, Poligloss a decrease of $12 \%$ and Zemdrain an increase of $1 \%$ from control. 


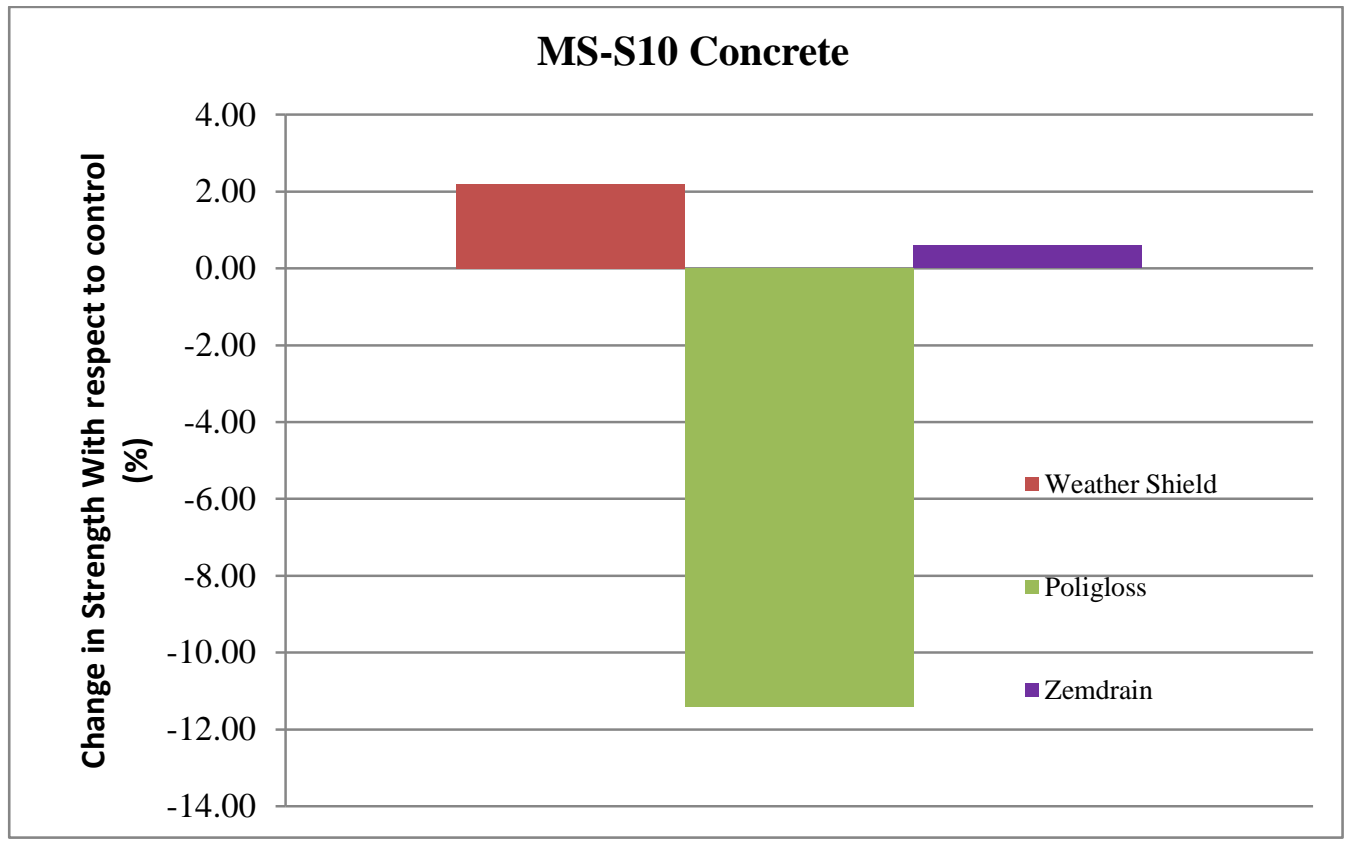

Figure 4.14: Comparison of change in strength from control (MS-S10 Mix)

Fig 4.15 shows the bar chart comparison of average crushing strength of Weather Shield, Poligloss and Zemdrain with control for HP-S10. Simple Weather Shield showed a decrease of $7 \%$, Poligloss a decrease of $3 \%$ and Zemdrain the same compared to control.

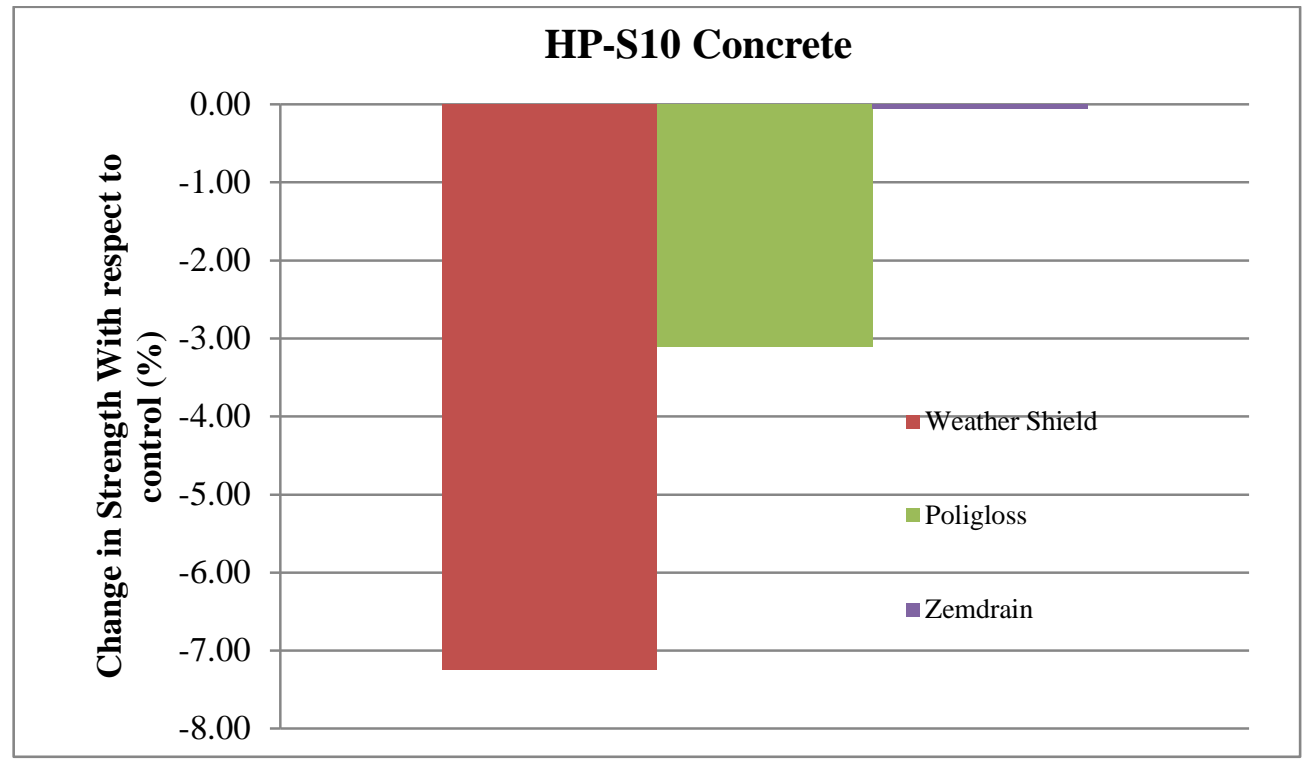

Figure 4.15: Comparison of change in strength from control (HP-S10 Mix) 
Fig 4.16 shows the comparison of compressive strength of Weather Shield, Poligloss and Zemdrain with control for SCC. Weather Shield showed a decrease of $9 \%$, Poligloss a decrease of $15 \%$ and Zemdrain showed an increase of $3 \%$ compared to control.

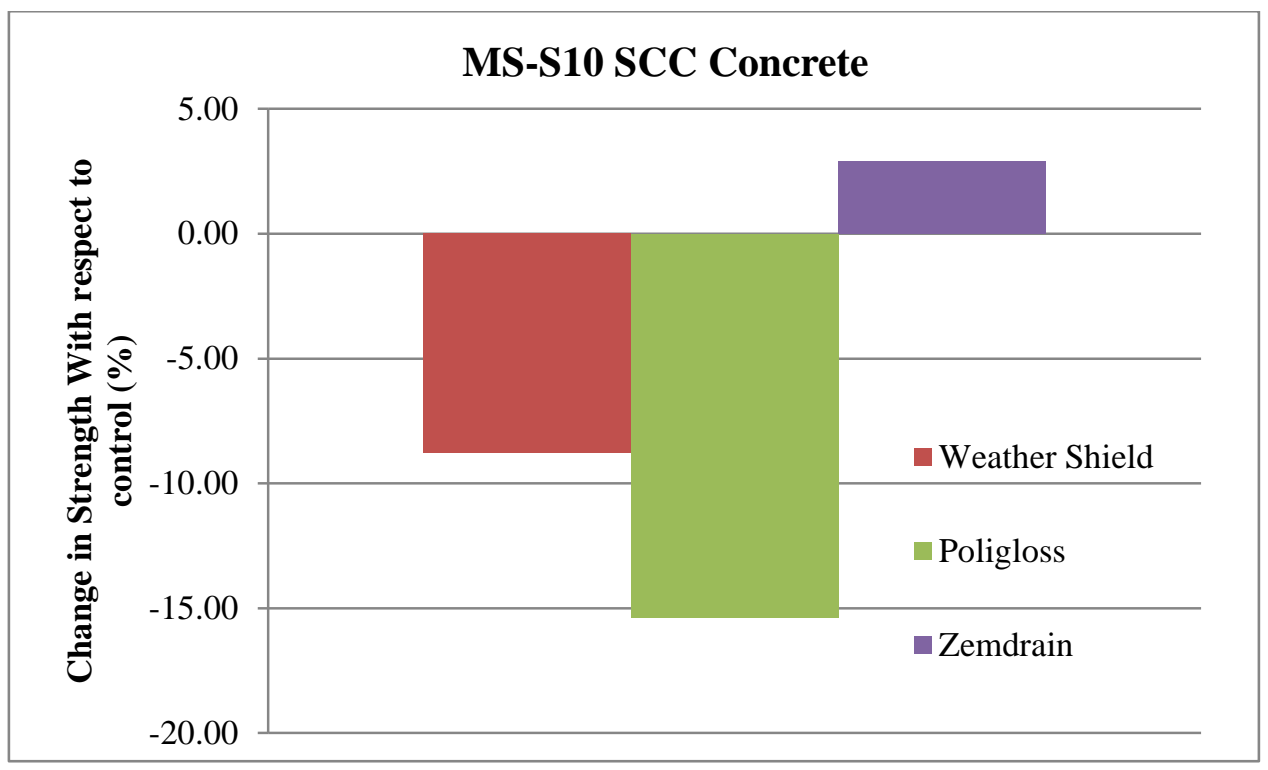

Figure 4.16: Comparison of change in strength from control (MS-S10 SCC Mix)

Poligloss cast concrete produced consistently lower cylinder compressive strength compared to control plastic mold while Weather Shield and Zemdrain produced higher or lower compressive strength depending on the concrete. However, concretes formed with Zemdrain tube developed compressive strength more or less similar to those of control plastic mold.

Table 4.10 shows the comparison of Schmidt hammer surface strength with cylinder compressive strength. For all the specimens, Schmidt hammer surface strength shows the lower strength as compared to cylinder strength. . The percentage variation lies between the ranges of $13 \%$ to $35 \%$ with the exception of 3 specimens. The decrease in surface strength is expected compared to the overall compressive strength. The surface strength may also be affected by the accuracy of Schmidt hammer, surface characteristics and human error. However, comparative study of forming tubes, surface strengths by Schmidt hammer are acceptable. 
Table 4.10: Comparison of Schmidt hammer with Crushing of specimen

\begin{tabular}{|c|c|c|c|c|}
\hline \multirow{4}{*}{ Concrete } & Sample & $\begin{array}{c}\text { Strength From } \\
\text { Crushing(MPa) }\end{array}$ & $\begin{array}{c}\text { Strength From } \\
\text { Schmidt } \\
\text { Hammer(MPa) }\end{array}$ & $\begin{array}{c}\text { \% Decrease } \\
\text { w.r.t Crushing }\end{array}$ \\
\hline \multirow{3}{*}{ Sakrete } & Weather Shield & 37.04 & 25.11 & 32.21 \\
\cline { 2 - 5 } & Poligloss & 33.39 & 24.63 & 26.24 \\
\cline { 2 - 5 } & Zemdrain & 31.03 & 28.89 & 6.90 \\
\hline \multirow{3}{*}{ MS-S10 } & Weather Shield & 52.43 & 39.44 & 24.78 \\
\cline { 2 - 5 } & Poligloss & 45.44 & 42.22 & 7.09 \\
\cline { 2 - 5 } & Zemdrain & 51.14 & 44.22 & 13.53 \\
\hline \multirow{3}{*}{ HP-S10 } & Weather Shield & 60.25 & 49.78 & 17.38 \\
\cline { 2 - 5 } & Poligloss & 62.94 & 51.22 & 18.62 \\
\cline { 2 - 5 } & Zemdrain & 64.92 & 54.67 & 15.79 \\
\hline \multirow{2}{*}{ MS-S10 } & Weather Shield & 61.88 & 37.78 & 38.95 \\
\cline { 2 - 5 } SCC & Poligloss & 57.41 & 37 & 35.55 \\
\cline { 2 - 5 } & Zemdrain & 69.81 & 39.89 & 42.86 \\
\hline
\end{tabular}

All concretes developed 28-day surface strength and cylinder more or less similar/comparable to the manufacturer specified strength. However, the 28-day cylinder strength of MS-10 SCC was higher than the manufacturer specified strength - for comparative performance study of forming tubes, this is not a concern.

Sha'aat (1994) also compared the surface strength formed from Zemdrain liner was 3 times higher than the impermeable formwork. Cuicui et al., (2012) checked the strength of surface with rebound hammer and they noticed the strength increase of $11-28 \%$ on formwork liner as compare to conventional molds. 


\subsection{WATER ABSORPTION AND DENSITY}

Table 4.11 summarizes the average water absorption after immersion, bulk density (dry and immersed), and volume of permeable pores of all specimens cast with Sakrete, MSS10, HP-S10 and MS-S10 SCC mix.

Table 4.11 Test Results for Average Absorption, Bulk Density and Volume of Permeable Pores

\begin{tabular}{|c|c|c|c|c|c|}
\hline Concrete & Sample & $\begin{array}{l}\text { Average Water } \\
\text { Absorption (\%) }\end{array}$ & $\begin{array}{c}\text { Average Bulk } \\
\text { Density, Dry } \\
\text { g/cm }{ }^{3}\end{array}$ & $\begin{array}{l}\text { Bulk Density After } \\
\text { immersion, g/ } \mathrm{cm}^{3}\end{array}$ & $\begin{array}{c}\text { Average } \\
\text { Permeable } \\
\text { Pores \% }\end{array}$ \\
\hline \multirow{4}{*}{ Sakrete } & Control & 5.618 & 2.249 & 2.375 & 8.253 \\
\hline & Weather Shield & 4.373 & 2.323 & 2.425 & 6.641 \\
\hline & Poligloss & 4.671 & 2.299 & 2.407 & 7.623 \\
\hline & Zemdrain & 4.907 & 2.238 & 2.348 & 7.897 \\
\hline \multirow{4}{*}{ MS-S10 } & Control & 3.000 & 2.308 & 2.378 & 5.920 \\
\hline & Weather Shield & 2.640 & 2.262 & 2.322 & 5.275 \\
\hline & Poligloss & 2.730 & 2.258 & 2.319 & 5.374 \\
\hline & Zemdrain & 2.490 & 2.266 & 2.322 & 4.985 \\
\hline \multirow{4}{*}{ HP-S10 } & Control & 2.900 & 2.278 & 2.344 & 5.757 \\
\hline & Weather Shield & 2.810 & 2.295 & 2.359 & 5.791 \\
\hline & Poligloss & 2.810 & 2.290 & 2.354 & 5.735 \\
\hline & Zemdrain & 2.710 & 2.273 & 2.334 & 5.422 \\
\hline \multirow{4}{*}{$\begin{array}{l}\text { MS-S10 } \\
\text { SCC }\end{array}$} & Control & 3.710 & 2.243 & 2.326 & 7.316 \\
\hline & Weather Shield & 3.690 & 2.205 & 2.286 & 7.272 \\
\hline & Poligloss & 3.790 & 2.197 & 2.280 & 7.493 \\
\hline & Zemdrain & 3.300 & 2.267 & 2.342 & 6.519 \\
\hline
\end{tabular}

Fig. 4.17 shows a comparison of average water absorption of Weather Shield, Poligloss and Zemdrain with control for Sakrete mix. Weather Shield shows a decrease of $22 \%$, Poligloss a decrease of $17 \%$ and Zemdrain a decrease of $13 \%$ compared with control (Plastic mould). 


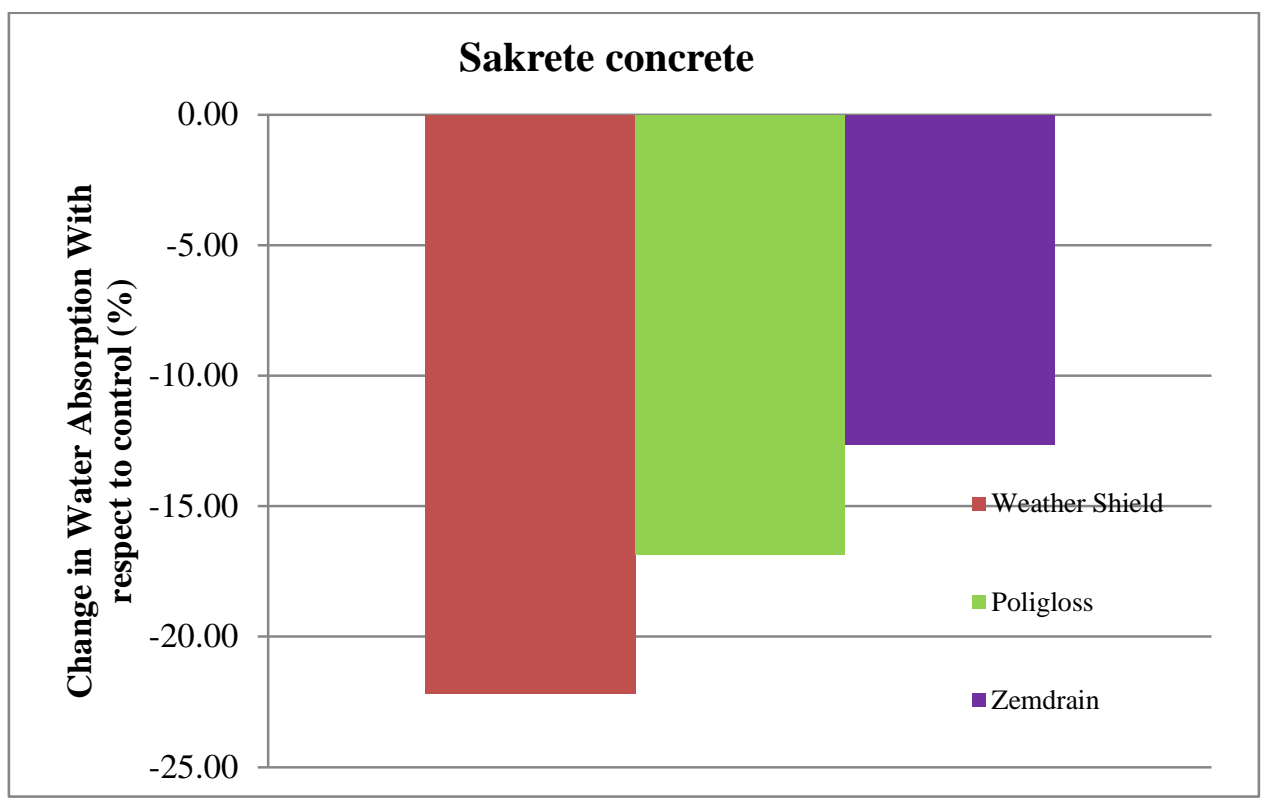

Figure 4.17: Comparison of change in water absorption from control (Sakrete Mix)

Fig 4.18 shows the bar chart comparison of average Water absorption of Weather Shield, Poligloss and Zemdrain with control for MS-S10 mix, Weather Shield showed a decrease of $12 \%$, Poligloss a decrease of $9 \%$ and Zemdrain a decrease of $17 \%$ from control.

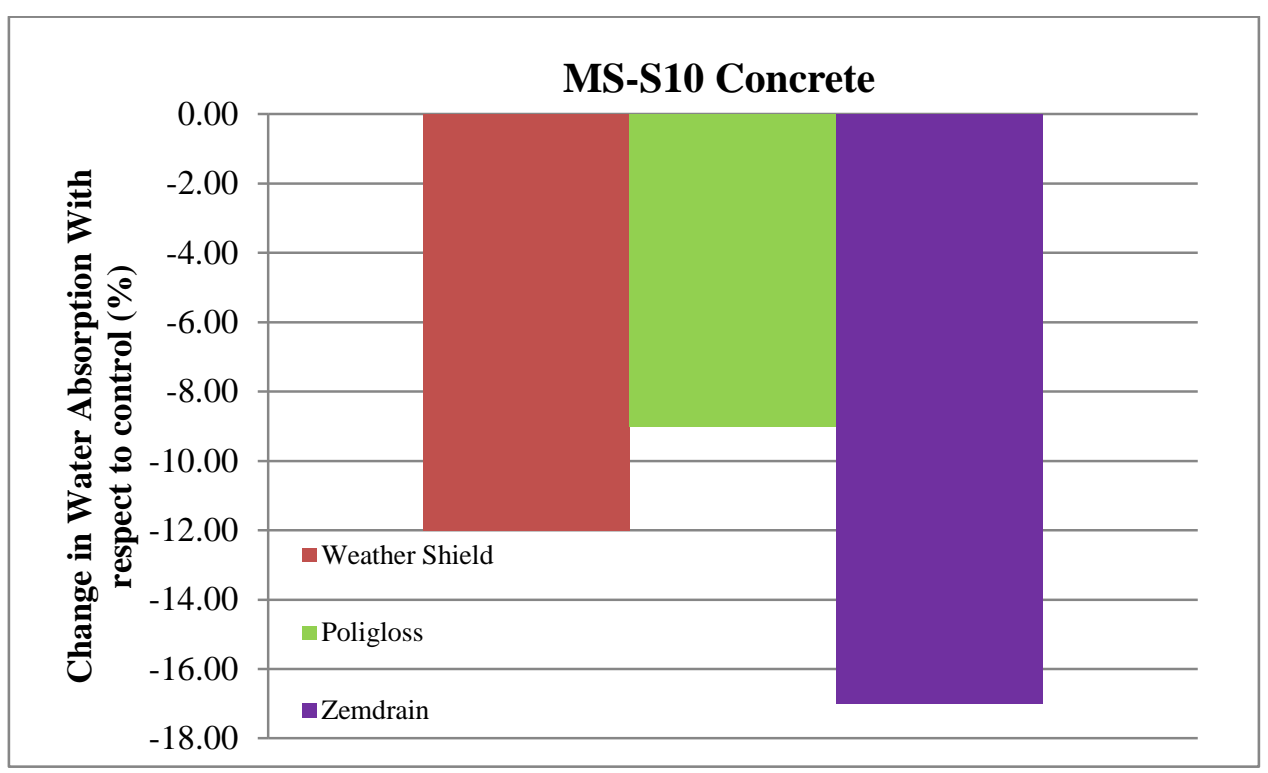

Figure 4.18: Comparison of change in water absorption from control (MS-S10 Mix 
Fig 4.19 shows the bar chart comparison of average Water absorption of Weather Shield, Poligloss and Zemdrain with control for HP-S10.Simple Weather Shield showed a decrease of 3\%, Poligloss a decrease of $3 \%$ and Zemdrain a decrease of 7\% from control.

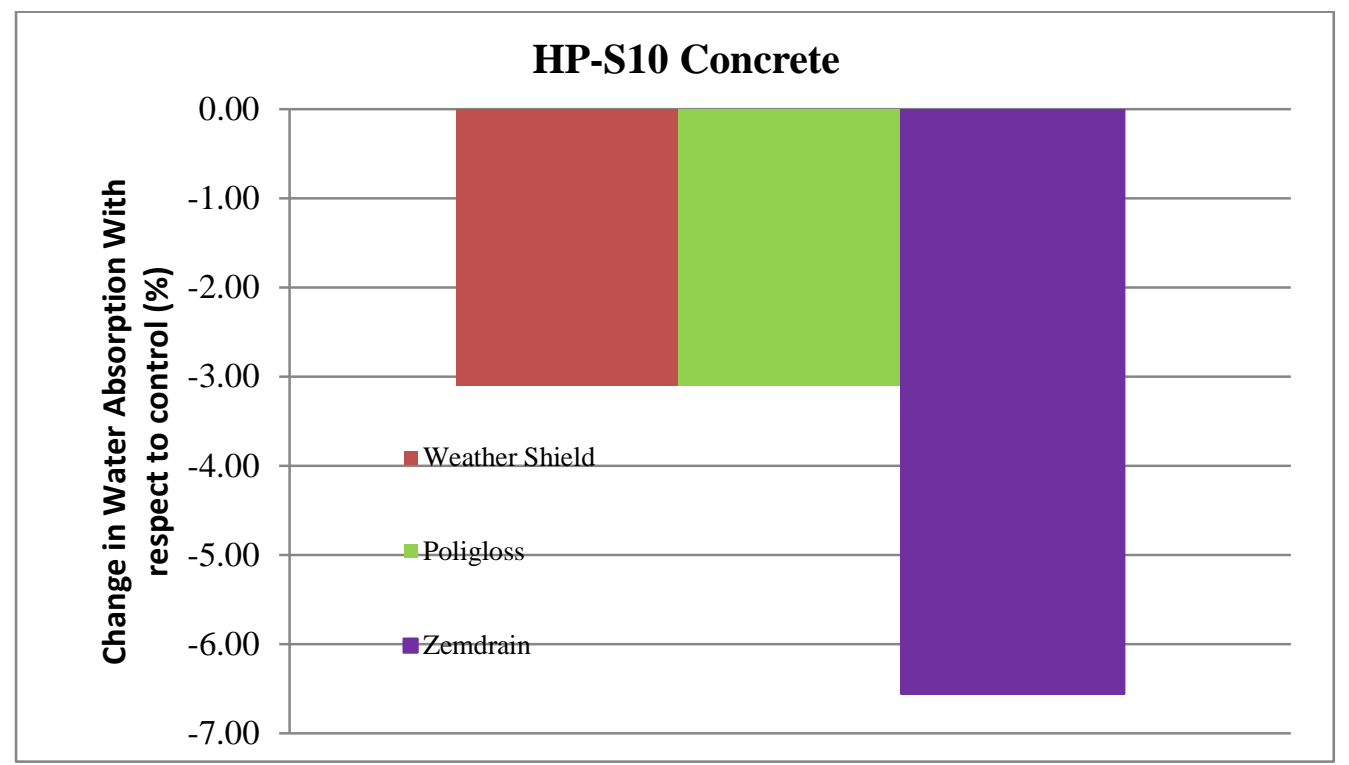

Figure 4.19: Comparison of change in water absorption from control (HP-S10 Mix)

Fig 4.20 shows the bar chart comparison of average Water absorption of Weather Shield, Poligloss and Zemdrain with control for SCC mix, Weather Shield showed a decrease of $1 \%$, Poligloss an increase of $2 \%$ and Zemdrain a decrease of $11 \%$ from control. 


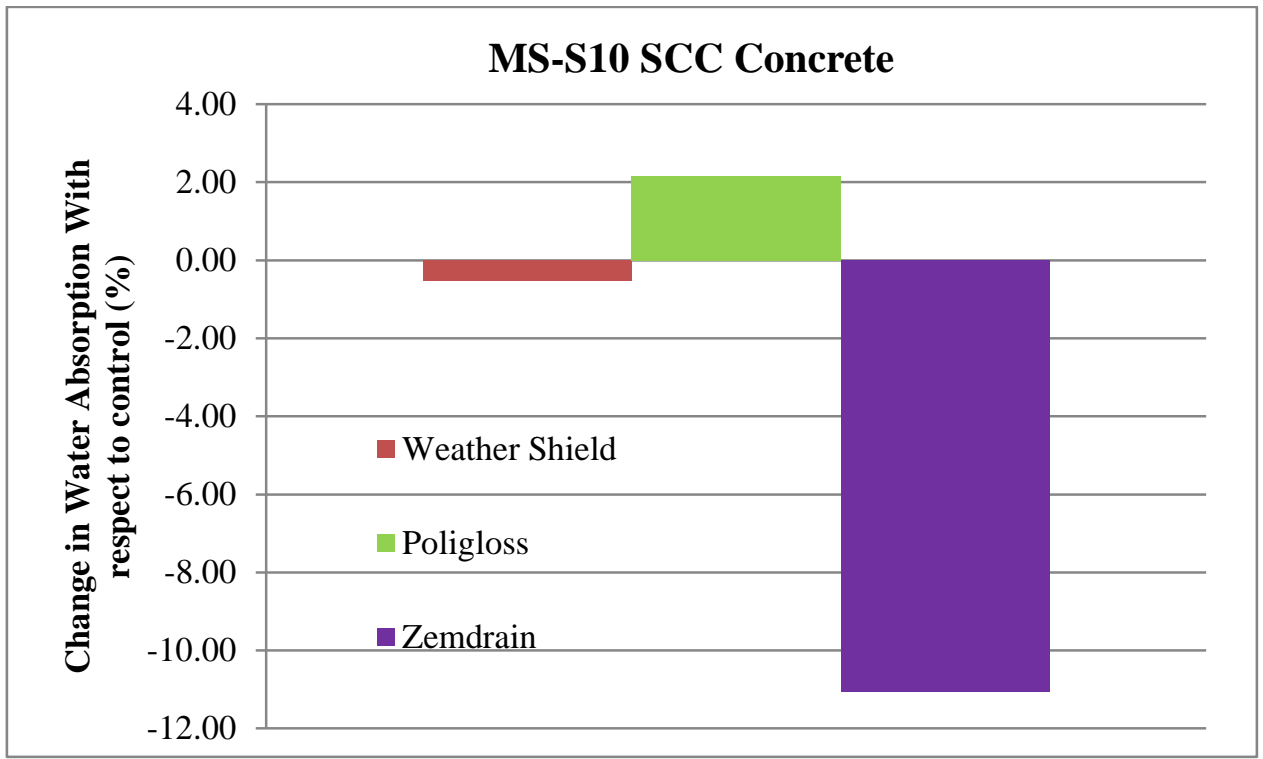

Figure 4.20: Comparison of change in water absorption from control (SCC Mix)

It is clear from the results that the water absorption and volume of permeable pores for concretes cast with all Newark tubes are less than those made with control plastic tubes. This can be attributed to the better surface finish produced by Weather Shield, Poligloss and Zemdrain tubes compared with conventional plastic molds. Price (1992) reported improvement of the concrete surface lined with Zemdrain. 


\subsection{INFULENCE OF NEWARK FORMING TUBES ON SORPTIVITY}

Table 4.12 summarizes the average absorption (I) after $48 \mathrm{~h}$ of immersion in water and the initial sorptivity calculate from the slope of absorption to square root of time. Data simulates the test results for all of the specimens cast with Sakrete, MS-S10, HP-S10 and MS-S10 SCC. In general, the initial sorptivity was lower for concretes cast with Newark tubes compared with those cast with control plastic molds.

Table 4.12 Sorptivity for Specimens

\begin{tabular}{|c|c|c|c|}
\hline \multirow{4}{*}{ Concrete } & Sample & $\begin{array}{c}\text { I }=\Delta \text { Mass/area/ } \\
\text { Density of water } \\
(\mathrm{mm}) @ \text { @ 48h }\end{array}$ & $\begin{array}{c}\text { Initial Sorptivity } \\
\left(\mathrm{mm} / \mathrm{s}^{1 / 2}\right)\end{array}$ \\
\hline \multirow{4}{*}{ Sakrete } & Control & 2.671 & 0.0064 \\
\cline { 2 - 4 } & Weather Shield & 0.845 & 0.0019 \\
\cline { 2 - 4 } & Poligloss & 1.232 & 0.0029 \\
\cline { 2 - 4 } & Zemdrain & 2.729 & 0.0067 \\
\hline \multirow{4}{*}{ MS-S10 } & Control & 0.597 & 0.0014 \\
\cline { 2 - 4 } & Weather Shield & 0.306 & 0.0007 \\
\cline { 2 - 4 } & Poligloss & 0.27 & 0.0006 \\
\cline { 2 - 4 } & Zemdrain & 0.244 & 0.0005 \\
\hline \multirow{4}{*}{ HP-S10 } & Control & 0.294 & 0.0007 \\
\cline { 2 - 4 } & Weather Shield & 0.275 & 0.0006 \\
\cline { 2 - 4 } & Poligloss & 0.27 & 0.0005 \\
\cline { 2 - 4 } & Zemdrain & 0.278 & 0.0006 \\
\hline \multirow{4}{*}{ MS-S10 SCC } & Control & 0.567 & 0.0013 \\
\cline { 2 - 4 } & Weather Shield & 0.421 & 0.001 \\
\cline { 2 - 4 } & Poligloss & 0.433 & 0.001 \\
\cline { 2 - 4 } & Zemdrain & 0.47 & 0.0011 \\
\hline
\end{tabular}

Figure 4.21 shows the comparison of water absorption (sorptivity) for each mix after 48 hours (cast with different formwork and different mix) from control specimen (cast with plastic mould). For Sakrete concrete Weather Shield showed the maximum percentage decrease of $68 \%$ as compare to control. Zemdrain showed the highest decrease of $59 \%$. For MS-S10 concrete Weather Shield showed the highest decrease of $25 \%$ as compare to 
control for MS-S10 SCC. Due to high strength and low porosity of HP-S10 concrete all of the specimens have to the same sorptivity as compare to control. Figure 4.22 shows the variation of average water absorption (I) with time (up to 48 hours) for each of the concretes cast with different Newark tubes including control plastic mold. In general, the 48-hour water absorption was lower for concretes cast with Newark tubes compared with those cast with control plastic molds. As expected, the initial rate of water absorption was higher and the rate decreased with time.
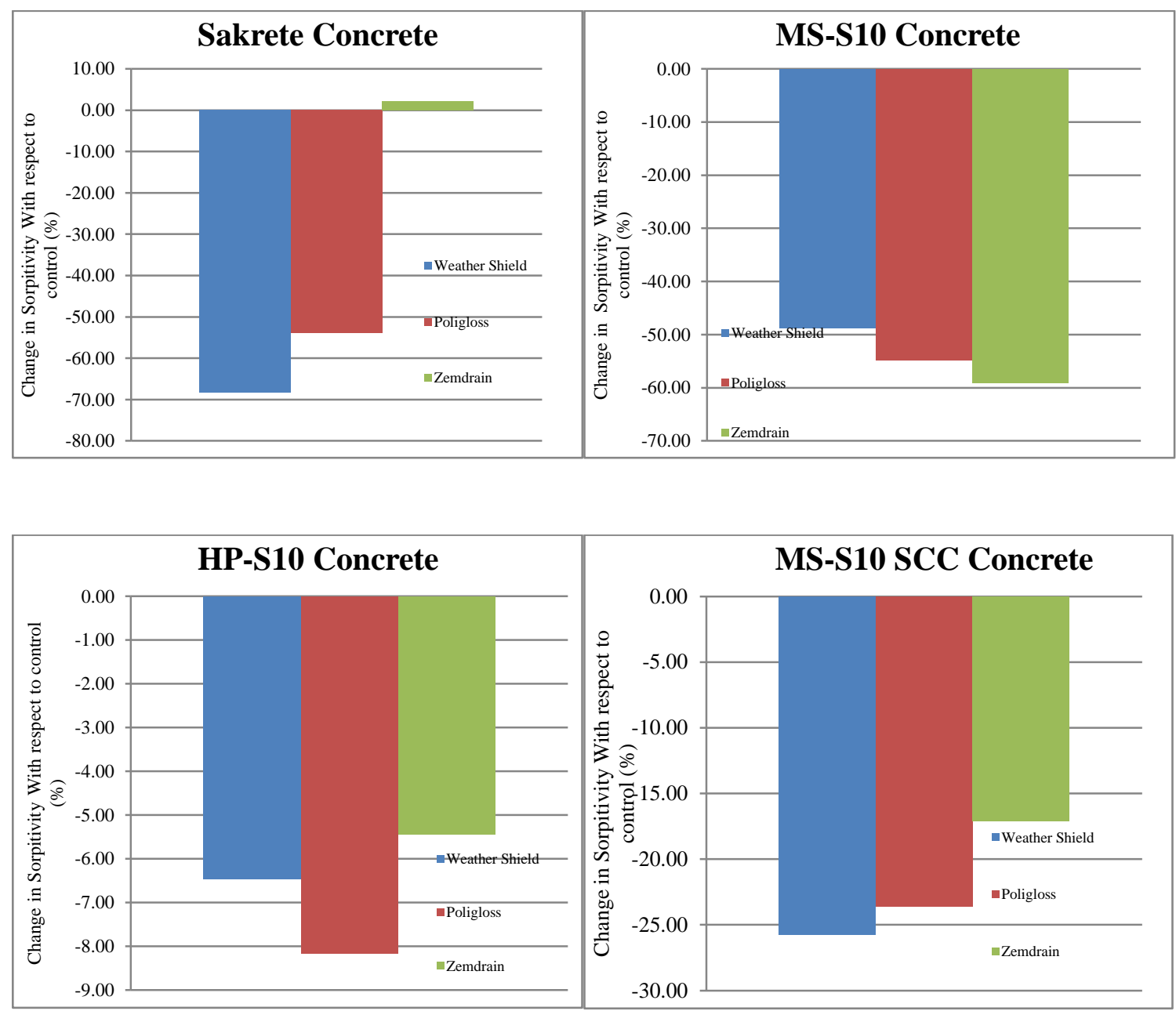

Figure 4.21: Comparison of change in sorptivity with respect to control (All concretes) 

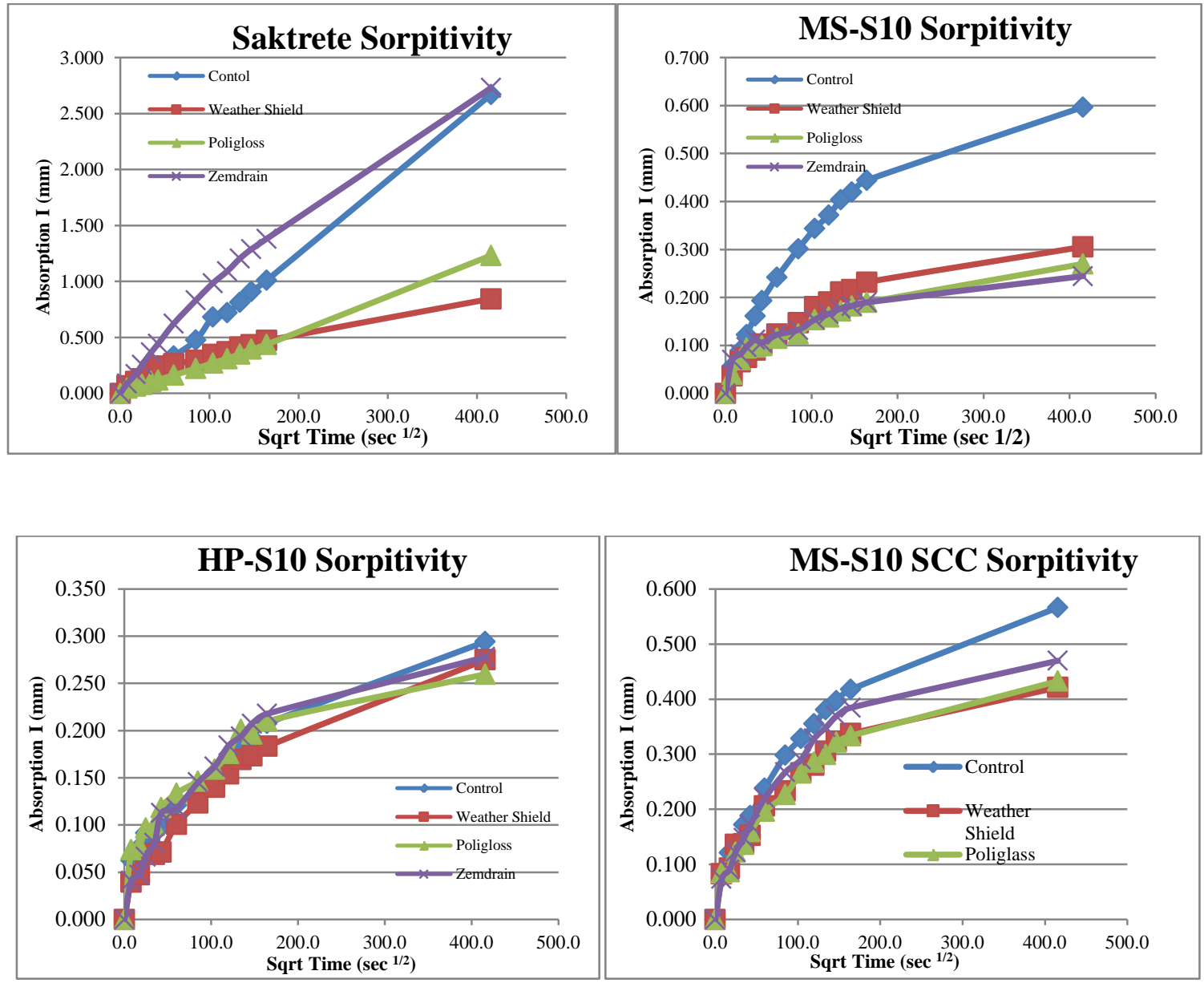

Figure 4.22 Absorption versus time for all of concrete with different forming tubes.

Philip and Chirag (2008) in there laboratory research found that by the application of formwork liners on 5 different cement (PC, PFA, GGBS, MK and CSF) with three different strengths (25MPa, 37MPa and 45MPa) and with 4 different types of admixtures(WR, SP, AE \& WP) capillarity porosity was decreased by 20\% , 30\% and 35 $\%$ for $25 \mathrm{MPa}$, 37MPa and 45MPa grade respectively. 


\subsection{INFULENCE OF NEWARK FORMING TUBES ON CHLORIDE PENETRATION}

Table 4.13 summarizes the average rapid chloride penetration test data of all specimens cast with Sakrete, MS-S10, HP-S10 and SCC mixes.

Table 4.13 Chloride penetration for Specimens

\begin{tabular}{|c|c|c|c|c|}
\hline \multicolumn{5}{|c|}{ Chloride penetration (Coulombs) } \\
\hline Concrete & Control & Weather Shield & Zemdrain & Poligloss \\
\hline Sakrete & 7075 & 3070 & 4440 & 6709 \\
\hline MS-S10 & 590 & 366 & 391 & 221 \\
\hline HP-S10 & 641 & 487 & 406 & 558 \\
\hline MS-S10 SCC & 710 & 654 & 675 & 688 \\
\hline
\end{tabular}

Fig 4.23 compares average chloride penetration resistance of Weather Shield, Poligloss and Zemdrain with control for Sakrete mix. Weather Shield provides 56\% more, Poligloss provides $37 \%$ more and Zemdrain provides 5\% more chloride resistance as compare to control. According to ASTM standards, range of all of the samples of Sakrete has very poor resistance to chloride resistance.

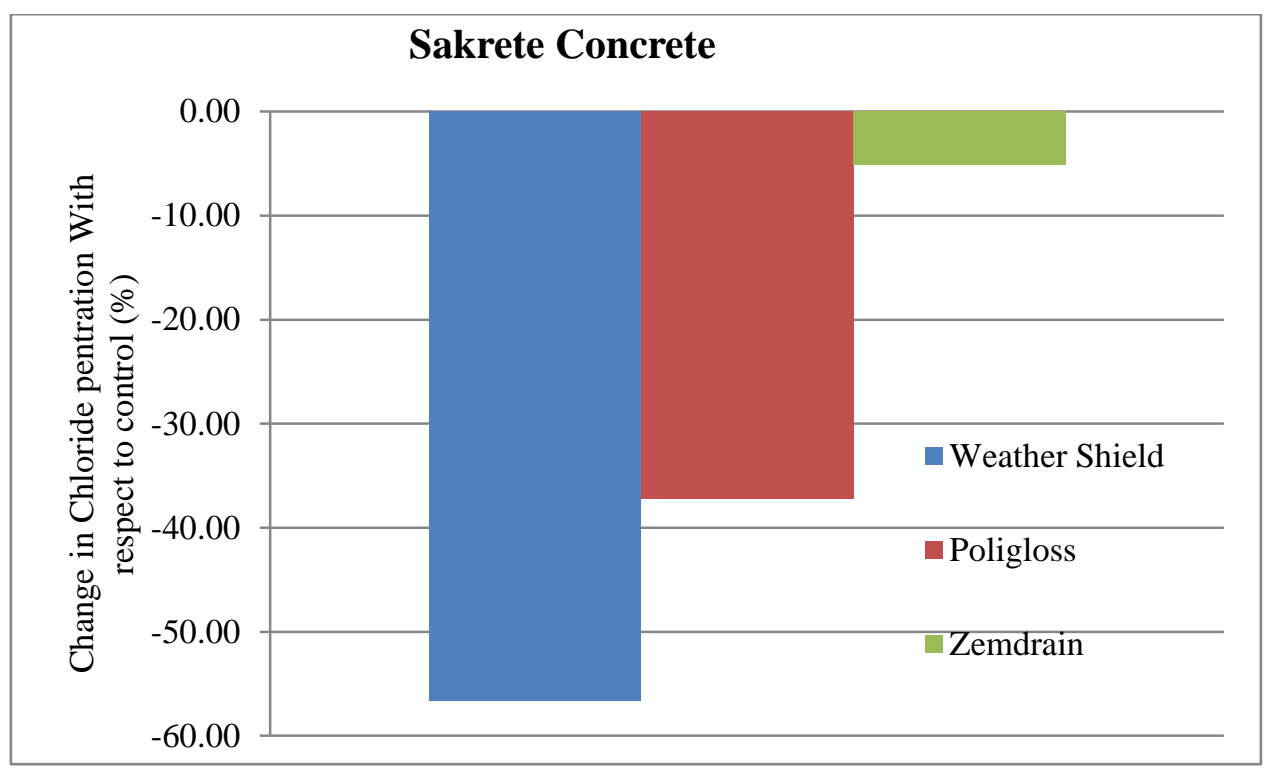

Figure 4.23: Comparison of change in chloride penetration from control (Sakrete) 
Fig 4.24 shows the bar chart comparison of average chloride penetration of Weather Shield, Poligloss and Zemdrain with control for MS-S10 mix, Weather Shield provides 38\% more, Poligloss provides $34 \%$ more and Zemdrain provides $63 \%$ more chloride penetration resistance as compare to control. According to ASTM standards all of the samples of MS-S10 mix have high resistance to chloride resistance.

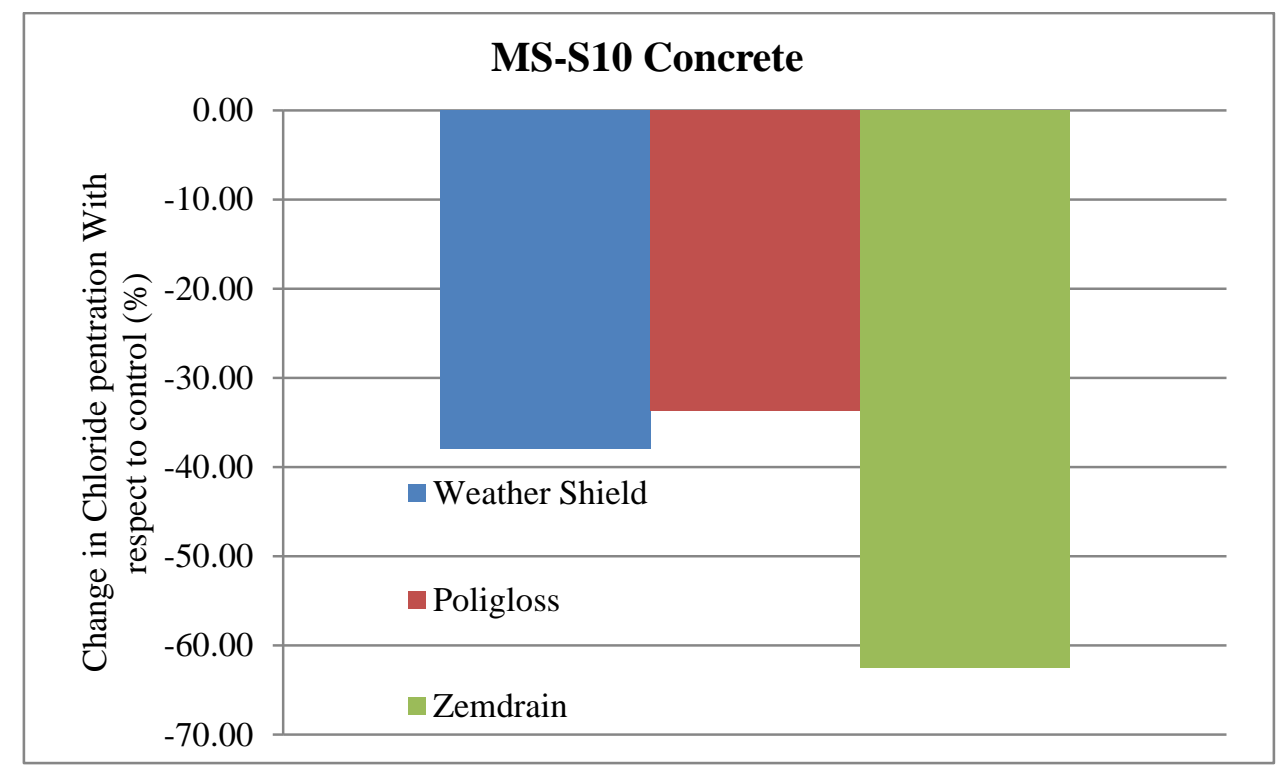

Figure 4.24: Comparison of change in chloride penetration from control (MS-S10)

Fig 4.25 shows the bar chart comparison of average Chloride Penetration of Weather Shield, Poligloss and Zemdrain with control for HP-S10, It is clear from the HP-S10 chart that simple Weather Shield provides $24 \%$ more, Poligloss provides $37 \%$ more and Zemdrain provides of $13 \%$ more chloride penetration resistance from control. According to ASTM standards all of the samples of HP-S10 have high resistance to chloride resistance 


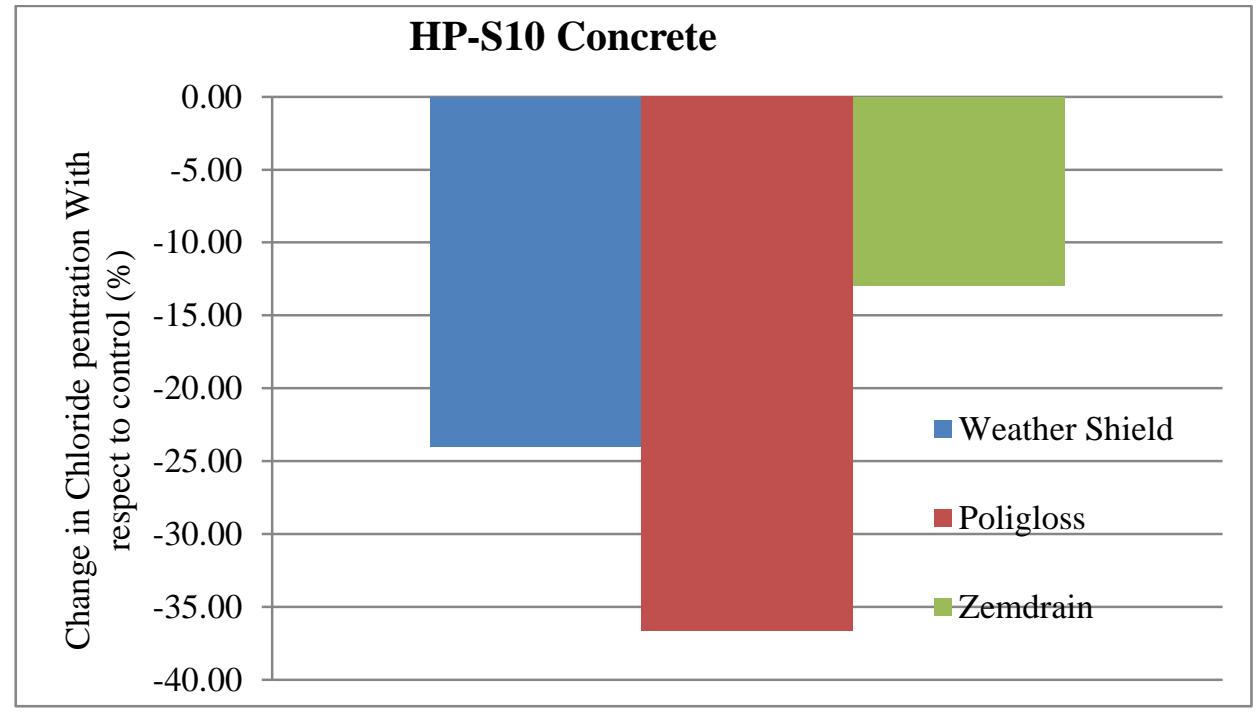

Figure 4.25: Comparison of change in chloride penetration from control (HP-S10)

Fig 4.26 shows the bar chart comparison of average Chloride Penetration of Weather Shield, Poligloss and Zemdrain with control for SCC mix, it is clear from the SCC chart that simple Weather Shield provides $8 \%$ more, Poligloss provides $5 \%$ and Zemdrain provides $3 \%$ more chloride penetration resistance from control. According to ASTM standards all of the samples of SCC mix have high resistance to chloride resistance.

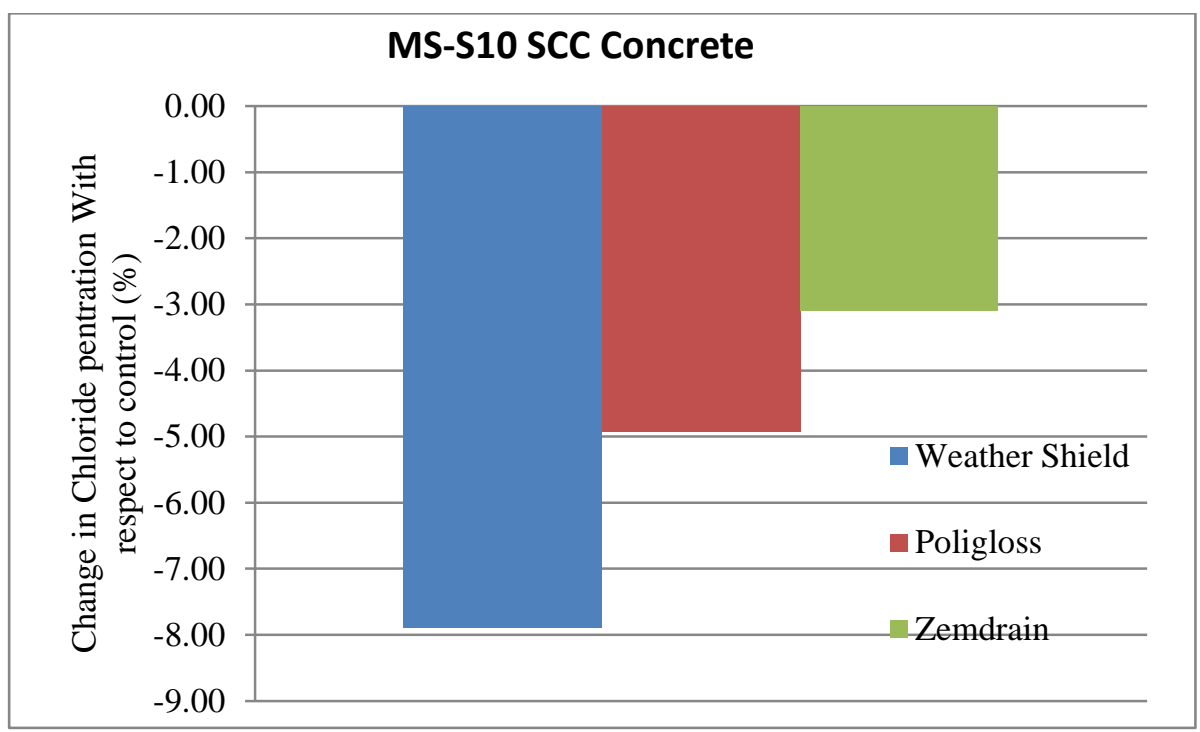

Figure 4.26: Comparison of change in chloride penetration from control (SCC Mix) 
It is also clear from the above charts that water Absorption for all Newark's Tube is less than control Specimen. The specimens which have less water absorption found to give more chloride penetration resistance.

Price(1992) also proved from his research by using concrete mix with Fly Ash (FA) and Ground Granulated Blast Furnace Slag that the chloride penetration was dramatically decreased by using the permeable formwork. Basheer et al., (1995) in their research found that regardless of the curing methodology and different mix all the formwork liner gives better performance than conventional formwork. 


\subsection{FREEZE THAW RESULTS}

Table 4.14 shows the weight and time to travel wavelength from one end of prism to other end after every 30 cycles for Sakrete mix. Fundamental traverse frequency(n) at every cycle can be calculated by taking inverse of travel time.

Table 4.14: Weight and Time of wavelength of each specimen at different cycles for Sakrete concrete.

\begin{tabular}{|c|c|c|c|c|c|c|c|c|c|c|c|c|}
\hline \multirow[b]{2}{*}{ Speciman } & \multicolumn{5}{|c|}{0 Cycles } & \multicolumn{3}{|c|}{30 Cycles } & \multicolumn{2}{|c|}{65 Cycles } & \multicolumn{2}{|c|}{95 cycles } \\
\hline & Weight (Kg) & $\mathrm{T}_{\mathrm{L}}(\mu \mathrm{s})$ & $\mathrm{T}_{\mathrm{S}}(\mu \mathrm{s})$ & $\mathrm{L}_{\mathrm{L}}(\mathrm{mm})$ & $\mathrm{L}_{\mathrm{S}}(\mathrm{mm})$ & Weight (Kg) & $\mathrm{T}_{\mathrm{L}}(\mu \mathrm{s})$ & $\mathrm{T}_{\mathrm{S}}(\mu \mathrm{s})$ & Weight (Kg) & $\mathrm{T}_{\mathrm{L}}(\mu \mathrm{s})$ & Weight (Kg) & $\mathrm{T}_{\mathrm{L}}(\mu \mathrm{s})$ \\
\hline Dummy & 7.533 & 88 & 17.2 & 401 & 101 & & & & & & & \\
\hline Control 2 & 7.914 & 89.4 & 19 & 401 & 100 & 7.929 & 93 & 23.5 & 7.944 & 133.2 & 7.986 & - \\
\hline Control 3 & 8.006 & 88.4 & 21.7 & 400 & 101 & 8.026 & 90.8 & 22.6 & 8.025 & 91.3 & 8.044 & 204.2 \\
\hline Weather Shield 1 & 7.577 & 89.2 & 47.3 & 402 & 99 & 7.594 & 107.8 & 23.3 & 7.606 & 124.1 & 7.636 & - \\
\hline Weather Shield 2 & 7.578 & 89.2 & 29.3 & 400 & 99 & 7.589 & 91.9 & 23.1 & 7.589 & 124 & 7.620 & - \\
\hline poligloss 1 & 7.551 & 86.2 & 18.5 & 399 & 100 & 7.566 & 96.9 & 24.2 & 7.564 & 372.6 & 7.554 & - \\
\hline poligloss 2 & 7.233 & 86.6 & 17.8 & 401 & 100 & 7.264 & 111.1 & 28.5 & 7.257 & 479.9 & 6.416 & - \\
\hline poligloss 3 & 6.712 & 86.9 & 16.5 & 402 & 100 & 6.731 & 100.2 & 25.4 & 6.719 & 244.4 & 6.693 & - \\
\hline Zemdrain 1 & 7.348 & 114.5 & 17.2 & 402 & 99 & 7.378 & 167.1 & 28.9 & 7.372 & - & 7.025 & - \\
\hline Zemdrain 2 & 7.428 & 136.2 & 17.9 & 400 & 99 & 7.446 & 152.6 & 25.5 & 7.457 & - & 7.336 & - \\
\hline Zemdrain 3 & 7.841 & 94.8 & 18.5 & 402 & 100 & 7.85 & 152.2 & 45.3 & 7.856 & 217.8 & 7.874 & - \\
\hline
\end{tabular}

Figure 4.27 shows variation of wavelength travel time $\left(\mathrm{T}_{\mathrm{L}}\right)$ with freeze-thaw cycles for each of Sakrete concrete specimen cast with Newark tubes and control (steel) mold. Wave length travel time generally increased with the increase of number cycles due to progressive deterioration by continuous freeze-thaw cycle. Sakrete concrete specimens did not survive more than 65 cycles and suffered mass loss, cracking and disintegration as shown in Fig. 3.13. This was expected for the low strength Sakrete concrete. 


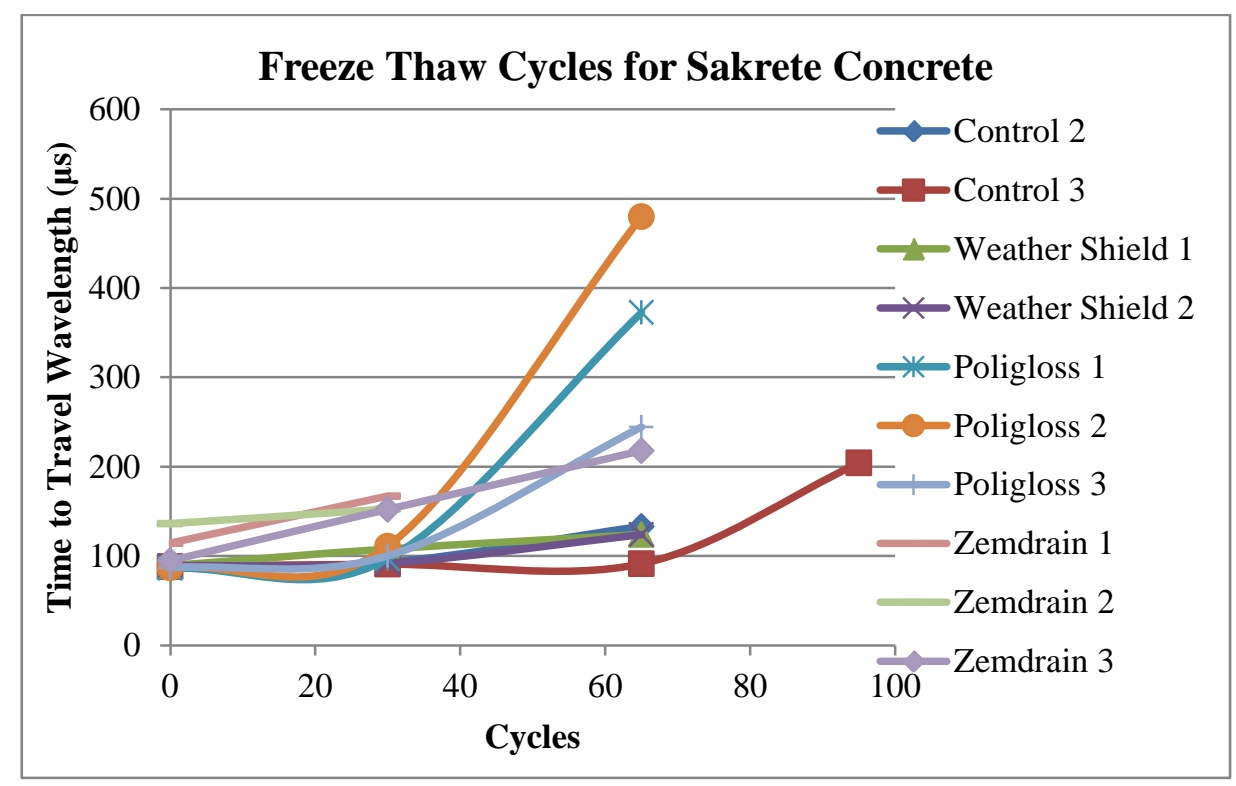

Figure 4.27: Time to travel Wavelength for each sample of Sakrete Concrete

Table 4.15 shows the relative modulus $\left(\mathrm{P}_{\mathrm{c}}\right)$ of each samples of Sakrete concrete. Relative modulus is a ratio of Frequency at $\mathrm{N}$ cycles to the frequency at Zero cycles. As the no of cycles increases, the frequency of wavelength decreases. Relative modulus shows the decrease of Dynamic Modulus after N cycles.

Table 4.15 Relative Modulus for each sample of Sakrete Concrete

\begin{tabular}{|c|c|c|c|c|c|}
\hline \multicolumn{7}{|c|}{ Relative Modulus } \\
\hline Samples & Time 0 Cycles $(\mu \mathrm{s})$ & Time N Cycles & $\mathrm{n}^{2}\left(\mu \mathrm{s}^{-2}\right)$ & $\mathrm{n}_{1}^{2}\left(\mu \mathrm{s}^{-2}\right)$ & $\mathrm{P}_{\mathrm{c}}(\%)$ \\
\hline Control 2 & 89.4 & 133.2 & 0.000125 & $5.636 \mathrm{E}-05$ & 45.05 \\
\hline Control 3 & 88.4 & 204.2 & 0.000128 & $2.398 \mathrm{E}-05$ & 18.74 \\
\hline Weather Shield 1 & 89.2 & 124.1 & 0.000126 & $6.493 \mathrm{E}-05$ & 51.66 \\
\hline Weather Shield 2 & 89.2 & 124 & 0.000126 & $6.504 \mathrm{E}-05$ & 51.75 \\
\hline Poligloss 1 & 86.2 & 372.6 & 0.000135 & $7.203 \mathrm{E}-06$ & 5.35 \\
\hline Poligloss 2 & 86.6 & 479.9 & 0.000133 & $4.342 \mathrm{E}-06$ & 3.26 \\
\hline Poligloss 3 & 86.9 & 244.4 & 0.000132 & $1.674 \mathrm{E}-05$ & 12.64 \\
\hline Zemdrain 1 & 114.5 & 167.1 & $7.63 \mathrm{E}-05$ & $3.581 \mathrm{E}-05$ & 46.95 \\
\hline Zemdrain 2 & 136.2 & 152.6 & $5.39 \mathrm{E}-05$ & $4.294 \mathrm{E}-05$ & 79.66 \\
\hline Zemdrain 3 & 94.8 & 217.8 & 0.000111 & $2.108 \mathrm{E}-05$ & 18.95 \\
\hline
\end{tabular}


Table 4.16 shows the durability factor (DF) after $\mathrm{N}$ cycles of freezing and thawing of each samples of Sakrete concrete. It is clear from the table that Weather Shield is most durable followed by Zemdrain and Poligloss. Weather Shield is more effective than control because the surface texture of Simple did not provide room for the freezing water to exceed the tensile strength of concrete, Whereas Zemdrain which has uneven texture Provide room to freezing water. Poligloss behave worst and have largest cracks

Table 4.16: Durability Factor for each sample of Sakrete Concrete

\begin{tabular}{|c|c|c|c|c|c|}
\hline \multicolumn{6}{|c|}{ Durability Factor } \\
\hline Samples & $\mathrm{P}(\%)$ & $\mathrm{N}$ (Cycles) & M (Cycles) & DF (\%) & Average DF (\%) \\
\hline Control 2 & 45.047074 & 65 & 150 & 19.52 & \multirow{2}{*}{15.69} \\
\hline Control 3 & 18.741013 & 95 & 150 & 11.87 & \\
\hline Weather Shield 1 & 51.663776 & 65 & 150 & 22.39 & \multirow{2}{*}{22.41} \\
\hline Weather Shield 2 & 51.747138 & 65 & 150 & 22.42 & \\
\hline Poligloss 1 & 5.3521568 & 65 & 150 & 2.32 & \multirow{3}{*}{3.07} \\
\hline Poligloss 2 & 3.256374 & 65 & 150 & 1.41 & \\
\hline Poligloss 3 & 12.642622 & 65 & 150 & 5.48 & \\
\hline Zemdrain 1 & 46.95243 & 30 & 150 & 9.39 & \multirow{3}{*}{11.18} \\
\hline Zemdrain 2 & 79.660889 & 30 & 150 & 15.93 & \\
\hline Zemdrain 3 & 18.945275 & 65 & 150 & 8.21 & \\
\hline
\end{tabular}

Norwegian Institute of Technology in Trondheim conducted a research on the freeze thaw resistance of high strength micro-silica cement mixes formed with Zemdrain. They investigated that Zemdrain liner showed the minor deterioration after 56 cycles, whereas conventionally cases concrete showed an accumulated material loss of over $6 \mathrm{~kg} / \mathrm{m}$ (International Survey, 1992) 


\subsection{SALT SCALING RESULTS}

Table 4.17 and Table 4.18 shows the initial dimensions, initial weight and weight after 50 cycles of de-icing salt of each sample for Sakrete and MS-S10 SCC concrete, respectively. Sakrete concrete has more salt scaling as compare to MS-S10 SCC, due to high strength and air entrainment admixture in MS-S10 SCC has almost $0 \%$ change in mass after 50 cycles.

Table 4.17: Salt scaling initial and final weight for each sample of Sakrete concrete after 50 Cycles

\begin{tabular}{|c|c|c|c|c|c|}
\hline S.No & Sample & Dimension & $\begin{array}{c}\text { Initial Weight } \\
(\mathrm{Kg})\end{array}$ & Weight After 50 Cycles (Kg) & \% Decrease \\
\hline 1 & Control (Wood) & $222 * 238 * 10$ & 12.89 & 12.84 & 0.388 \\
\hline 2 & Weather Shield & $228 * 233 * 9$ & 11.674 & 11.31 & 3.118 \\
\hline 3 & Poligloss & $228 * 220 * 9$ & 11.138 & 10.623 & 4.624 \\
\hline 4 & Zemdrain & $219 * 230 * 10.5$ & 12.597 & 12.54 & 0.452 \\
\hline
\end{tabular}

Table 4.18: Salt scaling initial and final weight for each sample of MS-S10 SCC after 50 Cycles

\begin{tabular}{|c|c|c|c|c|c|}
\hline S.No & Sample & Dimension & Initial Weight (Kg) & Weight After 50 Cycles (Kg) & \% Decrease \\
\hline 1 & Control (Wood) & $220 * 220 * 10$ & 10.594 & 10.593 & 0.009 \\
\hline 2 & Weather Shield & $230 * 220 * 11$ & 12.212 & 12.213 & -0.008 \\
\hline 3 & Poligloss & $235 * 216 * 9$ & 11.227 & 11.222 & 0.045 \\
\hline 4 & Zemdrain & $238 * 226 * 9.5$ & 10.795 & 10.794 & 0.009 \\
\hline
\end{tabular}

Figure 4.28 shows the of performance of Sakrete concrete cast with different formwork tube liners. Poligloss shows the highest decrease of $4.6 \%$, Weather Shield a decrease of $3 \%$, Zemdrain and Control shows the decrease of almost $0.5 \%$ after 50 cycles of deicing cycles. 


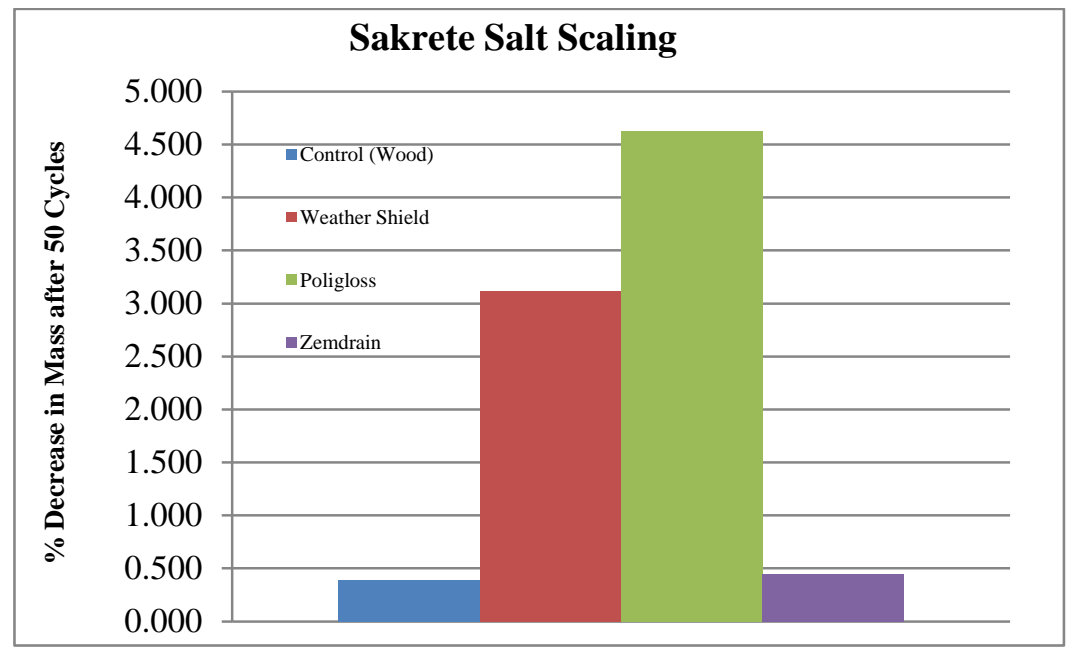

Figure 4.28: Percentage change in mass of Sakrete samples after 50 cycles

Figure 4.29 shows the pictures of Sakrete sample after 50 by visual inspection Zemdrain is performing well followed by Poligloss and Zemdrain as compare to control Specimen. Zemdrain doesn't give room to freeze salt water to scale because it has uneven texture and require more force to break tensile strength of concrete, while Poligloss and simple provide flat surface to salty water and it starts to scale.

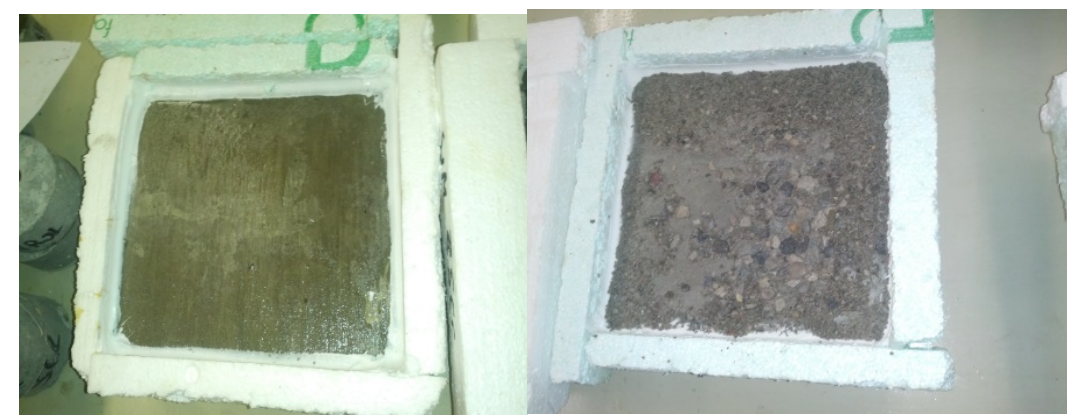

(a-Control wood)

(b-Weather Shield)

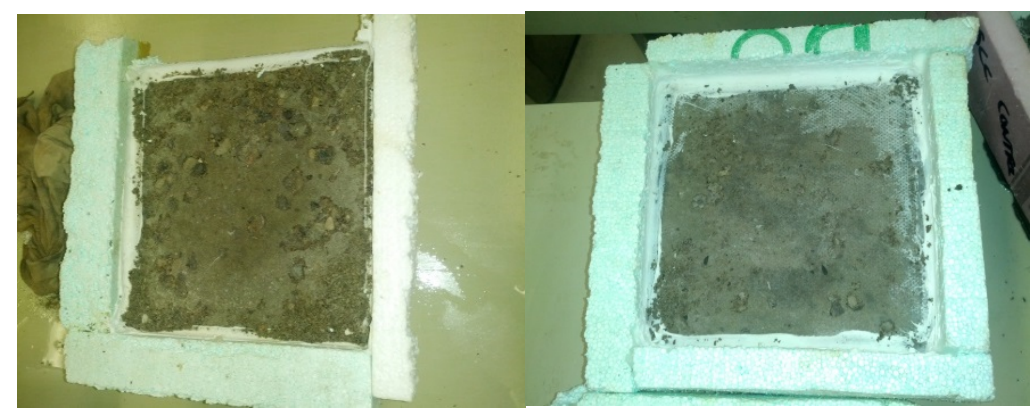

(c-Poligloss)

(d-Zemdrain)

Figure 4.29: Condition of Sakrete concrete Surface after 50 Cycle 
Figure 4.30 shows the pictures of SCC samples after 35 Cycles. According to visual analysis no scaling has been seen in any of the sample, this is because of the fact that SCC is strong concrete with high tensile strength. Final details can be better explained after 50 cycles.

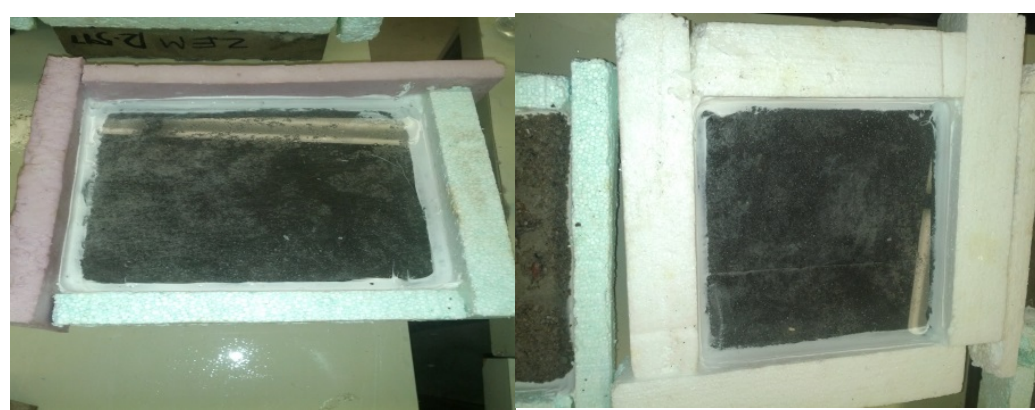

(a-Control wood)

(b-Weather Shield)

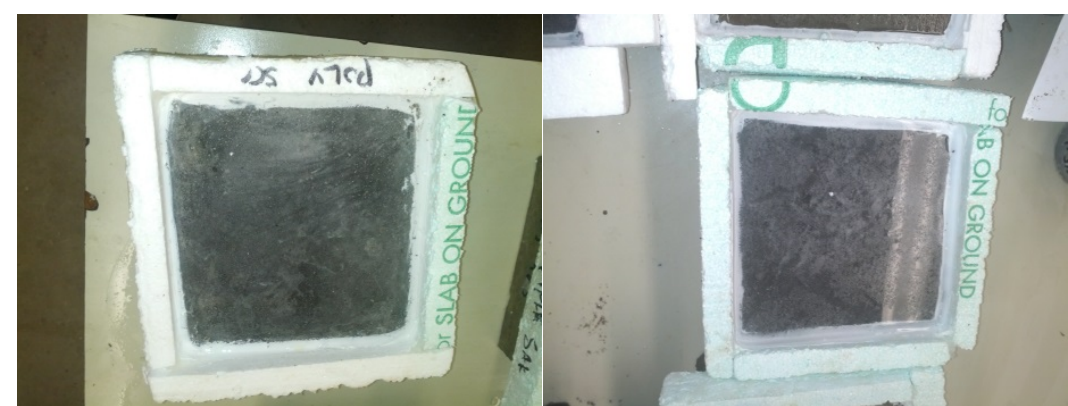

(c-Poligloss)

(d-Zemdrain)

\section{Figure 4.30: Condition of SCC concrete Surface After 50 Cycle}

Tests indicate that the formwork liners could produce enhances surface characteristics with increased density and increased strength with all varieties of mix .Type of Portland cement, slag, fly ash and silica fumes did not change the action of formwork liner. The use of formwork liner gave better resistance to de-icing chemicals when compared with air entrainment in blast furnace slag cement concrete with 75 percent ground granulated blast furnace slag replacing the OPC. (Stark \& Knaack, 1997) 


\subsection{AXIAL COMPRESSIVE STRENGTH OF FORMING TUBE}

Figure 4.31 shows the stress strain curve of a forming tube. Strains starts to increase linearly with the stress, at stress value of $3.25 \mathrm{MPa}$ strains start to increase without increase in stress. The stress start to increase again this fluctuation is due to the spiral winding in the forming tube. When first layer is crushed, another layer start to take load but strains keeps on increasing. By using the tube as a composite section strength gain of 3.24 MPa can be achieved. The modulus of elasticity of Weather Shield forming tube from stress strain curve was found to be 1130.5 MPa. Andrew et al., (2012) found the modulus of elasticity of paper based forming tube to be $2390 \mathrm{MPa}$.

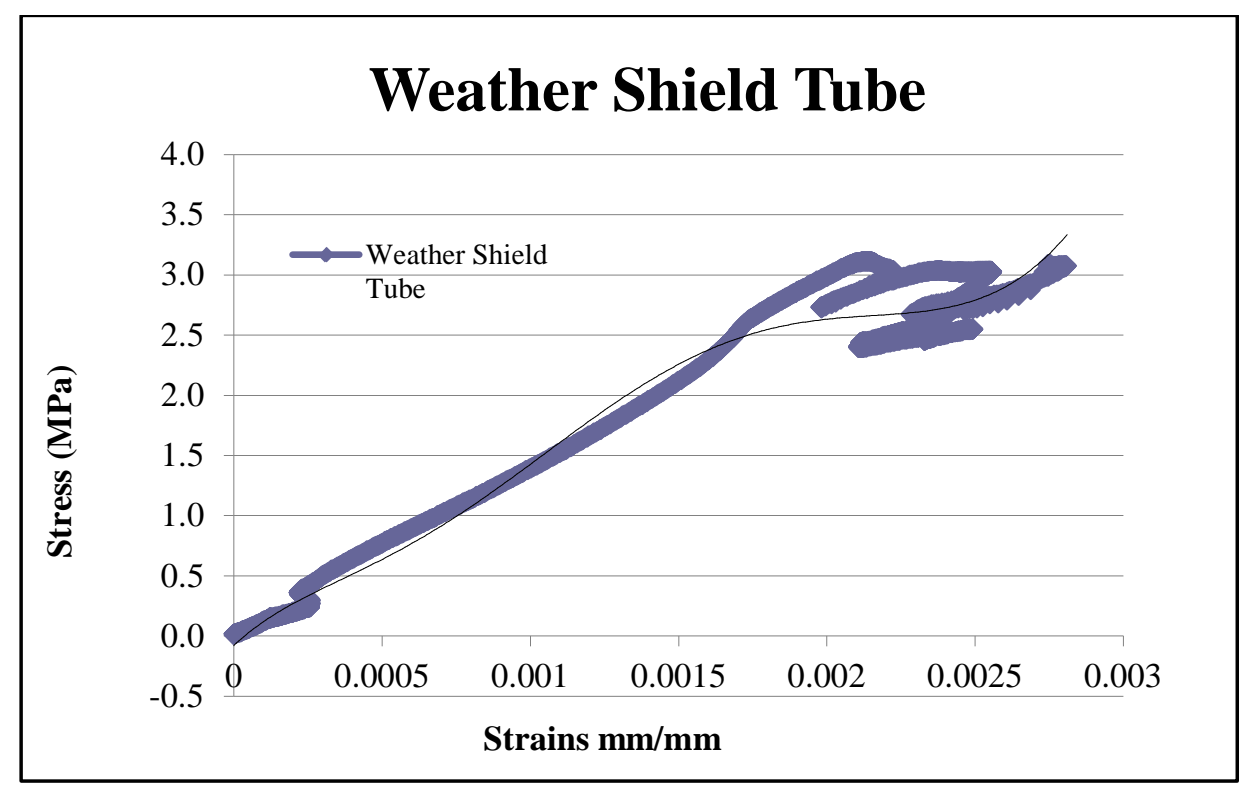

Figure 4.31: Stress strain curve of a forming tube. 


\section{CHAPTER 5: CONCLUSION AND RECOMENDTAIONS}

\subsection{INTRODUCTION}

This project was intended to do the performance evaluation of Engineered Newark concrete forming tubes for construction applications. Four commercial concretes were supplied by Newark Group, and on each of the concrete fresh state tests, mechanical property tests and durability tests were performed to evaluate the influence of forming tubes. Tests of compressive strength, surface hardness by rebound hammer, water absorption, sorptivity, chloride penetration, freeze-that and salt scaling resistance, were conducted on concretes made with different types of formworks. The overall conclusion drawn from this study was that the concrete surface properties could be improved by the use of formwork with permeability.

\subsection{FRESH PROPOERTIES}

Maximum pressure was developed by SCC concrete with a of 3.23 Psi. Max temperature was developed by HP-S10 concrete with the value of $58.5{ }^{\circ} \mathrm{C}$, as expected. All tubes performed well during casting and found to satisfactorily withstand fresh concrete pressure showing no bulging, and no water leakage along the forms .Minimal surface settlement and no bleeding/segregation were observed in all cast tubes.

\subsection{MECHANICAL PROPERTIES}

Table 5.1 summarizes the best performance from Weather Shield, Poligloss or Zemdrain forming tubes for mechanical properties. For all concretes, Weather Shield and Zemdrain showed the best overall performance with a percentage increase range of 2.5-11\%. The stiffness of Weather Shield tube was found to be $1130.5 \mathrm{MPa}$ 
Table 5.1 Performance evaluation of forming tubes for mechanical properties

\begin{tabular}{|c|c|c|}
\hline \multicolumn{3}{|c|}{ Mechanical } \\
\hline Concrete & Compressive Strength & $\begin{array}{c}\text { \% Increase from } \\
\text { worst }\end{array}$ \\
\hline Sakrete & Weather Shield & 10.77 \\
\hline MS-S10 & Weather Shield & 2.2 \\
\hline HP-S10 & Zemdrain & -0.06 \\
\hline MS-10 SCC & Zemdrain & 2.92 \\
\hline
\end{tabular}

\subsection{DURABILITY PROPERTIES}

Table 5.2 summarizes the best performance from Weather Shield, Poligloss or Zemdrain forming tubes for durability properties. Zemdrain was found to score the maximum performance points followed by Weather Shield and Poligloss. Although Poligloss scored less overall points, it provides the best surface characteristics. Compared with conventional formworks, all Newark forming tubes have exhibited better performance in majority of the tests.

Table 5.2 Performance evaluation of forming tubes for durability properties

\begin{tabular}{|c|c|c|c|c|c|c|c|c|c|c|}
\hline \multirow{3}{*}{ Concrete } & \multicolumn{10}{|c|}{ Durability property } \\
\hline & \multicolumn{2}{|c|}{ Water Absorption } & \multicolumn{2}{|c|}{ Sorpitivity } & \multicolumn{2}{|c|}{ Chloride Penetration } & \multicolumn{2}{|c|}{ Freeze thaw } & \multicolumn{2}{|c|}{ Salt Scaling } \\
\hline & $\begin{array}{c}\text { Best } \\
\text { Performacne }\end{array}$ & $\begin{array}{c}\% \text { Increase from } \\
\text { worst }\end{array}$ & $\begin{array}{c}\text { Best } \\
\text { Performacne }\end{array}$ & $\begin{array}{c}\% \text { Increase from } \\
\text { worst }\end{array}$ & $\begin{array}{c}\text { Best } \\
\text { Performacne }\end{array}$ & $\begin{array}{c}\% \text { Increase from } \\
\text { worst }\end{array}$ & $\begin{array}{c}\text { Best } \\
\text { Performacne }\end{array}$ & $\begin{array}{c}\% \text { Increase from } \\
\text { worst }\end{array}$ & \begin{tabular}{|c|} 
Best \\
Performacne
\end{tabular} & $\begin{array}{c}\% \text { Increase from } \\
\text { worst }\end{array}$ \\
\hline Sakrete & Weather Shield & 22.16 & Weather shield & 68.36 & Weather Shield & 56.6 & Weather Shield & 43.00 & Zemdrain & 14.00 \\
\hline MS-S10 & Zemdrain & 17.00 & Zemdrain & 59.13 & Zemdrain & 62.5 & - & & - & \\
\hline HP-S10 & Zemdrain & 6.65 & poligloss & 8.16 & poligloss & 36.2 & - & & - & \\
\hline MS-10 SCC & Zemdrain & 11.01 & \begin{tabular}{|l|} 
Weather Shield \\
\end{tabular} & 25.75 & Weather Shield & 7.9 & - & & Zemdrain & 0.00 \\
\hline
\end{tabular}


Certain specifications and benefits are claim by Newark group in the brochures of Weather Shield, Poligloss and Zemdrain. Table 5.3 shows the specification of each formwork liner that was observed during the experimental program.

Table 5.3 Specification of Formwork liner observed by experiments

\begin{tabular}{|c|c|c|c|}
\hline Liner & \multirow{2}{*}{ Weather Shield } & \multirow{2}{*}{ Poligloss } & \multirow{2}{*}{ Zemdrair } \\
\hline Specification & & & \\
\hline $\begin{array}{l}\text { Weather Shield } \\
\text { Technology }\end{array}$ & - & - & - \\
\hline Handles Vibration & - & - & - \\
\hline Easy placement & • & $\cdot$ & - \\
\hline Easy Pouring & • & • & • \\
\hline Easy Stripping & • & • & - \\
\hline LEED ${ }^{\circledR}$ Qualified & - & & \\
\hline $\begin{array}{l}\text { QuickStrip }^{\mathrm{TM}} \\
\text { Technology }\end{array}$ & & - & - \\
\hline Unique DuPont ${ }^{\mathrm{TM}}$ & & & • \\
\hline Improved Column Finish & & - & • \\
\hline Improves Durability & - & & • \\
\hline
\end{tabular}




\section{REFERENCES}

\subsection{Standards}

ASTM C39 (2012). Standard method for Compressive Strength of Cylindrical Concrete Specimens. Philadelphia, PA

ASTM C642 (2012). Standard method for Density, Absorption, and Voids in Hardened Concrete. Philadelphia, PA

ASTM C1585 (2012). Standard Test Method for Measurement of Rate of Absorption of Water by Hydraulic-Cement Concretes . Philadelphia, PA

ASTM C1202 (2012). Standard method for Electrical Indication of Concrete’s Ability to Resist Chloride ion penetration, Philadelphia, PA

ASTM C666 (2012). Standard method for Resistance of Concrete to Rapid Freezing and Thawing. Philadelphia, PA

ASTM C672 (2012). Standard Test Method for Scaling Resistance of Concrete Surfaces Exposed to Deicing Chemicals. Philadelphia, PA

\subsection{Web sites}

http://industrial.kpmindustries.com/Product_Catalogue/products/Concrete/HPS10_Concrete.aspx (Access date: 14-05-2013)

http://industrial.kpmindustries.com/Product_Catalogue/products/Concrete/MSS10_Concrete.aspx (Access date: 14-05-2013)

http://consumer.kpmindustries.com/Product_Catalogue/ByCategory/SakreteProducts.aspx (Access date: 14-05-2013) 
http://industrial.kpmindustries.com/Product_Catalogue/products/Concrete/MS-S10_SelfConsolidating_Concrete.aspx(Access date: 14-05-2013)

http://www.newarkgroup.com/products/newark-construction-products.aspx. (Access date: 20-05-2013)

\subsection{References}

ACI, Committee 347. (2004). Guide to Formwork for Concrete. ACI Standard, 1-32.

Andrew, J.Spottiswoode., Lawrence, C Bank., \& Aviad, Shapira (2012). Investigation of paperboard tubes as formwork for concrete bridge decks. Construction and Building Materials, 30(1) 767-775

Basheer, L., Nanukuttan, S., \& Basheer, P. (2008). The influence of reusing 'Formtex' controlled permeability formwork on strength and durability of concrete. Materials and Structures, 41(8), 1363-1375.

Basheer, P., \& Sha'at, A. L. (1995). Controlled permeability formwork-its influence on carbonation and chloride ingress. Concrete under Severe Conditions Environment and loading, 2, pp. 1205-1215. Sapporo, Japan.

Basheer, P., McCauley, A., \& Long, A. (1997). Influence of moisture condition of concrete on the performance of surface treatments. American Concrete Institute, 170(1), 1049-1072.

Beddoe, R. (1993). The effect of formwork linings on surface concrete. Munich: University of Technology, Munich Report.

Cai, H., \& Liu, X. (1998). Freeze-Thaw Durability of Concrete: Ice Formation Process. Cement and concrete Research, 28(9), 1281-1287. 
Cigna, R., Andrade, C., Nürnberger, U., Polder, R., Weydert, R., \& Seitz, E. (2003). Corrosion of steel in reinforced concrete structures. Italy: European Commission Book.

Coutinho, S. J. (2001). Effect of Controlled permeability formwork on white cement. American Concrete Institute, 98(2), 148-171.

Cuicui, C., Jianzhong, L., Gong, C., \& Jiaping, L. (2012). Effect of controlled permeable formwork on the improvement of concrete performances. Procedia Engineering, 27(1), 405-411.

David, W. (1994). Controlled permeability formwork . Concrete, 2(28), 20-22.

Nolan, E., Basheer, P.A.M, \& Long, A.E. (1995). Effects of three durability enhancing products on some physical properties near surface concrete. Concrete and Building materials, 9(5), 267-272.

Gardner, N. (1982). The effect of superplasticizer and flyash on formwork pressures. Forming Economical Concrete Buildings . special report pp 1-12.

Géraldine, V., Mickaël, T., \& Gérard, P. (2007, April 25). Measurement methods of carbonation profiles in concrete: Thermogravimetry, chemical analysis and gammadensimetry. Cement and Concrete Research, 37(1), 1182-1192.

Gerhardt TD. (1990). External pressure loading of spiral paper tubes: theory and experiment. American society of mechanical engineers,112(4):114-50.

Harrison, T. (1991). Introducing Controlled permeability formwork. Boston: The Aberdeen Group Report.

Karl, J.H, \& Solacolu, C. (1993). Verbesserung der Betonrandzone: Wirkung und Ein satzgrenden der saugenden. Schiungsbahn Beton, 43(5), 222-225. 
Johnston, D. W. (2008). Concrete Construction Engineering Handbook. New Jersey: Taylor \& Francis Group.

Long, A., Shäat, A., \& Basheer, P. (1995). The influence of controlled permeability formwork on the durability and transport properties of near surface concrete. Advances in concrete technology, 154(1), 41-54.

Malone, P. G. (1999). Use of Permeable Formwork in Placing and Curing Concrete. Vicksburg: US Army Crops of Engineers. Book.

McCarthy, M., \& Giannakou, A. (2002). In-situ performance of CPF concrete in coastal environment. Cement Concrete Research, 32(3), 451-457.

McCarthy, M., Giannakou, A., \& Jones, R. (2001). Specifying concrete for chloride environments using controlled permeability formwork. Materials and Structures, 34(9), 556-576.

McCarthy, M., Hir, R., \& McKenna. (1999). Total design using controlled permeability formworks. Dundee: University of Dundee Report.

McKenna, P. (2005). Controlleed Permeability Formwork. Concrete, 39(10), 28-31.

Metin, A., Osman, S., \& Serkan, S. (2004). Effects of formwork surface materials on concrete lateral pressure. Construction and Building Materials, 19(4), 319-325.

Mindess, S., Francis Young, J., \& Darwin, D. (2003). Concrete Book. New Jersey: Pearson Education, Inc.

Philip, M., \& Chirag, B. (2008). The role of Controlled Permeability Formwork in life cycle design. Tailor Made Concrete Structures, Report 81-84.

Price, W.F (2000). Controlled Permeability Formwork. CIRIA Report. 
Puente, I., Santilli, A., \& Lopez, A. (2010). Lateral pressure over formwork on large dimension concrete blocks. Engineering Structures, 32(1), 195-206.

Rankin, G., \& Cummings, S. (1999). In-situ evaluation of surface properties of concrete cast using Zemdrain formwork liner . Belfast: Dock Street Bridge. Report

Nagataki, S., Nireki, T \& Tomosawa, F. (1993). The influence of penetrating sealers on the deicer salt scaling resistance of concrete. Durability of Building materials and components, 6(1), 487-496.

Scherer, G. W., \& Valenza, J. J. (2006). Mechanism for salt scaling of a cementations surface. Materials and Structures, 40(10), 259-268.

Scherer, G. W., \& Valenza, J. J. (2007). A review of salt scaling: II. Mechanisms. Cemenet and Concrete research, 37(7), 1022-1034.

Schubel, P., Warrior, N., \& Elliott, K. (2007). Evaluation of concrete mixes and mineral additions when used with controlled permeable formwork. Construction and building materials, 22(7), 1536-1542.

Schubel, P., Warrior, N., Elliott, K., \& Jones, M. (2007). An Investigation into the critical factors affecting the performance composite controlled permeable formwork liners Part I - Drainage medium. Construction and Building materials, 22(7), 1551-1559.

Sousa Coutinho, J. (2003). The combined benefits of CPF and RHA in improving the durability of concrete structures. Cement concrete composites, 25(1), 51-59.

Sha'at, A. (1994). Assessment methods of improving the durability of concrete surface. Belfast: Queens University Report. 
Sha'at, A., Long, A., Montgomary, F., \& Basheer, P. (1992). The influence of controlled permeability formwork on the quality of concrete cover. American concrete institute, (special report) SP-139, 91-105.

Skjolsvold, O. (1991). Testing of concrete with and without Zemdrain liner on the formwork. Oslo: Norwegian Institute of Technology Report.

Stark, J., \& Knaack, U. (1997). Effect of draining formwork material Zemdrain on the resistance of portland cement and blast furnace cement concrete to frost and de-icing chemical attack. Germany: F. A. Finger-Institut für Baustoffunde der BauhausUniversitat Weimar Report.

Price, WF. (1992). The effect of Zemdrain CPF on the resistance to chloride penetration of concretes exposed to salt spray conditions in hot climate. London: Taywood engineering limited Report.

Price, WF. (1992). The use of Zemdrain controlled permeability formwork with concrete containing blend cements. London: Taywood Engineering Limited Report.

Wilson, D. (2002). Improving concrete quality and durability without using chemicals. World Conference of Concrete Materials and Structures (WCCMS). Kuala Lumpur, Malaysia Conference.

Wilson, D. (2007). A holistic approach to concrete surface durability. CI premier PTE LTD. Singapore Conference. 